University of San Diego

Digital USD

2005-05-01

\title{
How School Counselors Gain Support to Implement Comprehensive Guidance and Counseling Programs
}

Jo Ann Grant EdD

University of San Diego

Follow this and additional works at: https://digital.sandiego.edu/dissertations

Part of the Leadership Studies Commons

\section{Digital USD Citation}

Grant, Jo Ann EdD, "How School Counselors Gain Support to Implement Comprehensive Guidance and Counseling Programs" (2005). Dissertations. 743.

https://digital.sandiego.edu/dissertations/743

This Dissertation: Open Access is brought to you for free and open access by the Theses and Dissertations at Digital USD. It has been accepted for inclusion in Dissertations by an authorized administrator of Digital USD. For more information, please contact digital@sandiego.edu. 
A dissertation submitted in partial fulfillment of the requirements for the degree of

Doctor of Education

University of San Diego

May 2005

\section{Dissertation Committee}

Lonnie L. Rowell, Ph.D., Chair Edward F. DeRoche, Ph.D., Member Clarence Johnson, Ph.D., Member Reyes Quezada, Ed.D., Member 
(C) Copyright by Jo Ann Grant 2005

All Rights Reserved

Reproduced with permission of the copyright owner. Further reproduction prohibited without permission. 


\begin{abstract}
The school counseling field is evolving from a focus on ancillary activities to a commitment to comprehensive guidance and counseling programs. Understanding strategies school counselors have used in gaining support from key stakeholders to implement comprehensive guidance and counseling programs can be a valuable addition to the literature of school counseling. The present study investigated how elementary and secondary school counselors gained support when implementing comprehensive guidance and counseling programs based on the National Standards for School Counseling Programs. A qualitative methodology was used in the study.

The findings revealed that: (a) counselors studied believed their role in gaining support to implement comprehensive guidance and counseling programs was to take leadership, (b) counselors in the study were able to gain support from site administrators as a result of building a "trusting relationship," (c) collaboration with stakeholders and increasing the visibility of counselors and counseling programs was a strategy that counselors used to gain support, and (d) district support is an important factor in institutionalizing comprehensive guidance and counseling programs across school sites.

The findings point to the importance of leadership in understanding the barriers to change, recognizing the impact change has on school systems, and creating a strategic plan to overcome resistance to change. The findings of this study offer leaders in school counseling new awareness that might be useful in preparing future counselors to become leaders and change agents within their schools.
\end{abstract}




\section{ACKNOWLEDGEMENT}

I am extremely thankful to the members of my committee who willingly read many drafts of my dissertation and patiently responded to the numerous questions that I asked.

Dr. Lonnie L. Rowell gave up his valuable time to meet with me on a continual basis to discuss my ideas and thoughts regarding my study. I am grateful for Dr. Rowell's willingness to share his knowledge and his commitment toward editing all of my chapter drafts over the past two years we worked together.

Dr. Edward F. DeRoche guided me in my writing and more importantly, supported and motivated me though this process. Thank you for spending your time reviewing my drafts and asking many questions to make sure I was moving in the right direction.

Dr. Clarence Johnson was willing to be a part of my committee despite living outside of San Diego and shared his extensive knowledge of school counseling. Thank you for directing me toward current school counseling research as well as sharing your counseling experiences with me!

Dr. Reyes Quezada provided valuable insight that helped me to finalize my dissertation. I am very grateful for Dr. Quezada's willingness to join my committee during the last phase of my study.

Counselors, site administrators, and district supervisors willingly participated in my study despite their busy schedules. They welcomed my questions and allowed me the opportunity to learn about their experiences with implementing comprehensive guidance and counseling programs.

I thank my family and friends for their continual support as I worked toward achieving my goal. Thanks for listening to me whine, moan, and groan about the unlimited number of tasks that I had to complete. I promise you - no more!

Last, I owe a special thanks to my father, Frederick H. Grant. Despite his busy traveling schedule, he still made sure to review the many drafts of my dissertation and to respond to my questions immediately - no matter what time zone he happened to be in. Thanks Dad! 


\section{TABLE OF CONTENTS}

SIGNATURE PAGE. . . . . . . . . . . . . . . . . . . . . . . .

IRB PROJECT ACTION SUMMARY. . . . . . . . . . . . . . . . iv

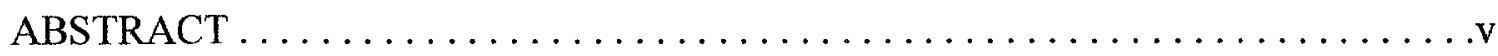

ACKNOWLEDGMENTS $\ldots \ldots \ldots \ldots \ldots \ldots \ldots \ldots \ldots \ldots \ldots \ldots \ldots$

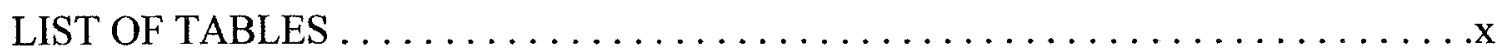

LIST OF FIGURES $\ldots \ldots \ldots \ldots \ldots \ldots \ldots \ldots \ldots \ldots \ldots \ldots \ldots \ldots \ldots \ldots \ldots \ldots$

\section{CHAPTER}

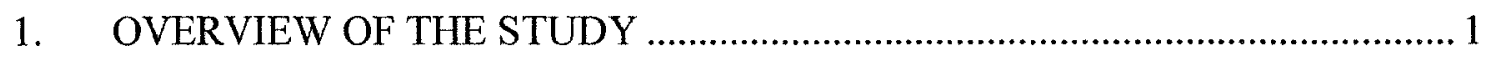

Statement of the Problem ..................................................................... 1

Background of the Problem................................................................... 5

Purpose of the Study ....................................................................... 10

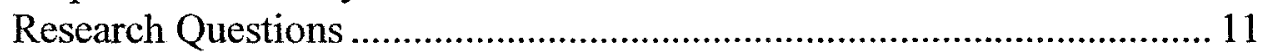

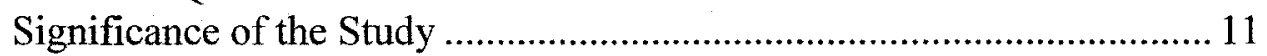

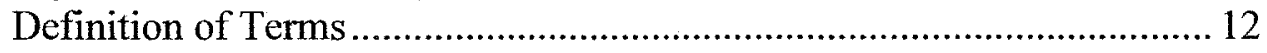

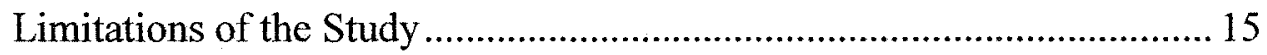

Organization of the Study ................................................................. 16

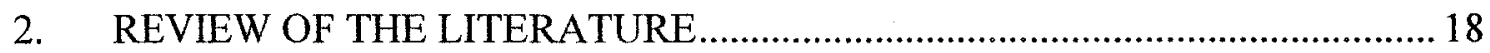

Introduction .............................................................................. 18

Change in School Counseling Programs................................................ 19

The Rise of Comprehensive Guidance and

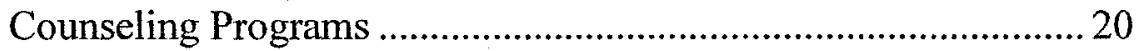

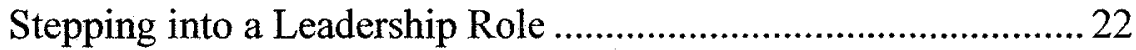

Creating Change in Education..............................................................2 27

Why Change Fails in Education............................................. 28

Making Change Successful ................................................ 30

Organizational Change ..................................................................... 33

Change at the Organizational Level ........................................... 34

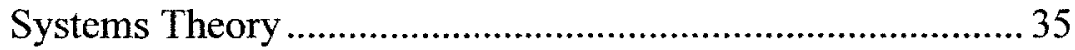

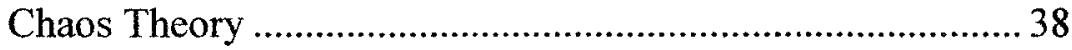

Change at the Individual Level ................................................. 40

Strategies to Create Deep Change ..................................................... 42

Collaboration .................................................................... 42

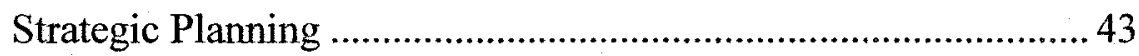

Conclusion 


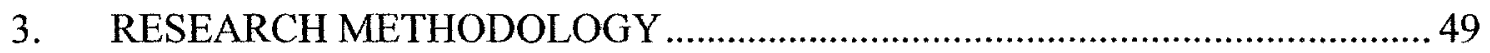

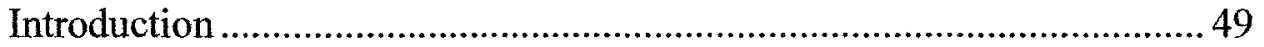

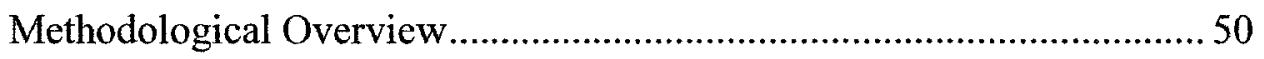

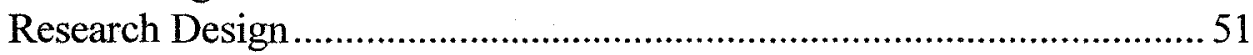

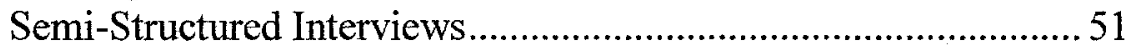

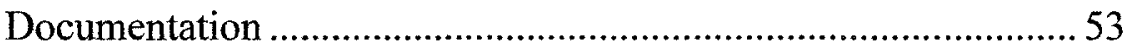

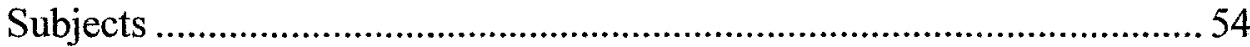

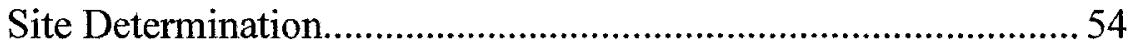

Selection of Participants.......................................................... 57

Protection of Participants ....................................................... 58

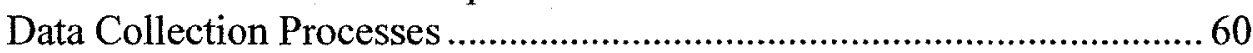

Semi-Structured Interviews.................................................. 60

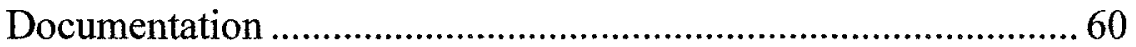

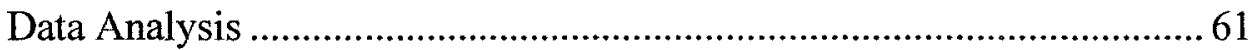

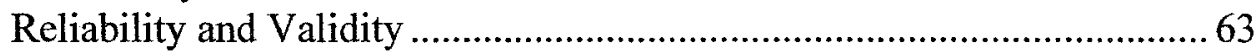

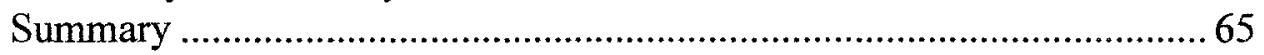

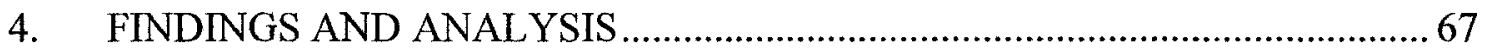

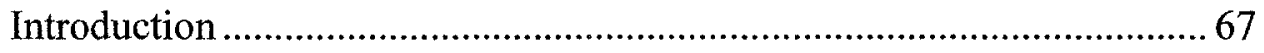

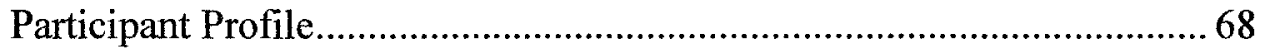

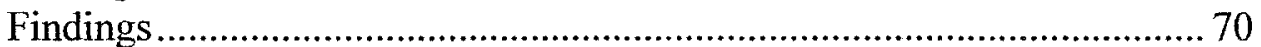

Definition of School Counseling Models ..................................7 71

Theme One: Counselors Stepping into a Leadership Role ........... 75

Enthusiasm and Excitement for Change ............................. 77

Educating Stakeholders About the Change ............................ 78

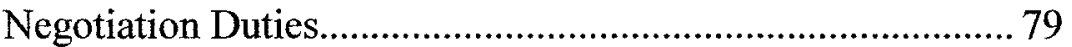

Administrators' Support Based on Trust................................ 82

Theme Two: Increasing the Visibility of Counselors and

Counseling Programs ......................................... 86

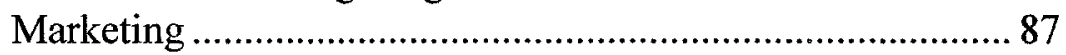

Using Data.................................................................. 93

Activities and Services that Bring Recognition ..................... 98

Theme Three: Working Collaboratively to Gain Support........... 100

Theme Four: Limited Support from District Office.................... 104

Theme Five: Overcoming Resistance to Change ........................ 108

Summary ..................................................................... 113

5. SUMMARY, IMPLICATIONS AND RECOMMENDATIONS .................... 121

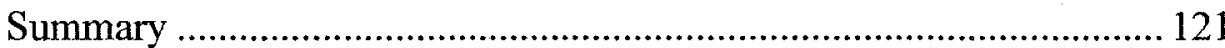

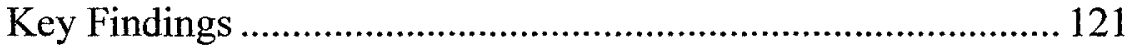

The Role of Counselors..................................................... 121

The Role of Site Administrators...................................... 122

The Role of District Supervisors ..................................... 124

Strategies to Gain Support............................................... 125

Implications and Recommendations .............................................. 127

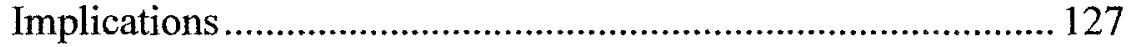


Leadership. 128

Political Involvement ..................................................134

Limited District Support ..................................................138

Competing School Counseling Program Models..................140

Recommendations for Further Study ...................................142

Concluding Remarks..........................................................145

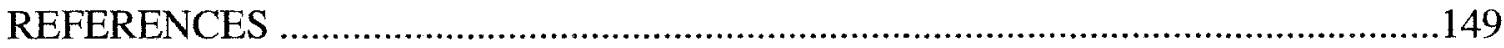

\section{APPENDIX}

A. National Standards for School Counseling Programs....................................158

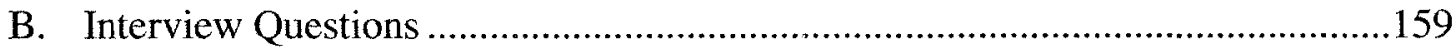

C. School Counseling Program Selection Questionnaire .......................................160

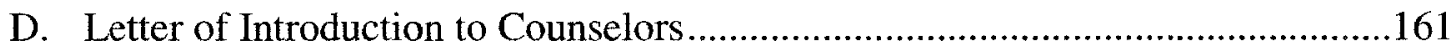

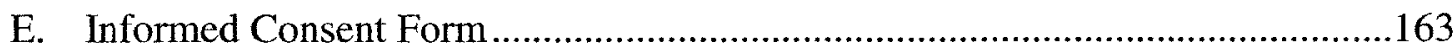

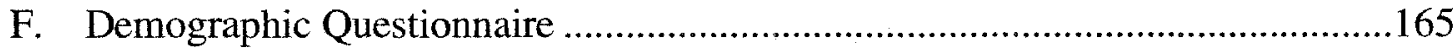

G. Letter to Participants with Transcribed Interview ........................................166 


\section{List of Tables}

Table 1. School and Community Profile p. 69

Table 2. Summary of Students' Ethnic Background

p. 70 


\section{List of Figures}

Figure 1. Research Design Structure

p. 52 


\section{CHAPTER ONE: OVERVIEW OF THE STUDY}

\section{Statement of the Problem}

Elementary and secondary school counseling practices are undergoing dramatic changes as they evolve from ancillary activities to the organization, implementation and evaluation of comprehensive guidance and counseling programs. These program changes, however, are currently dynamic and reactive in nature rather than following documented strategies or guidelines that are based on past success stories. The fact that no defined strategies exist for gaining support from key stakeholders to implement change is a major stumbling block for counselors intent on updating their guidance and counseling programs.

Traditionally, guidance and counseling programs were created and managed based on a "position orientation" model (Gysbers \& Henderson, 2000, p. 16). This translates into a counseling program in which administrators assign duties, goals, and projects to counselors. In this model administrators decide the needs of students and counselors merely respond to duties assigned to them, which can change regularly. As a result, counselor duties vary from school to school and can include academic and career counseling as well as non-counseling duties such as discipline, testing, lunch duty, substitute teaching, scheduling and clerical responsibilities. To the extent that counselors do not have an organizational structure and place within the school system, "duties are often assigned on an ad hoc basis rather than being derived from a comprehensive and guidance counseling program" (Gysbers, Lapan \& Jones, 2000, p. 352). This type of model makes it difficult for counselors to respond to student needs in a planned and consistent manner and makes it difficult for school officials to understand how 
counseling services contribute to student achievement.

According to Gysbers et al. (2000), "The contemporary way to organize guidance and counseling is the comprehensive program approach" (p. 349). A comprehensive guidance and counseling program gives counselors a structured job description outlining a set of duties that are aligned with school, district and even state and national education goals (Gysbers, 2001). In this model, counselors work individually with grade levels but also collaboratively with administrators and district staff to determine support services and programs that meet student needs and school objectives. This model transforms counselors' role from a marginal player assigned to general duties to a leadership role and a significant member of the school team.

The idea of comprehensive guidance and counseling programs surfaced in the $1970 \mathrm{~s}$ and was fueled by key models that translated into "practical, workable programs to be implemented in the schools" (Gysbers \& Henderson, 2001, p. 248). These models were a direct result of a need to "reorient guidance and counseling from what had become an ancillary and supplementary set of services in schools delivered by persons in positions (school counselors) to a comprehensive program" (Gysbers et al., 2000, p. 350). Comprehensive guidance and counseling models emphasize creating guidance and counseling programs that are results-based and involve student competencies and program activities that enhance not only student academics and career awareness but "focus on the needs, interests and issues related to the various stages of student growth" (Campbell \& Dahir, 1997, p. 9). In summary, these models provide a framework for counselors to develop their guidance and counseling programs based on the unique needs of their students as well as the educational objectives of their school. 
Recognizing the struggles counselors had in demonstrating their role in improving student achievement as well as meeting student needs, the American School Counseling Association (ASCA) initiated a process of assessing "the state and national leadership's attitudes and beliefs towards the development of national standards for school counseling programs" (Campbell \& Dahir, 1997, p. 5). By 1997, ASCA adopted the National Standards for School Counseling Programs (see Appendix A). The purpose of these standards is "to impart specific skills and learning opportunities through academic, career, and personal/social development experiences in a proactive and preventive manner for all students" (Campbell \& Dahir, p. 1). The National Standards for School Counseling Programs provides a framework for comprehensive and guidance counseling programs that are developmental and based on measurable competencies.

With the adoption of the National Standards by ASCA, school counseling is poised for a wave of reform that can strengthen the profession as well as the link between guidance and counseling and the school reforms sweeping the nation since the 1980s (Rowell, 2002). As a result, counselors are being challenged to implement comprehensive guidance and counseling programs in their school and district settings. Sink and MacDonald (1998) found that "24 states had produced by March 1, 1997, some type of comprehensive guidance and counseling model" (p. 92) demonstrating that some counselors have accepted the challenge of creating change in their school counseling programs.

Although most practitioners in the field of guidance and counseling agree that change needs to occur (e.g., Bemak, 2000; Campbell \& Dahir, 1997; Gysbers et al., 2000; House \& Hayes, 2002; Johnson \& Johnson, 2003; Lapan, 2001; Sears, 1993), there appears to be 
limited research focusing on how counselors can successfully create such change. The literature to date examines the new skills that counselors need to meet the needs of all students (e.g., House \& Hayes, 2002; House \& Martin, 1998; Keys \& Bemak, 1997; Sears, Haag, \& Granello, 2002) and documents counselors' difficulties with change due to fear, lack of initiative, and/or limited leadership skills (e.g., Baker, 2001; Louis, Jones, \& Barajas, 2001; Napierkowski \& Parsons, 1995; Sears et al., 2002). Much of the literature focuses on the step-by-step process of implementing comprehensive guidance and counseling programs (e.g., Dahir, Sheldon, \& Valiga, 1998; Gysbers \& Henderson, 2002; Johnson \& Johnson, 1997; Lapan, 2001). Some evaluations on the effectiveness of comprehensive guidance and counseling programs have been completed along with reporting on the number of schools that have implemented this new approach (e.g., Lapan, Gysbers, \& Sun, 1997; MacDonald \& Sink, 1999; Sink \& MacDonald, 1998).

There is some research that provides insight into factors that help counselors successfully implement comprehensive guidance and counseling programs. For example, studies show that counselors need training and support during the initial implementation phase (Sink \& Yillik-Downer, 2001); success of implementing change increases if the idea originates directly from the school community rather than the district office or some outside source (Finnan \& Hopfenberg, 1997); and administrators play an important role in the implementation of new programs within schools (Louis et al., 2001).

Last, Gysbers and Henderson's (1997) book, Comprehensive Guidance Programs That Works - II, presents success stories of various counselors who implemented comprehensive guidance and counseling programs and the challenges they faced in implementing such change. Unfortunately, while the personal stories shared by 
counselors provide a general idea of the complexity and commitment involved in creating change and the importance of gaining support (Fields \& Manley, 1997; Jensen \& Petersen, 1997; and Maliszewski, 1997), none provide any insight into specific strategies used to gain support from key stakeholders.

Overall, no research has been found that focuses on strategies school counselors have used to gain support for implementing comprehensive guidance and counseling programs. Clearly, if gaining support from stakeholders is an important part of organizational change (Fullan, 1992), studies are needed that examine specific strategies for gaining such support. More specifically, for counselors working to implement comprehensive guidance and counseling programs, studies are needed to identify successful strategies that counselors can use in gaining support from school staff, school administrators, district student support supervisors, parents, students, school board members, and community-based service providers.

\section{Background of the Problem}

The rapid changes occurring in society create new challenges for counselors attempting to provide support to all students. These changes include, for example: increases in divorce, high drop out rates, greater alcohol and drug abuse, violence, increase in teen pregnancy, mental illness, and teenage suicide (e.g., Gysbers, 2001; Keys \& Bemak, 1997; Neukrug, Barr, Hoffman, \& Kaplan, 1993). According to the California Department of Health Services (1998), 20\% of youth (ages 9 to 17) have some diagnosable mental disorder, suicide is the third leading cause of death (7.3\%) among California youth ages 15 to 19 , and $43.6 \%$ of $11^{\text {th }}$ graders have had at least one alcoholic drink while $26.2 \%$ binge drink. Furthermore, according to O'Neil (1992), there is 
increasing concern regarding the "growing gap between the capabilities of high school graduates, especially those not bound for college, and the skills, knowledge, and habits of mind that employers seek" (p. 6). In order to address these challenges schools need to revise current guidance and counseling programs to provide better support to students.

In addition, counselors are under pressure, along with all educators, to demonstrate how they help meet school goals and improve student achievement. According to Johnson (2000), "Currently, everyone in the school establishment is being called upon to demonstrate accountability and provide evidence of efficacy through measured outcomes" (p. 33). Baker (2000) defines accountability as "demonstrating that something worthwhile is happening" (p. 31). Unfortunately, questions of whether guidance and counseling help to improve academics lingers in the minds of administrators and school board members along with concern as to whether funds should be allocated to guidance and counseling programs rather than curriculum needs or teacher allotments (Otwell \& Mullis, 1997). Anderson and Reiter (1995) further state that in times of budget crisis a "cost-cutting trend is to dismantle and eliminate school counseling programs" (p. 276). As a result, counselors are under pressure to demonstrate at the local and state level that "they have a greater effect on students' academic achievement than schools without counselors" (Otwell \& Mullis, p. 344).

In addition to questions of accountability, the challenge counselors' face at the school and district level is confusion regarding the role of a school counselor. This confusion stems from districts not having a clear job description for counselors. Without a clear understanding of counselors' role within a school, counselor duties are often based on a "position orientation" model (Gysbers \& Henderson, 2001). Specifically, an ambiguous 
role definition at the school and district level results in administrators directing what counselors should do which often has become bookkeeping and other office work. This burdens counselors with performing non-counseling duties and weakens their capacity to demonstrate accountability. Many board of education policies still emphasize the position of a counselor rather than articulating a commitment to a comprehensive guidance program. Gysbers et al. (2000) studied 24 school board policies for guidance and counseling and discovered that the policies did not include the components of comprehensive guidance and counseling models. The three researchers stated that "When school board policies for guidance and counseling are written in this manner [position perspective], we believe they tend to marginalize guidance and counseling in the schools, thus reducing the impact guidance and counseling can have on student development" (p. 352). However, creating a "clear role description at the district level could guide and encourage principals to legitimize the role of the school counselor as central to academic achievement" (Louis et al., p. 71). Gysbers et al. (2000) further state, "When policies for guidance and counseling are written from a program perspective it places guidance and counseling conceptually and structurally in the middle of school reform and educational improvement" (p. 353). Aligning current district educational policies with comprehensive guidance and counseling can solidify counselors' role leading to improved student support services for students. In order to revise these policies and have them more aligned with comprehensive guidance and counseling models, counselors need to work with school administrators and district personnel to convince them that change is needed (Gysbers et al., 2000).

This is true at the state level as well. As long as counselors continue to spend their 
time focusing on clerical tasks associated with assessment and scheduling rather than creating programs that support student achievement, they will continue to be ignored in the state accountability reforms (Louis et al., 2001). As counselors continue to be ignored as significant players in improving student achievement, funding toward counseling programs will remain a low priority. According to Louis et al., there is a trend toward allowing state policymakers to have more control over school improvement efforts. This means school districts must justify to the state how they are spending funds. As guidance and counseling is not perceived to have a direct connection to improving academic achievement, schools are finding it difficult to justify to states allotting funding for counseling (Otwell \& Mullis, 1997). Conversely, if change begins to occur at the school and district level it can lead to further change at the state level resulting in a revision of state policies so they too, are aligned with the concept of comprehensive guidance and counseling programs. This can lead both to a better understanding of how guidance and counseling programs help to meet school educational objectives and to more funding.

Sadly, counselors' lack of presence within current reform initiatives demonstrates that stakeholders do not view counselors as significant players in improving student achievement. According to Dahir (2001), "School counseling programs were ignored as a means to improve student achievement and help students prepare for the future" (p. 321). A good example is the Goals 2000 school reform initiative, which states by 2000 all students will come to school ready to learn and all high school graduation rates will increase to at least $90 \%$ (U.S. Department of Education National Education Goals website, February $6,2004,92$ ). Unfortunately, counselors are not mentioned in this particular reform initiative. While the national and state focus on improving education 
continues, counselors continue to be ignored as part of the solution.

Another challenge faced by counselors is changing their perception of their role. Research clearly states (Baker, 2000; Dahir, 2001; Dollarhide, 2003; Gysbers \& Henderson, 2001; Herr, 2002) that for change to occur, counselors must lead the way. However, many counselors do not perceive themselves as leaders or change agents. According to Louis et al. (2001), "There is a strong sense across districts that many counselors have not tried to define a professional role based on their training" (p. 3). Many do not conceive the role they must play in order to make change happen. Bemak (2000) believes counselors have not taken on an "active leadership role" (p. 324) to create change within school systems. Implementing comprehensive guidance and counseling programs can result in solidifying the counselor's role within a school, providing counselors a framework for developing student competencies and designing activities that support student achievement, and allow counselors to demonstrate at the district and state level that they do play a significant role in meeting educational objectives. To accomplish this task, however, and gain the support they will need to create change, counselors need to perceive themselves as leaders and change agents.

Although research supports the significance of fully implementing comprehensive guidance and counseling programs, (Gysbers \& Henderson, 2000; Lapan et al., 1997; Sink \& MacDonald, 1998), change is difficult to create and sustain. Researchers note the difficulty of implementing organizational change in general, and more specifically, organizational change in schools. Myrick (1987) notes, "In many respects, the educational system may be among the slowest to respond to new trends and issues. They are like solid rocks, resisting the waves of change until little pieces are chipped away" (p. 
435). Furthermore, DuFour, Guidice, Magee, et al. (2002) state, "The ability of public schools to engage in significant, fundamental change is increasingly being called into question" (p. 19). As counselors attempt to move in new directions, they face resistance both within existing guidance and counseling programs and from the school community at large (Myrick, 1987; Napierkowski \& Parsons, 1995). According to Napierkowski and Parsons, "Schools like most organizations, resist change and operate out of a culture of 'maintenance"" (p. 365). To create lasting change will require "involving the public in a broad commitment to change" rather than involving just the few committed reformers who want the change to occur (Tyack \& Tobin, 1994, p. 478).

If lasting change in school counseling programs is to occur, counselors will need to convince key stakeholders that change is needed. Counselors have the ammunition to fight for change but the question remains, how can counselors succeed in creating "real" change within school systems where many others have failed? Unfortunately, no research has been found that squarely focuses on how counselors can create change in school systems. Therefore, the present study focuses on investigating strategies used by counselors who have been successful in gaining support from key stakeholders to implement comprehensive guidance and counseling programs, and thus may be highly beneficial to counselors planning to implement such change.

\section{Purpose of the Study}

While research on comprehensive guidance and counseling programs is available only a few research studies could be found that appeared to focus on how school counselors gain support from key stakeholders to begin implementing change. The purpose of the present study was to investigate how elementary and secondary counselors gain support 
to implement comprehensive guidance and counseling programs based on the National Standards for School Counseling Programs.

Research Questions

The research questions for this study were designed to explore how school counselors gain support from key stakeholders to implement comprehensive guidance and counseling programs within their schools. This study addressed the following questions:

1. What do counselors believe is their role in gaining support to implement comprehensive guidance and counseling programs?

2. What do administrators believe is their role in supporting counselors' efforts to gain support to implement comprehensive guidance and counseling programs?

3. What does district staff responsible for supervision of student support services believe is their role in supporting counselors' efforts to gain support to implement comprehensive guidance and counseling programs?

4. What strategies do counselors use to gain support from key stakeholders in implementing comprehensive guidance and counseling programs?

Significance of the Study

This study provides insight into strategies that counselors use in obtaining support from key stakeholders to implement change. The information gleaned from this study may assist counselors in their efforts to strengthen school counseling programs. In addition, the study may lead to improvements in professional training programs, thus increasing beginning school counselors' skills in creating lasting change. This study can also contribute to further understanding factors that facilitate or hinder implementation of comprehensive guidance and counseling programs. In a practical sense, it was the 
researcher's hope that the findings of this study may prove useful to the Center for Student Support Systems (CS3) administered by University of San Diego's School of Education, whose goal is to "strengthen the link between research and practice among school counselors ... and to strengthen regional and state databases regarding the design, implementation, administration, and evaluation of comprehensive, results-based guidance counseling and support student programs" (February 2, 2003, \6). It was also the researcher's hope that sharing strategies used to successfully gain support from stakeholders to implement comprehensive guidance and counseling programs may increase the success of other counselors in creating change.

\section{Definition of Terms}

The following terms have been defined for clarification purposes:

National Standards for School Counseling Programs: The National Standards are defined as the "essential elements of a quality and effective school counseling program. The standards address program content and the knowledge, attitudes and skill competencies that all students will develop as a result of participating in a school counseling programs" (Campbell \& Dahir, 1997, p. 3).

Comprehensive Guidance and Counseling Programs: A comprehensive guidance and counseling program consists of three components: content, an organizational framework and resources. According to Gysbers (2001), "It focuses on results and emphasizes an organizational structure consisting of content (competencies), organizational framework (structural components and program components), and resources (human, financial, and political)" (p. 101). The goal of comprehensive guidance and counseling programs is that "all students can and should profit from the activities and services to facilitate their 
academic, personal/social, and career development" (Gysbers, 2001, p. 103). Overall, the comprehensive guidance and counseling programs emphasize serving "equally all students, parents, teachers, and other recipients . . . It means understanding students' cultural, sociological, psychological, economic and family backgrounds" (Gysbers, 2001, p. 103).

Student Support Services: According to the U.S. Department of Education, "The Student Support Services (SSS) program provides opportunities for academic development, assists students with basic college requirements, and serves to motivate students towards the successful completion of their postsecondary education" (March 6, $2005,11)$. The U.S. Department of Education further states that, "The goal of SSS is to increase the college retention and graduation rates of its participants and facilitate the process of transition from one level of higher education to the next" ( 11 ). Under the umbrella of student support services are counseling, attendance improvement, school psychologist (special education testing), dropout prevention and recovery, social services and foster youth programs. Specifically, counseling services can include guidance curriculum, individual student planning, and direct services that address the academic, career, personal, and social development of students.

Results-Based Student Support Programs: Results-Based Student Support Programs, a model created by Johnson and Johnson (1991), emphasize the identification of student outcomes and "specific-based guidance competencies" (p. 12) "that focus on the student as the primary client, not on the services provided" (p. 11). This type of program increases the ability of counselors to meet the needs of students as well as gives counselors the ability to demonstrate accountability through meeting standardized 
student competencies.

Ancillary Services: Guidance and counseling programs have traditionally been based on ancillary activities - counselors performing a combination of counseling (individual counseling, group counseling, etc.) and non-counseling (scheduling, lunch duty, discipline etc.) duties instead of creating comprehensive guidance and counseling programs based on measurable competencies.

Key Stakeholders: These are individuals or groups who affect or are affected by any change within an organization. For this particular study, key stakeholders include school counselors, student support personnel, principals, assistant principals, district staff responsible for supervision of student support services, teachers, students, parents, community members, school board members, and superintendent.

\section{District Staff Responsible for Supervision of Student Support Services: School} districts often have personnel who are responsible for managing all student support services within the district. They often provide training for all counselors as well as hold meetings that allow counselors within the district to interact with one another.

Strategies: This refers to any type of planning, managing, and/or directing that school counselors perform in order to gain support from key stakeholders to implement comprehensive guidance and counseling programs.

Gaining Support: For the purposes of this study, gaining support is the process in which counselors "sell" their idea of creating comprehensive guidance and counseling programs to key stakeholders. It is the leadership styles and strategic planning that counselors use in order to "sell" this new program. 


\section{Limitations of the Study}

The results of the study are not generalizable to guidance and counseling programs in general because only six schools participated in the study. Instead, this study seeks to take the first steps in examining a topic that has not been fully explored. The study seeks to explore strategies that counselors used to gain support for implementing comprehensive guidance and counseling programs. While results are not directly generalizable to other guidance and counseling programs, the information gained may lead to further research studies in this area.

A second limitation is the inability of counselors and key stakeholders to recall the process of gaining support. Although the study only used guidance and counseling programs that have gained support within the last three to five years, detailed recollections regarding individuals' feelings, perceptions, behaviors as well as strategies used to gain support may not be as clear as when they were undergoing this process (Sudman \& Bradburn, 1982).

A third limitation of the study is that data was based on self-reports from counselors and administrators regarding their experience with gaining support to implement comprehensive guidance and counseling programs. Data based significantly on the experiences and perspectives of participants are "subject to distortion because of the attitudes or roles of the informant in the community" (Sudman \& Bradburn, p. 115). In order to minimize this third limitation, the researcher encouraged participants to review interview transcripts to ensure accuracy. This hopefully reduced any misinformation or inferences inadvertently made by the researcher as participants had the opportunity to correct any mistakes in translation or interpretation of interviews. 
A fourth limitation is researcher bias. As the researcher is an advocate of implementing comprehensive guidance and counseling programs, the researcher may have inadvertently influenced the data through the interviewing process or through interpretation of the data in order to conclude with favorable results. However, through following an interview protocol, sound interview techniques and data analysis procedures, errors surrounding influencing or leading participants in their answers were hopefully reduced.

Lastly, the study focuses on strategies that counselors' used to gain support to implement comprehensive guidance and counseling programs. Therefore, the researcher assumes that the impetus to implement this type of change was initiated by school counselors. However, this may not always be the case. Some schools that have created change within their guidance and counseling programs may have done so based on the initiative of the school district, the staff responsible for the supervision of student support services within a district, school administrators or some combination of all these stakeholders, rather than the initiative of counselors.

\section{Organization of the Study}

This chapter provided the background to the study and discussed the statement of the problem. The purpose of the study and the importance of studying how counselors gain support from key stakeholders to implement comprehensive guidance and counseling programs were also discussed. The four research questions and definition of terms used in the study were listed as well. The chapter concluded with limitations of the study.

To provide background to the challenges that counselors face in creating change, chapter two highlights the difficulties in creating change within school systems and how 
counselors can apply organizational change theories to make change successful. Chapter two also discusses leadership issues and the need for counselors to take a leadership role in gaining support to implement comprehensive guidance and counseling programs.

A detailed explanation of the methodology used in the study is outlined in chapter three. The data for this study was collected through a series of interviews with counselors, administrators and district personnel responsible for supervision of student support services. Open-ended questions were asked in order to allow participants to fully discuss their experiences related to creating change in their guidance and counseling programs (Merriam, 1998). These questions were directly related to the research questions of the study, which provided the basic framework to this study. Human subject concerns as outlined by the University of San Diego Committee for the Protection of Human Subjects are discussed as well.

Interviews from the six schools were analyzed looking for common practices and strategies utilized to gain support from key stakeholders to implement comprehensive guidance and counseling programs. Comparisons were also made between participants' views and responses to determine commonalities that facilitate the implementation of comprehensive guidance and counseling programs. This information will be presented in chapter four.

Chapter five concludes the study by reviewing the purpose and research questions, summarizing the review of the literature, presenting the findings, identifying further recommendations as well as areas for future research. 


\section{CHAPTER TWO: REVIEW OF THE LITERATURE}

\section{Introduction}

The review of the literature further explores the rise of the comprehensive guidance and counseling program model and the challenges counselors face in implementing this new approach. The purpose for the literature review is to examine current research regarding organizational change and school reform in order to better understand barriers that counselors face in implementing comprehensive guidance and counseling programs.

The body of research discussed in the literature review includes only a few research studies focusing on the actual experience of creating change within school counseling programs due to the limited research that could be found on this topic. Instead, articles and books written by school counseling professionals have been included that provide background information and conceptual discussions related to the challenges counselors face in creating change. Research on organizational change and creating change within education systems was included as these topics also shed light on the challenges counselors face in conducting change efforts. According to Goens and Clover (1991), "Schools have not only been resistant to reform, but they appear to be immune to longterm, significant change" (p. 37). Understanding the general complexities of creating change within organizations as well as the history of school reform and why so many proposed changes have failed is critical in investigating challenges that counselors face in gaining support to implement comprehensive guidance and counseling programs.

The literature review is divided into four sections. The first section explores literature concerning the need for change in school counseling programs and the significance of counselors stepping into a leadership role to gain support from key stakeholders to 
implement new programs. As the most difficult challenge counselors' face is creating systemic change within school systems, next follows a discussion of theories regarding why school reform efforts have failed and an examination of effective strategies that have been used to successfully create change. Third, a review of organizational change theories and how counselors might apply these theories to successfully create change in their school counseling programs is presented. The chapter concludes with a review of strategies that researchers in organizational change have identified as effective in creating lasting change.

\section{Change in School Counseling Programs}

Some taxpayers, to include school board members, administrators, teachers, parents and community members repeatedly question the need for school counselors in this era of ever-increasing educational costs. "How do we know that what counselors do is effective and contributes to students' academic achievement?" (Schwallie-Giddis, Maat, \& Park, 2003 , p. 170) is a question that is asked repeatedly by school board members, administrators, teachers, parents and local community taxpayers with no satisfying answer (Schwallie-Giddis et al.). According to Dahir and Stone (2003), "Accountability governs $21^{\text {st }}$ century school buildings and systems" (p. 214). Dahir and Stone define accountability as "Sharing responsibility to collectively remove barriers that impede learning and involves all the critical players in a school setting" (p. 215). The school counselor is one of these critical players and is faced with the challenge of organizational change to remain in step with today's educational requirements and, more importantly, to maintain credibility with the paying public and key stakeholders.

Historically, responsibility for demonstrating accountability was placed directly on 
principals and teachers (Dahir \& Stone, 2003). Today, counselors are also expected to demonstrate their "overall effectiveness" in meeting school goals (Fields \& Hines, 2000). Overall effectiveness is determined by factors such as academic success, lower drop out rates, positive school climate, and decrease in violence. According to Campbell and Dahir (1997), The National Standards provides a model that assists counselors in "planning, developing, and evaluating a school counseling program which is comprehensive, developmental, and systematic" (p. 4). Implementing comprehensive guidance and counseling programs based on the National Standards allows counselors to demonstrate their role in improving student achievement. If counselors are going to survive the accountability era they need to create a counseling program that allows them to be accountable. A comprehensive guidance and counseling program allows counselors to meet both student needs and school-wide objectives by establishing goals, outlining procedures and services to meet goals, and collecting data to support stated accomplishments (Myrick, 2003). The following section discusses the rise of comprehensive guidance and counseling programs and the importance of counselors stepping into a leadership role to gain buy-in from key stakeholders regarding changes needed to better serve students.

\section{The Rise of Comprehensive Guidance and Counseling Programs}

According to Johnson and Johnson (2003), "Although education has undergone numerous reform movements, most guidance programs have stayed the same changed only by adding new duties and responsibilities in response to each new educational crisis" (p. 180). Reviewing the evolution of guidance and counseling in schools, many researchers (e.g., Gysbers, 2001; Gysbers \& Henderson, 2001; Herr, 2002; Johnson \& 
Johnson, 2003) have stated that counselors' duties have changed based on current social trends or community needs. For example, in the beginning, school counseling focused on vocational guidance in an attempt to prepare students for work. As the industrial revolution changed worker requirements, focus centered around preparing young adults to enter the industrial workforce. Another example is the passage of the National Defense Education Act of 1958 as a result of the Soviet launching of Sputnik. The overwhelming concern that America was losing the technology race resulted in an increase in the number of counselors in secondary schools to ensure that students who demonstrated strong aptitudes toward math and science were guided toward that direction (Herr, 2001).

Today, counselors' duties continue to change based on current social trends or school needs, not the needs of students. For instance, in times of budget cuts, counselors often find themselves performing more administrative duties such as discipline or more clerical duties such as inputting class schedule information in the computer. Eventually, these types of duties become permanent adding more non-counseling duties to a counselor's job. This trend is called "mission creep," and has caused counselors to spend "eighty percent of their time responding to the needs of twenty percent of their students, typically high achieving or high risk" (Hatch \& Bowers, 2002, p.15). What is more, according to Gysbers (2001), "One message that emerges from a review of the past is that there have been and there continues to be a wide variety of purposes put forward for guidance and counseling by many different groups" (p. 101). The result is the creation of counseling programs that are position-service orientated (Gysbers \& Henderson, 2001). In other words, the focus is on the position and duties counselors perform rather than developing a holistic guidance and counseling program integrated into the overall educational program 
offered by schools.

In the 1970s' the concept of "guidance and counseling for development" (Gysbers \& Henderson, 2001, p. 248) emerged which emphasized the need to focus on the program of guidance and counseling not the position of counselor. The new organizational structure provided by various models of comprehensive guidance and counseling programs (Gysbers \& Henderson, 2000; Johnson \& Johnson, 1991; Myrick, 1987) emphasized creating holistic guidance and counseling programs, that are "results-based featuring reviews and evaluations" (Myrick, 2003, p. 175). Johnson and Johnson (2003) add, "Services have traditionally been based on student demand and local need. Competencies are based on professionally identified educational, career, and personal/social needs of students" (p. 181). According to Herr (2001), "The planning and implementation of comprehensive guidance programs continue to evolve as the desired standard approach to school counseling in the United States" (p. 244). Change is slow, however, since key stakeholders must first change their perspective of counseling and realize the importance of creating a comprehensive guidance and counseling program rather than adding or changing the duties of counselors in response to current crises. Stepping into a Leadership Role

Although research supports the significant impact of comprehensive guidance and counseling programs (e.g., Gysbers \& Henderson, 2000; Gysbers and Henderson, 1997; Sink \& MacDonald, 1998), counselors are plagued by barriers that interfere with the likelihood of successfully implementing such change. Barriers include a lack of consistency and agreement about counselor roles (e.g., Gysbers, 2001; Louis et al., 2001; Paisley \& McMahon; 2001; Sears et al., 2002); counselors' limited collaboration efforts 
with staff, parents, and/or outside agencies to provide support to students (e.g., Bemak, 2000; Bemak \& Hanna, 1998; House \& Hayes, 2002); counselors' limited participation in school politics (e.g., Allen, 1998; Gysbers et al., 2000); and a need for leadership and change agent skills among counselors (e.g., Baker, 2000; Dollarhide, 2003; Hatch \& Bowers, 2002; House \& Hayes, 2002; Johnson \& Johnson, 2002; Rowell, 2002; Taylor \& Adelman, 2000).

Counselors' most significant challenge may be stepping into a leadership role. According to Hatch and Bowers (2002), "Leadership skills are critical to the successful implementation of new or remodeled programs at the school, district, and state levels" (p. 16). However, there are questions surrounding what constitutes good leadership and what leadership practices can lead to successful change. Bolman and Deal (1997) believe that leaders rely on a personal "frame" (or context) to gather information, make judgments and make decisions. According to Bolman and Deal, "Frames are both windows on the world and lenses that bring the world into focus. Frames filter out some things while allowing others to pass through easily. Frames help us order experience and decide what to do" (p. 12). Today's organizations are complex, deceptive, and turbulent. This makes it difficult to manage. Perspectives that are too narrow or clouded lead to poor decisionmaking and poor leadership. Bolman and Deal's frames help leaders see the larger picture and prevent outside influences (judgments, biases, etc.) from creating road blocks to change. Organizations are filled with individuals who have different interpretations of what is happening at any given moment. Each of these interpretations holds some truths as well as some biases and judgments. Leaders that are able to match frames to particular situations have the advantage of seeing a complex problem from a certain perspective. 
that allows decision-making to be more effective. The four frames include Structural, Human Resource, Political and Symbolic. Based on Bolman and Deal's (1997) theoretical framework of leadership, Dollarhide (2003) believes:

If school counselors are to be leaders of school counseling programs and transformation efforts, understanding the contexts in which leadership occurs, the activities involved in each context, and the skills required for those activities can be a way of conceptualizing and applying effective leadership of school counseling programs (p. 304).

Dollarhide emphasizes the need for "effective leadership" by counselors in order for them to become more active in school reform movements. Dollarhide, supported by House and Hayes (2002) and O'Dell and Rak (1996), believes "Effective leadership is evident when there is a strong counselor commitment to organize the program around student competencies and when the counselor's time is devoted to the design, implementing and accounting for a comprehensive school counseling program" (p. 305).

Using Bolman and Deal's (1997) four leadership frames Dollarhide (2003) outlines how effective leadership can assist counselors in successfully creating change. The first frame is Structural Leadership which emphasizes "goals, specialized roles and formal relationships" (Bolman \& Deal, p. 13). In this frame, individuals are focusing on creating rules and policies, establishing goals and allocating responsibilities to staff. According to Dollarhide, counselors in this frame are leading activities that create the groundwork for establishing a comprehensive guidance and counseling program. This can include collecting data to determine student goals and needs, assigning different roles and/or duties to other counselors and support staff, establishing new policies, and creating teams focusing on implementing change.

The second frame is Human Resource Leadership. This leadership frame views 
organizations as an extended family that involves individuals who have "needs, feelings, skills and limitations" (Bolman \& Deal, 1997, p. 14). Leaders in this framework see the potential resources that people have to offer with their positive attitude, energy, skills and ideas. They stress the relationship between people and organizations. In this context, Dollarhide (2003) indicates counselors are visible and accessible, believe in people and express this belief to others, and work to empower others to believe in it too. Skills needed in this framework are "communication, empowerment, trust building and listening" (Dollarhide, p. 305).

The third frame is Political Leadership. In this frame, leaders view organizations as jungles or contests. Organizations are in constant conflict because of high competitiveness and high diversity among employees. People manipulate, create alliances for personal gain, and use coercion to move ahead. Leaders view conflict as normal and inevitable. In fact, conflict can lead to positive outcomes because new ideas or solutions to problems can be introduced. There is a winner mentality in this framework where the winner holds all the power. In this framework, Dollarhide (2003) states that counselors build stronger relationships with stakeholders, use persuasion and negotiation to create change, are aware of the informal and formal structures of power in the school, and advocate for the implementation of comprehensive guidance and counseling program. Skills needed for these activities are "negotiation, persuasion, collaboration and advocacy" (Dollarhide, p. 305).

Unfortunately, Dollarhide (2003) says that "Political leadership, however, may be a more non-traditional role for many counselors and cause counselors to experience anxiety and dissonance" (p. 305). As a result, the political leadership frame may be difficult for 
counselors to use in making decisions. By nature of their jobs, counselors often spend most of their time helping students whether it is through individual counseling or scheduling classes. Consequently, most counselors are not aware of the political trends within their schools, districts, or even at the state level. In addition many counseling graduate programs do not prepare counselors to be political activists or advocates of change (Lee, 1988). So these roles are often foreign and uncomfortable for counselors as they have had no training in this area. However, if counselors are going to lead the way to change they will need to be skilled in using the tools associated with the Political Leadership frame. According to Rowell (2002),

All the new models, new standards, new programs and new techniques in school counseling are either privileged into practice or shrugged off to institutional backburners or academic dustbins by the political decisions of legislatures, governors ... school boards, superintendents, principals, and others (p. 4).

In order to ensure that comprehensive guidance and counseling programs are not ignored, counselors need to become better acquainted with school politics. Bemak (2000) further argues that in order for counselors to become key players in school reform, they need to be aware of social and political trends since these trends often dictate the types of reforms that are implemented.

The last frame is Symbolic Leadership, which views organizations as a culture with beliefs, values and customs. Organizations are like a theatre where employees are actors acting out a role (Bolman \& Deal, 1997). Dollarhide (2003) states that in this frame counselors become "effective models in efforts to meet the needs of students, inspiring others to follow their example" (p. 305). They establish relationships with the community and articulate a vision surrounding the success of students and have faith in the vision. Skills needed in this frame are "expressing vision clearly, inspiring others, modeling 
behaviors and designing symbols" (Dollarhide, p. 305).

Bolman and Deal (1997) state, "Multiple realities produce confusion and conflict when individuals view the same event through different lenses" (p. 266). From situation to situation, leaders can use the different leadership frames to make decisions. In one situation, collecting and analyzing data is needed, yet in another situation, building communication is necessary. As counselors step into a leadership role to advocate for comprehensive guidance and counseling programs they can rely on these four frameworks of leadership to strategize how to gain support from key stakeholders to create change.

\section{Creating Change in Education}

Despite the numerous school reforms that have been introduced to schools (e.g., year round schools, business-school partnerships, privatization of schools and magnet schools, etc.) most school reform initiatives do not last. According to Perelman (1987), "Public education is an extremely conservative social institution. It has resisted innovation in the past more thoroughly than other segments of society" (p. 12). What is more, the education system is tightly interconnected. Changes made in guidance and counseling programs do not just remain within the school counseling department but involve the entire education system. All staff members and departments within the school and school district are affected by any change that occurs. Therefore, if counselors are going to be able to implement comprehensive guidance and counseling programs, gaining support from the administration team, school staff, students and parents is essential.

Furthermore, in order to ensure that counseling and guidance programs do not just become another idea swept away by the rigid and unyielding structure of school systems, 
examining why past school reforms have failed is important. This section examines school reform and highlights barriers to creating change within education.

\section{Why Change Fails in Education}

Theorists have offered a variety of explanations for the failure of school reform initiatives. Fullan (1997) believes change is difficult to sustain in education not due to resistance, but due to the proliferations of numerous innovations that are continuously being implemented in schools. For instance, in the 10 years between 1987 and 1997, approximately 361 ideas were proposed in order to improve schools (Carpenter, 2000). Fullan (1997) further states there is now an expectation that to "fix" schools new innovations must be introduced. This is why school stakeholders react to public criticism or concern by adapting the latest innovation. Examples of "hot" innovations are sitebased management, peer coaching and mentoring, and cooperative learning.

In addition to the many innovations that are introduced to schools, Herr (2002) asserts school reforms fail because the ideas proposed have not been well thought out. In his view, many reform proposals suggested do not consider outside factors that may affect the success of the reform. Outside factors may include the socioeconomic, ethnic, and cultural background of students; the environment in which the school is situated; the amount of parent involvement; and politics and budget allocations. According to Herr (2002), "It is as though the persons proposing school reform assume that schools occur in a vacuum, that they are unaffected by the social and economic conditions that swirl around schools and that create individual children's needs" (p. 223). For example, school reforms focusing on increasing curriculum standards and making teachers more accountable for student learning assume that these steps will automatically improve 
student outcomes (Herr, 2002). However, students are facing a variety of issues (family, peers, cultural diversity, etc.) that interfere with their ability to learn. Making teachers more accountable for student outcomes is not going to improve student achievement if barriers to learning are not removed first.

Another reason why change is difficult to create is because during the early stages of the change process, people are filled with anxiety, uncertainty and fear of the unknown (Fullan, 1997). As a result, people need to believe in the necessity for change before they are willing to give their support. Schools that adopt one innovation after another create an environment where change is not considered valuable. This attitude becomes part of the school culture and soon new innovations are treated as annoying new procedures that must be completed. There is no buy-in to the positive impact the innovation may have on student learning. Without buy-in, these new innovations do not last. According to Morgan (1988), "In the management of innovation, it is very important to create a climate, or corporate culture, in which value is placed on the ability to learn, to change, and generally to develop and promote new ideas" (p. 70).

Tyack and Tobin (1994) believe failure to gain support or "buy in" from key stakeholders often results in failure of school reform. Morgan (1997) further states that in today's organizations, stakeholder power is becoming stronger than shareholder power. Organizations are influenced and "run" by these stakeholders. As a result, involving stakeholders in the planning process or just to solicit feedback is critical to successfully creating change. Tyack and Tobin believe that many school reform leaders "lack political savvy" (p. 477) to obtain buy-in from key stakeholders. To gain support there is more involved than just having a good idea. One must be able to market it to the right people to 
convince them that change is needed because without full support there is little likelihood that it will take root.

Schwann and Spady (1998) observed hundreds of schools implementing change efforts and they discovered five interdependent reasons why productive change did not occur: Purpose wasn't compelling enough, didn't develop the purpose right, didn't start using it immediately, didn't align people, and didn't align the organization. The results of this study demonstrate the importance of developing and sharing a clear vision, linking change to positive outcomes and meeting organizational goals, and immediately modeling the new behaviors for others to follow. Fullan (1997) states "New ideas of any worth to be effective require an in-depth understanding, and the development of skill and commitment to make them work' (p. 37). Therefore, in order for counselors to align stakeholders behind their organizational change, everyone must have a thorough understanding of the meaning behind the proposed change.

"The purpose of educational change presumably is to help schools accomplish their goals more effectively by replacing some structures, programs and/or practices with better ones" (Fullan \& Stiegelbaurer, 1991, p. 15). This purpose has become lost in the many innovations that have been presented and adopted in school systems. In order to successfully gain support, counselors need to convince stakeholders that comprehensive guidance and counseling is not just another idea. To accomplish this, counselors will have to show the connection between comprehensive guidance and counseling programs and improved student achievement.

\section{Making Change Successful}

Clearly, a critical component for counselors to create change within schools is gaining 
support from key stakeholders. In particular, principals play an important role in creating change within a school as they are the leader at the school site. If counselors are going to move forward in implementing comprehensive guidance and counseling programs, they will need to gain the support of their principals. Fullan (1992) indicates "Much research points to the critical role of the principal's support for implementation of educational innovations at the school level" (p. 49). In order to effectively implement change, the principal must take an "active role in initiating and/or responding to change efforts within the school" (p. 49). Fullan (1992) further states, "When principals pay attention to particular innovations, there will be a greater degree of implementation in the classrooms of the school" (p. 82-83).

In a study conducted by Anderson and Shirley (1995), the ability to implement the Coalition of Essential Schools' Nine Principles within 15 schools was explored. The researchers concluded that the principal played an important role in the likelihood of the project being successful. Principals had the knowledge regarding the purpose of the project and were willing to provide the leadership to ensure the success of the project. In addition, Anderson and Shirley noted that "Community, district, and external factors tended to inhibit successful project implementation, rather than facilitate it" (p. 420).

In another study, Berman and McLaughlin (1977) found that the principal sets the tone for teachers in whether to take change seriously or not. Along with support from the principal, gaining community support is also very important. Fullan (1992) notes, "Community support for or against change is likely to be a major factor in local decisionmaking and commitment" (p. 51). Fullan (1992) further states that when parents support 
a new innovation and apply the necessary pressure, they increase the likelihood of school board members and administrators supporting the change. On the other hand, parents who oppose a particular innovation can "easily thwart implementation, no matter how good the innovation or how committed school personnel are to its use" (p. 51).

Lehr and Sumarah (2002) conducted a study that focused on factors that impact the successful implementation of comprehensive guidance and counseling programs. They found success depends on the participation and support of others in the school and adequate time and resources allocated to the program. Lehr and Sumarah summarized that the collaboration between principals and counselors is important to successfully implementing comprehensive guidance and counseling programs. On an interesting note, counselors involved in the study believed, "Success of their program was directly related to the strong leadership and support given by Department of Education, school boards, and principals" (p. 297).

Last, Peterson, McCarthy and Elmore (1997) conducted research on three schools that successfully created change. The researchers discovered these similarities in each of the schools: Teachers met together to discuss curriculum and instruction in both whole groups and small teams, all staff members were involved in shared decision making about personnel, resources, instruction, and curriculum, and they all created a vision or philosophy statement related to student learning that was enacted through the structural changes.

These research studies support the importance of counselors gaining principal support to successfully create change. As principals are the school leader they have the ability to facilitate or hinder counselors' efforts to implement comprehensive guidance and 
counseling programs. What is more, collaboration and participation of all stakeholders in the change process help to ensure that changes do not remain superficial but become rooted into the school culture.

\section{Organizational Change}

Overall, creating change within an organization is extremely difficult since true change requires the culture of the organization to undergo a transition. Goens and Clover (1991) believe that "change and transformation require a great deal of risk taking by a large number of people" (p. 101) who must change their way of thinking and disregard old assumptions in order to take on new ones. Counseling has existed for years as an ancillary service in schools, without the framework of comprehensive guidance and counseling programs. The focus has been on the job duties of counselors and not on creating a comprehensive program comprised of standards, competencies and services. Implementing comprehensive guidance and counseling programs will require stakeholders to change their old ways of thinking about counseling and recognize the importance of creating a holistic guidance and counseling program. According to Pecca (1994), "because change is giving up the old for the new, this give up process is the most difficult element of change because of the individual's need for security which is based upon familiarity" (p. 7).

Understanding the complexities associated with the transformation process of "letting go" can better prepare counselors to not only gain support from key stakeholders but maintain that support as well. According to Quinn (1996), "Deep change can occur at both the organizational and the personal level" (p. 4). Understanding the complexities of change at both levels can provide counselors with insight into barriers that prevent deep 
change and strategies to overcome barriers to make change successful.

\section{Change at the Organizational Level}

According to Quinn (1996), "Organizations and change are not complementary concepts" (p. 5). Organize is defined as "to establish or to institute" (Webster's New World Dictionary, 1987). Quinn defines organize as "to systematize, to make behavior predictable" (p. 5). Organizations respond to both external and internal expectations. For example, a high school counselor's external expectation is that all students will pass required classes to graduate with a high school diploma. The internal expectation is the procedures and rules related to class registration and failing or passing a class. Quinn states that as these expectations become formalized they ensure the organization runs smoothly. A negative side effect is that behavior becomes stagnate and predictable. Soon these behaviors take root and become embedded into the culture of the organization.

As today's society is continuously reacting to the environment, an organization must have the ability to be flexible and change as needed to meet society needs. According to Quinn (1996), an organization that allows itself to become routine and predictable will eventually move toward decay and stagnation because it will not be able to remain competitive and meet customer needs. In this context, counselors are currently facing a slow death as they have allowed themselves to become trapped in their routine services and predictable behaviors. They can no longer meet student and community demands and the result has been that "customers" do not see them as a valuable service and have slowly turned elsewhere. When decay begins, an organization has a choice: Adapt or continue the road toward slow death. Slow death occurs when the option for deep change is rejected and keeping the status quo is accepted. From this perspective, for years 
counselors have rejected deep change and as a result, they have continued down a path of gradual disintegration within the school system.

Today counselors have the opportunity to make positive changes through the implementation of comprehensive guidance and counseling programs. Many counselors have decided to reject the status quo and accept the challenge of creating deep change within their school counseling programs. Despite this motivation and determination, creating change is difficult as many counselors have never stepped into a leadership or change agent role. Applying models of organization change for problem-solving and strategic planning may help counselors successfully create change.

\section{Systems Theory}

Creating change in today's organizations is not a solitary event. Change eventually infiltrates every aspect of an organization. The Systems Theory recognizes the complexity involved in creating change and emphasizes the importance of looking at "patterns of change rather than static "snapshots"" (Senge, 1990, p. 68). Furthermore Systems Theory "emphasizes the multiplicity and complexity of factors that affect the functioning of any person or group over time" (Evans, 1996, p. 11). From the systems perspective a change in one part of the system causes a ripple effect leading to changes in other parts of the system (Keys, 1999). A good example is an elementary school that has a bullying problem among fourth graders. This problem leads to higher discipline problems in the classroom, decrease in academic performance among students who are being bullied, and an increase in parent telephone calls regarding how their children are being treated in school. In response to these negative behaviors, a counselor presents a series of classroom lessons on bullying to all fourth graders. The outcome is that more 
students feel comfortable to let the counselor know if they are being bullied leading to the identification of students who are bullies or are showing signs of becoming bullies. The counselor can provide support groups to students who are being teased as well as intervention groups to modify the behavior of students who bully. As a result, teachers have less discipline problems in the classroom and send fewer referrals to administrators. Students are able to focus more on their academic studies which improve their grades and test scores. Parents are happy that the school responded to their concerns and have created a solution to the problem.

From a systems perspective the previous event has lead to several outcomes. First, the counselor has demonstrated how counseling services can decrease referrals and help students improve their academic abilities. Second, the counselor has demonstrated that counseling services can help in reducing the number of referrals sent to the administrators. Third, the counselor has demonstrated to parents that they are a support to their children and offer a valuable service. All of these outcomes are directly connected to the counselor providing classroom lessons on bullying. This example demonstrates that individuals can create change within systems by performing a simple task and individuals can change as a result of change in the larger system (Keys, 1999).

System thinkers also believe in the importance of remaining abreast of the broader, "underlying systemic patterns" (Evans, 1996, p. 10) in order to help organizations successfully cope with change. As today's society is interconnected and interdependent, "problems are usually embedded in complicated and interactive webs that cannot be viewed or dealt with from one single perspective" (Luke, 1998, p. 11). As a result, System Theorists emphasize the importance of looking at the broader picture from many 
different perspectives in order to find the true heart of the problem. Heifetz (1994) refers to looking at the broader picture as "getting on the balcony ... to discern the larger patterns on the dance floor - to see who is dancing with whom, in what groups, in what location, and who is sitting out which kind of dance" (p. 254). According to Heifetz (1994), if you are dancing on the dance floor, you are easily distracted by the music, your dance partner and dance steps. Thus, you cannot observe what is happening underneath the surface. You need to reach the balcony to determine the heart of the problem.

Counselors wishing to create change must first be able to reach the balcony and discern what is really happening within the organizational structure of their school. For example, accountability is an important part of a school because it is connected to funding. Schools that show their students are meeting state academic standards and achieving the necessary scores on tests will receive praise from the school district and the state. This leads to continued support and funding. With this knowledge counselors can use accountability to gain support because comprehensive guidance and counseling programs are standards-based and are aligned with school and state goals. Thus, implementing this program helps schools meet their achievement goals. Connecting the change to positive outcomes such as improving achievement or meeting school standards helps counselors align and maintain support for change. Unfortunately, counselors have difficulty seeing the "bigger picture" because their role has been reduced to being "gatekeepers of the status quo" (House \& Martin, 1998, p. 286). House and Martin further state that as gatekeepers, counselors become "sorters and selectors rather than advocates" (p. 286). Counselors have allowed their role to be reduced to a collection of non-counseling duties as a result of being easily influenced by administrators and a lack 
of leadership (Walz, 1997). Breaking this tradition is important if counselors are going to be able to reach the balcony where they can collect the necessary information to recognize that change is needed and to strategize how to gain support for change.

\section{Chaos Theory}

Today's organizations are surrounded by uncertainty, confusion and rapid changes. Chaos Theory acknowledges these characteristics and emphasizes accepting the randomness and irregularities and watching for "random energy patterns and facilitating their movement toward organizational goals" (Snyder, Acker-Hocevar \& Wolf, 1995, p. 31). This theory is about "learning and adapting under unstable and uncertain conditions" (Fullan, 1999, p. 6). In order to create change, Chaos Theory encourages one to embrace the "natural order of chaos and to guide patterns of irregularity toward a vision, mission and a set of goals" (Snyder et al., p. 32). Trying to predict or analyze what may happen is impossible under these extreme conditions and decisions made on these premises often lead to wrong conclusions. Yet despite this confusion and chaos, behaviors are not random (Goff, 1998), but are based on external or internal decisions that lead to patterns (Hannah, Smeltzer-Erb, \& Ross, 2001). So while the change process cannot be controlled as it is filled with uncertainty and confusion, patterns that emerge can be identified and conditions can be created to foster positive patterns rather than negative ones (Hannah et al., 2001).

For example, counselors wishing to implement comprehensive guidance and counseling programs cannot predict the impact that this change may have on the organization or individual. Creating scenarios or strategic plans based on assumptions is dangerous and often leads to failure. However, counselors can identify negative patterns 
(counselors performing lunch duty, registration, discipline) that are occurring in the counseling department and foster conditions that will change these patterns into positive ones (classroom guidance lessons, group counseling, and career counseling).

According to Hannah et al. (2001), a common image used in Chaos Theory is that of a butterfly flapping its wings. Morgan (1997) states that as a butterfly flaps its wings, this act has a substantial impact on another part of the system which in turn affects another part of a system and so on. The insignificance of a butterfly flapping its wings therefore creates a ripple effect that touches every aspect of a system. Thus, counselors wanting to move toward comprehensive guidance and counseling programs need to understand that schools are not static entities. A school is a living, breathing entity that reacts, grows, and changes based on its surroundings. As a result, Chaos Theory literature emphasizes the importance of collaboration with all parts of the system (Gunter, 1995). In other words, inviting stakeholders from different departments to be involved in the change process is invaluable for several reasons: (a) counselors have the opportunity to gain buy-in from stakeholders, (b) as changes in the counseling department create a ripple effect, stakeholders' involvement may minimize the negative reaction to changes, and (c) stakeholders' perspective of the change can provide unique insight that can help in planning for change.

Counselors face many challenges in creating change within school systems. However, understanding the complexity of organizations and how to change the inner workings of an organization is important if counselors hope to succeed. Organizational change theories all discuss the interconnectedness of all systems within an organization. Any change in one system creates a domino's effect creating change in other systems. 
Therefore, the ability of counselors to reach the balcony to visualize this domino's effect is essential in identifying current patterns and creating strategies to foster positive changes leading to the implementation of comprehensive guidance and counseling programs.

\section{Change at the Individual Level}

Quinn (1996) states,

In an age of continuous change, organizations must match their environments by being more responsive, and people must match their organizations by being more responsive. If organizations must make deep change more frequently, so must the people who work in organizations (p. 6).

Just like organizations can become stagnate and predictable, so can individuals. Once predictable behaviors and patterns become embedded in the culture of an organization change is difficult to create. Schein (1985) defines organizational culture as "the deeper level of basic assumptions and beliefs that are shared by members of an organization" ( $p$. 6). These assumptions and beliefs are so automatic and ingrained that people perceive them as the "correct way to perceive, think and feel" about problems (Schein, 1992, p. 12). When change is introduced within an organization it threatens its culture, which is why creating change can be extremely difficult. According to Goens and Clover (1991), change affects the "daily rituals, ceremonies, and symbols" of an organization causing anxiety (p. 90). Furthermore, the stronger the culture, the harder it can be to create change. Goens and Clover also state, "Culture causes organizational inertia; it's the brake that resists change because that's precisely what culture should do - protect the organization from willy-nilly response to fad and short-term fluctuation" (p. 158). Therefore, in order to create change within an organization, "a shift in the perception of reality and how one thinks about it" (Goens and Clover, p. 9) must occur. Fullan (2001) 
refers to this process as "reculturing" or changing the way things are done within an organization (p. 44). For example, for change to occur in guidance and counseling, counselors need to convince stakeholders that the way guidance and counseling programs currently operate must change to better serve students and to improve fiscal accountability. Additionally, a comprehensive program of guidance for all students should be at the center of day-to-day school life, not at the periphery.

Most organizations do not change just because they are requested to do so. According to Goens and Clover (1991), "Neither people nor organizations change unless they perceive the necessity to do so" (p. 19). Even after key stakeholders recognize the need for change and are willing to support change, there is still the challenge of letting go of the "old ways." For example, in the comprehensive guidance and counseling program model counselors do not handle student discipline. For some counselors and administrators letting go of this duty may be difficult for different reasons. Some counselors enjoy the responsibility of disciplining students because they feel they are a part of the administrative team. Furthermore, refocusing on supporting students rather than disciplining students can be a challenging transition especially if discipline has been part of a counselor's job for a lengthy period of time. For administrators, this type of change may be viewed as negative because it adds more responsibility to their already busy day. Understanding the affects that change can have on key stakeholders both professionally and emotionally is important in maintaining the support and keeping stakeholders focused on why change is needed.

Overall, creating change within an organization is a complex task that must overcome many obstacles along the way. The complexity of creating change is summarized by 
Marris' (1975) statement, "The impulse to preserve the thread of continuity is thus a crucial instinct of survival" (p. 20). This "survival instinct" is not surprising since peoples' behaviors are based on their core values and beliefs (Pecca, 1994). For people to change their behavior they must give up their old values and beliefs in lieu of new ones. This transformation leads one to unfamiliar territories that "produce anxiety and fear because people can no longer predict what these new behaviors will produce" (Pecca, p. 7). According to Fullan (1997), "If there is one cardinal rule of change in human condition, it is that you cannot make people change" (p. 37). In order for counselors to be able to create change, the key lies in understanding the complexities surrounding change and the influence it has on people.

\section{Strategies to Create Deep Change}

As many scholars have written (Tyack \& Tobin, 1994; Quinn, 1996, Fullan, 1997) creating change is not easy. In fact, there are many organizational barriers that make change difficult such as "multiple layers of hierarchy, a tradition of top-down change, short-term thinking, lack of top-management support for change, limited rewards, lack of vision and an emphasis on the status quo" (Quinn, p. 134). As a result, counselors face formidable barriers in gaining support to implement comprehensive guidance and counseling programs in schools. Yet, through understanding the relationship between organizations, communities, and individuals, organizational change researchers have highlighted two strategies that assist in creating systemic change.

\section{Collaboration}

The first strategy is collaboration. According to Gordon (2001), "Collaborative efforts by members of a community to effect school change have proven to be a viable strategy" 
(p. 7). As change in the counseling department will lead to a ripple of changes in other departments, establishing collaborative partnerships with teachers, administrators, counselors, office staff and district staff is an excellent strategy in aligning key stakeholders behind the proposed change. As mentioned earlier, Peterson's et al. (1997) research study revealed that having all staff members involved in shared-decision making about the change was an important component of how three schools participating in the study were able to successfully create change.

Implementing a comprehensive guidance and counseling program will not result in positive changes for everyone involved, at least not immediately. For instance, teachers may have to be more involved in lunch duty or testing, administrators may have to create the master schedule and counselors may not be available for substitute teaching. These changes can be perceived as negative because they increase the workload of other individuals. Yet, the long-term results are positive as student achievement will improve, teachers will have more support, and discipline and referrals will decrease. This is the message that other departments need to receive and accept as valid. By collaborating with key stakeholders and including them in the process of change, counselors have a better chance of gaining support despite the changes in job responsibilities and procedures.

\section{Strategic Planning}

The second strategy is using strategic planning. According to Beerel (1998), strategic planning is, "A formal process designed to interpret the organization's environment for the purpose of identifying its adaptive challenges and guiding its responses so as to optimize longer term competitive advantage" (p. 163). Strategic planning requires one to envision the future and to create a vision or goal that "resonates with organization 
stakeholders" (Beerel, p. 161). To be successful at strategic planning one cannot view the organization in a binary way. As the Systems and Chaos Theories both state, the world is unstable and continuously changing so in order to create change, you must be able to see the multiple layers of an organization.

The primary goal of strategic planning is to "identify key change signals" (Beerel, 1998, p. 167). Beerel further states that identifying key change signals enables an organization to anticipate or respond positively to future events; alerts the organization to new values, behaviors or actions that may be growing; allows organization to take advantage of strategic growth opportunities or threats; and helps an organization to be proactive rather than reactive. Key change signals foreshadow major shifts in values and new behaviors. Along with identifying key change signals is recognizing the adaptive challenges, which are hidden deep below the surface of an organization and work to keep the organization stagnate.

According to Beerel (1998), there are four main activities in strategic planning. The first activity is "monitoring the external and internal environment" (p. 173). This activity requires identifying major external systems and internal issues that impact the organization. For example, counselors would need to consider the local school board, state and national education departments, community members, and identify political, social, and economic issues that may impact the organization. Internal issues are important as well as they are usually connected to what is happening in the external environment. In order to identify the key change signals counselors need to be able to switch back and forth from the small and big lens to see the "big picture."

In the past, the strategic planner was an objective outsider or consultant. However, 
according to Beerel (1998), any individual who is able to "see below the surface," has excellent communication and people skills, and is able to create a suitable holding environment for the difficult steps involving change is an excellent candidate to be a strategic planner. Counselors have the requisite skills for the job. They are excellent observers, able to interact with diverse individuals and able to act as mediators in conflict situations. Additionally, counselors are in the perfect role to have access to information that lets them know the strengths and weaknesses of a school as a whole. In that sense they are in the best position to understand the adaptive challenges within a school.

The second activity is identifying and interpreting key change signals. In order to identify and interpret key change signals counselors need to be able to reach the balcony to really see what is happening not only within the school, but in the larger system. For example, a key change signal is the continuous laying-off of counselors when school budgets are reduced. This practice has happened for years and really foreshadowed the current predicament that counselors are in today. If counselors had stepped up to the balcony they might have been able to see the importance of accountability and the need for counselors to demonstrate the significant role they play in meeting school goals.

The third activity is identifying and formulating the adaptive challenge. This is the heart of strategic planning as there can be no strategy if the adaptive challenges have not been identified. An adaptive challenge is one that is not easily seen from the surface but is rather hidden. As a result, leadership is needed to identify the source of the problem and to help others recognize the urgency in addressing the problem by creating changes. For example, members of the counseling field have allowed themselves to add or change job duties based on "knee-jerk" reactions from society and political concerns. This has 
resulted in counselors having a mixture of counseling and non-counseling duties rather than the development of a holistic counseling program. Now with the accountability movement, counselors are facing extinction because they have allowed themselves to be slowly removed from a pure counseling focus. The adaptive challenge that counselors face is two-fold. First, counselors need to become aware of how accountability and increasing standards has created an urgent need for them to reassess their role within the school and how they can demonstrate accountability in meeting school goals. The comprehensive guidance and counseling program provides a tool to accomplish this task, however, many counselors have yet to realize the importance of implementing this change in their school. The second adaptive challenge is that counselors need to step into a leadership role to align their peers behind the need for change as well as school stakeholders so that change can move forward.

Once the adaptive challenges have been identified, the fourth activity is the "mobilization of organization resources for adaptive work" (Beerel, 1998, p. 182). Accepting the idea of change is difficult and as a result, it can become overwhelming for individuals. Thus, according to Beerel, the role of the strategic planner is to encourage, motivate, and challenge the organization and individuals to respond to threats the organization is facing. Demonstrating how comprehensive guidance and counseling programs will better support students, teachers and administrators as well as meet school goals is an important message to broadcast to stakeholders so they see the need for change and are willing to take the risks associated with change. As this is a period of great stress it is important to "establish a holding environment for the organization to make important changes" (Beerel, p. 183). The leadership ability of counselors is crucial 
in sending the message of change but also for monitoring the stress level of individuals and providing resources to help deal with the stress so it does not become overwhelming.

The fifth activity is identifying strategic growth opportunities. It is important that strategies match the changing realties. Strategies also need to take in consideration the political, economic and demographic trends. According to Beerel (1998), “A strategic growth opportunity can be defined as a window of opportunity that will exist in the future, given that certain things will occur" (p. 184). Currently, counselors have a window of opportunity due to the increase in challenges students face (e.g., drugs, suicide, poverty and disability), higher requirements in the workplace, and increase in academic standards. Counselors are needed more than ever to assist students in dealing with personal and academic problems. This is their window of opportunity to show stakeholders that counseling is necessary to help students succeed. Counselors must therefore develop strategies that demonstrate to key stakeholders how important their role is in helping schools and students meet their goals.

\section{Conclusion}

This review of the literature demonstrates the need for counselors to have a solid understanding of the complexity of creating change and the dynamics associated with changing the culture of an organization if they hope to be successful as change agents. Initiating change is a complex and difficult process that threatens the culture of an organization because it questions current practices and behaviors. Because fear and anxiety are a part of the change process, people need strong motivation to initiate and maintain change. That motivation now stems from dwindling monetary resources and close scrutiny of educational programs by budgetary officers. 
Overall, change within guidance and counseling programs is now a high priority at the national, state and local levels. According to Dahir and Stone (2003),"Sharing accountability for school improvement with all stakeholders is a driving force for transforming the work of counselors in our nation's schools" (p. 221). In response to this priority, some counselors have been able to successfully implement comprehensive guidance and counseling programs. To date, however, no research has been found that examines specifically how counselors gain support from key stakeholders for implementing comprehensive guidance and counseling programs. Accordingly, the present study investigates the role counselors' play and the strategies they have used to successfully gain support from key stakeholders to implement a comprehensive guidance and counseling program. The next chapter describes the methods and procedures used to investigate the research questions of this study. 


\section{CHAPTER THREE: RESEARCH METHODOLOGY}

Introduction

The purpose of this study was to investigate how elementary and secondary school counselors gain support to implement comprehensive guidance and counseling programs based on the National Standards for School Counseling Programs (Campbell \& Dahir, 1997). The following research questions guided the study:

1. What do counselors believe is their role in gaining support to implement comprehensive guidance and counseling programs?

2. What do administrators believe is their role in supporting counselors' efforts to gain support to implement comprehensive guidance and counseling programs?

3. What does district staff responsible for supervision of student support services believe is their role in supporting counselors' efforts to gain support to implement comprehensive guidance and counseling programs?

4. What strategies do counselors use to gain support from key stakeholders in implementing comprehensive guidance and counseling programs?

This study was based on a qualitative research design. The researcher utilized semistructured interviewing to gather data from counselors, administrators and district student support supervisors regarding their experiences with creating change within school counseling programs. In particular, the interviews provided descriptions of the experiences and perspectives of participants in relationship to the role they played in creating change and strategies used to gain support from key stakeholders.

This chapter reviews the methodology including the methodological overview, qualitative research design, subject population, selection of participants, protection of 
human subjects, and data collection process. The chapter concludes with procedures utilized in data analysis and a summary.

\section{Methodological Overview}

This study investigated strategies that counselors used to gain support from key stakeholders to implement comprehensive guidance and counseling programs. As mentioned in chapter one, few studies exam the strategies school counselors have used to gain support for program change efforts. The study also examined the role counselors, administrators and district student support supervisors' play in creating change. In order to investigate this phenomenon a qualitative study was initiated. Qualitative methodology allowed the researcher to explore how counselors gain support for making program changes by gathering descriptive data on the experiences of counselors and other key stakeholders. The researcher hoped to add insight and understanding regarding the phenomenon of creating change in school counseling programs.

Qualitative methodology refers to "research that produces descriptive data: People's own written or spoken words and observable behavior" (Taylor \& Bogdan, 1984, p. 5). Qualitative studies do not involve proving or disproving hypotheses that are made prior to beginning a study. According to Bogdan and Biklen (1998), "You are not putting together a puzzle whose picture you already know. You are constructing a picture that takes shape as you collect and examine the parts" (p. 6). Essentially, qualitative researchers utilize descriptive data based on the perspectives and experiences of participants in hopes of gaining insight into a particular area of study. Therefore, in qualitative research nothing is assumed trivial and everything is viewed as having the 
potential to be an important clue that may lead to a new understanding about a particular issue (Bogdan \& Biklen, 1998). As a result, qualitative methodology is often used in studies where little research has been conducted (Merriam, 1998).

\section{Research Design}

The research design for this study enabled the researcher to discover how counselors gain support to create change in school counseling programs. Figure 1 outlines the research design structure. Once participants were identified, a semi-structured interview protocol was followed in conducting individual and group interviews that explored the experiences of counselors and key stakeholders in implementing comprehensive guidance and counseling programs. The analysis of the interviews provided specific answers to the research questions regarding the roles counselors and stakeholders play in creating change and the strategies counselors use to gain support.

\section{$\underline{\text { Semi-Structured Interviews }}$}

In order to investigate the research questions, the researcher utilized a semi-structured interview format with school counselors, school administrators (principal and assistant principals), and district staff responsible for supervision of student support services. The semi-structured interview format uses a list of questions that act as a guide (see Appendix B), but does not require that questions be asked in the same format or sequence. According to Merriam (1998), in semi-structured interviewing "the largest part of the interview is guided by a list of questions or issues to be explored, and neither the exact wording nor the order of the questions is determined ahead of time" (p. 74). There were two major advantages to this approach to interviewing. First, this interview style allowed the researcher to respond to any issue or topic that arose and did not restrict the 
researcher to a set of pre-determined questions. Second, the flexibility and "conversational" style of interviewing allowed the researcher to explore new issues or topics that the researcher was not aware of to fully investigate the challenges counselors faced and the strategies they used that led to success in implementing change (Merriam, 1998).

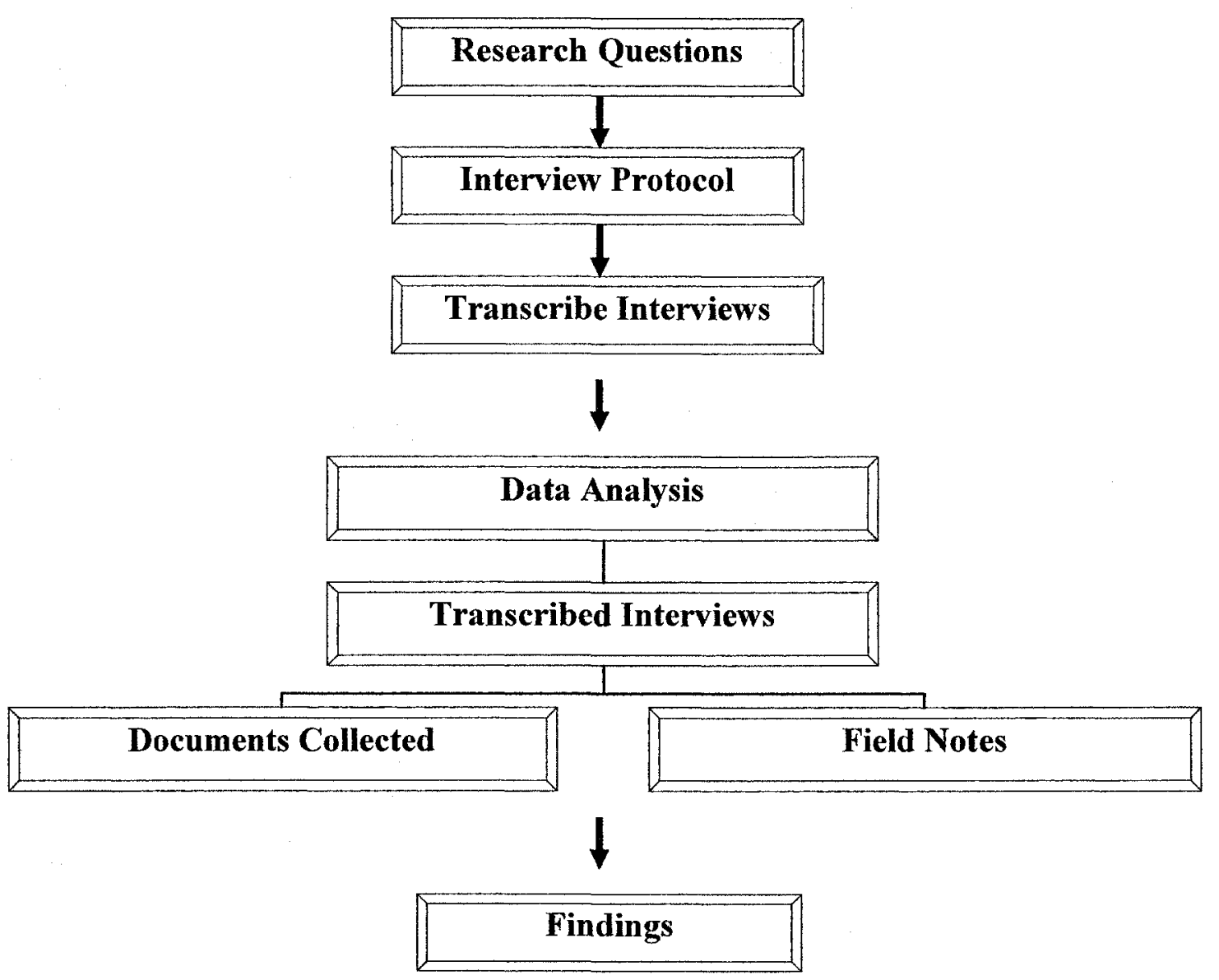

Figure 1: Research Design Structure

Interviews were conducted on an individual basis in order to increase the confidentiality as well as comfortability of participants to speak freely about their experience. Per request at one school, a group interview was conducted due to the large 
number of counselors and time constraints at the site. Depending on the time constraints of some participants, initial interviews ranged from 20 minutes to one and a half hour. Upon approval of participants, all interviews were audio taped and transcribed.

Furthermore, the researcher took notes during the interviews. Follow-up interviews were conducted via e-mail and/or telephone.

\section{Documentation}

In addition to conducting interviews, the researcher collected archival documentation that provided additional information or insights relevant to the research questions. The documents collected served two purposes. The first purpose was to assist participants in recalling specific events related to change efforts. According to Sudman and Bradburn (1982) using records can improve the accuracy of recall of participants. As participants had already undergone the process of gaining support within the last three to five years, it was hoped that past records from the process would help to refresh their memories. Records included minutes from meetings, power point presentations, curriculum outlines, competencies created, and public records such as the School Accountability Report Card (California Department of Education, October 19, 2003), which provided detailed descriptions of school profiles.

The second purpose for collecting archival documents was to assist with discovering answers to the research questions. Documentation, including both official and unofficial documents such as curriculum outlines, marketing pieces such as brochures, PowerPoint presentations and comprehensive guidance and counseling plans, provided additional information regarding strategies counselors used to gain support. These documents were collected through school websites, district offices, visiting school counseling programs, 
and in conjunction with interviewing participants.

\section{Subjects}

\section{$\underline{\text { Site Determination }}$}

Two elementary schools, two middle schools and two high school counseling programs from Southern California that had successfully gained support from key stakeholders to implement change within their school counseling programs were selected. In order to select counseling programs, a purposive sampling strategy was used. This type of sampling is based on selecting a sample from a specific population that allows the researcher to gain information about a particular area of study (Chein, 1981). As the researcher was investigating strategies that counselors used to gain support to implement change within school counseling programs, purposive sampling allowed the researcher to select schools that had already experienced this process.

In order to begin purposive sampling, a "selection criteria" for participants was determined (Merriam, 1998, p. 61). Two criteria for selecting the school counseling programs were used. The first criteria was that at least one of the school counselors must have participated within the last three to five years in a local or regional training including: San Diego County Office of Education workshop on designing and implementing comprehensive guidance and counseling programs, the National Standards training sponsored by ASCA, or the California Counselor Leadership Academy trainings sponsored by the Los Angeles County Office of Education. This criterion was selected because these workshops are designed not only to introduce school counselors to comprehensive guidance and counseling programs, but teach them the step-by-step process of implementing a comprehensive program in their own schools. This knowledge 
base is necessary for counselors to have in order to successfully implement this type of change.

The second criterion was that school counselors had gained support from key stakeholders and had begun implementing a comprehensive program within the past three to five years. When potential participants were contacted, a selection questionnaire (see Appendix C) based on materials from Johnson and Whitfield (1991), the Los Angeles County Office of Education Counselor Leadership Academy (February 6, 2004), and the expertise of Dr. Lonnie Rowell, Director at the Center for Student Support Systems (CS3) at the University of San Diego was used to determine if the potential participants met this second criteria. This criterion was selected for two reasons. The first reason was that in order to elicit insight into counselors' experiences of creating change, participants had to have already experienced this phenomenon. The second reason was to reduce possible errors related to memory. Sudman and Bradburn (1982) indicate that the more salient the event the easier it is for individuals to recall past events. The saliency of a topic is related to the unusualness of an event, the economic or social benefits, consequences of an event, and how long ago the event took place. As a result, the researcher decided to interview participants who had undergone the experience of gaining support within the past three to five years.

In order to determine which school counseling programs met both criteria, the researcher first consulted with one of the sponsors from each of the three trainings to obtain a list of elementary, middle and high school counselors who had participated in trainings. In addition to contacting sponsors from each workshop, the researcher relied on the network selection strategy to locate potential participants as needed. The network 
selection strategy involves collecting participants from other research subjects who have already participated in the study (Merriam, 1998). Last, the researcher relied upon the expertise and knowledge of the Director of CS3, Dr. Lonnie Rowell, in choosing counseling programs to use in the study.

Based on recommendations from sponsors of training programs and through contacts using the network strategy, a list of elementary, middle and high school counseling programs were identified as potentially meeting the first criteria. The next step involved contacting each school to verify counselors' attendance at one of the training programs and to determine the time period of when counselors began implementing comprehensive guidance and counseling programs. Protocol of contact varied from school to school. For some schools contact was made directly with the head counselor. Other schools required contact to begin with the school administrator and then once permission had been received, contact could be established with the head counselor. Elementary schools and some middle schools do not have "head counselors" as they may have only one or two counselors on staff. In such cases, contact was made directly with the counselor.

If positive responses regarding the first criteria were obtained, with permission, the selection questionnaire was mailed to the counselor contacted to determine if the counseling program met the second criteria. Again, the purpose of the selection questionnaire was to determine if counselors had gained support from key stakeholders and had begun implementing a comprehensive guidance and counseling program within the past three to five years. During the initial contact, counselors were provided with background information of the researcher, an overview of the study, and the purpose of the selection questionnaire. If counselors were interested in participating in the study, a 
copy of the selection questionnaire and introduction letter (see Appendix D) were sent to the counselor to either fill out on their own or as a group effort.

Each selection questionnaire was assigned a code so that confidentiality of the questionnaire could be maintained. An enclosed stamped envelope was provided so participants could easily return the selection questionnaire. Participants were requested to not write their name on the questionnaire so again, confidentiality could be maintained. Once the selection questionnaire was returned, analyzed and determined to meet the second criteria, the counselor was contacted again to arrange for an interview. Thirteen selection questionnaires were sent out and a total of eleven were returned. After analyzing the selection questionnaires, ten schools were found to meet both criteria. The researcher contacted each school and was able to select six schools that volunteered to participate in the study. It must be noted that although an attempt was made to select schools that reflected diversity in student demographics, school budgets, base scores on the Academic Performance Index (API), and counselor-student ratios, because of the difficulty in locating schools that met both selection criteria and were available to participate in the study, the selection of participants was based solely on availability.

\section{$\underline{\text { Selection of Participants }}$}

Two elementary schools, two middle schools, and two high schools were selected to participate in the study. A total of 16 counselors, 6 site administrators who had oversight responsibility for counselors, and 4 district personnel that supervised student support services were interviewed over a four month period. Principals, assistant principals and district student support supervisors were included because these key stakeholders have the power to grant permission to allow for change. Therefore, their support is critical in 
the initial stages of implementing comprehensive guidance and counseling programs. It must be noted that seven participating counselors indicated that they had no active supervisor at the district level or that the district student support supervisor was "in name only" and did not participate in the establishment of a comprehensive guidance and counseling program at the school site. Therefore, although 6 school districts were represented in the study, only 4 district student support supervisors were interviewed.

Prior to the start of the interviews, participants were provided an overview of the study and an opportunity to ask any questions or express any concerns. Informed consent documentation (see Appendix E) was secured from all participants prior to the start of the interview. In addition, a demographic questionnaire (see Appendix F) was given to the 16 counselors interviewed in order to create a profile on their experiences as a counselor. The one-page demographic questionnaire was created to collect general demographic information on the work experiences of counselors and to obtain a school profile. The demographic questionnaire consisted of nine questions. Questions included number of years working as a counselor, the number of years working at elementary or secondary schools, student case loads, and number of counselors working at the current site. Each school was assured that all results would be written in a confidential manner with appropriate protection of the identities of all participants and the location of all participating school sites. Permission to tape record interviews was obtained and confidentiality was emphasized.

\section{Protection of Participants}

Several steps were taken to protect the confidentiality of participants in this study. First, participants were assured that participation was voluntary and that there were no 
repercussions should they choose not to participate. Second, participants were given an informed consent form regarding the study. Participants were told the purpose of the study, how the data would be used, and how privacy would be addressed with the hope that this information would help participants make an informed choice as to whether or not to participate in this study. Third, participants and school sites were given the option of keeping the results of each interview and survey results confidential. Fourth, the research proposal was submitted to the Institutional Review Board for review and approval before any research was conducted. Last, the data will be stored in a locked cabinet for the next five years. After five years, all written data will be shredded and taped interviews erased to protect the confidentiality of participants.

Throughout the entire data collection process, participants were reminded that the questionnaires and interviews tape recorded would remain confidential and locked in a secure place. Each participant was provided a copy of the transcription of their interview. The transcribed interviews were assigned a code so that confidentiality of the interview could be maintained. A letter (see Appendix G) was attached to the transcribed interview instructing participants that they may make any changes or additions they wish to ensure the accuracy of the interviews. According to Merriam (1998), allowing participants to review data collected to ensure for plausibility helps to improve the internal validity of the study. Participants were provided with a stamped addressed envelope to easily return the transcription if changes or additions were made. The researcher abided by all changes. The school that requested a group interview gave permission to have all counselors review the transcribed group interview in its entirety. 


\section{Data Collection Processes}

\section{Semi-Structured Interviews}

A total of 16 counselors, 5 principals, 1 assistant principal, and 4 district personnel were interviewed from 6 schools. Counselor interviews ranged from 45 minutes to over one and a half hour. Principal and assistant principal interviews ranged from 25 minutes to 40 minutes. District student support supervisors' interviews ranged from 20 minutes to 40 minutes. Interviews were conducted face-to-face at the school site or district office. One interview was conducted via telephone. One group interview was also conducted per counselors request due to time constraints.

Most interviews were arranged through the contacted counselor. The counselor organized the interviews with the counselors, administrators and district student support supervisor or provided information on how to reach the district supervisor. Each participant was provided an overview and purpose of the study. A summary of the privacy protection rules was discussed and the informed consent form was reviewed and discussed as well. Permission was granted before tape recording the interview. Participants were informed that they would receive a copy of the interview transcription and would have the opportunity to add or change any information to ensure accuracy. Participants were informed that they would receive one final copy of the dissertation study if desired.

\section{Documentation}

Much documentation collected was provided willingly by counselors without request. Documentation included curriculum, counseling handbooks, PowerPoint Presentations on comprehensive guidance and counseling programs presented to administrators and board 
members, and marketing tools used to obtain buy-in. Any identifying marks on the documents were erased or hidden by the researcher to maintain confidentiality. In addition, documentation was collected from the school websites including the counseling department websites and School Accountability Reports. Information obtained from the School Accountability Reports was used to develop a profile on the school including the diversity of students, community and staff, school budget, and test scores that could be used to disaggregate the data as desired.

\section{Data Analysis}

Based on the guidelines stated by Merriam (1998), the following steps were followed to analyze the collected data. The first step involved the researcher transcribing all 26 interviews herself. The second step involved reviewing all interview transcripts thoroughly to obtain an objective overview of the experiences of all participants. The researcher reviewed the transcripts many times in order to be fully immersed in the experiences of the participants. While reviewing the transcripts the researcher wrote down any notes, observations or comments in the margin area. The purpose of writing these thoughts on the margin was to isolate the most striking aspects of the data (Merriam). In additional to reviewing the interview transcripts, the researcher also reviewed all documentation collected and field notes taken by the researcher during the interviews.

Once the interview transcripts, documentation, and field notes were reviewed, the third step was to code the data. According to Merriam (1998), coding data is assigning a "short-hand designation to various aspects of your data so that you can easily retrieve specific pieces of the data" (p. 164). The designations can be words, phrases or numbers. 
Coding the data allows the researcher to more easily manage all the data. A specific data analysis coding strategy used in the study was Category Construction, which is "constructing categories or themes that capture some recurring pattern" (Merriam, 1998, p. 179). Category Construction allows a researcher to cross-analyze data on several levels. The goal of this type of data analysis is to compare "one unit of data" with the next in order to find "recurring regularities in the data" (Merriam, p. 180). According to Lincoln and Guba (1985), a unit of data is defined by two criteria. The first criterion is that the unit should reveal relevant information to the study and motivate the researcher to think beyond what is apparent in the data. The second criteria is that the data should be "the smallest piece of information about something that can stand by itself - that is, it must be interpretable in the absence of any additional information other than a broad understanding of the context in which the inquiry is carried out" (Lincoln \& Guba, p. 345). Both criteria were used in creating the units of data for this study.

Following the Category Construction process, while reviewing each transcribed interview, field notes, and documents, the researcher coded the data and searched for "regularities and patterns" (Bogdan \& Biklen, 1998, p. 171). The researcher searched for phrases or words that were unique or provided a different perspective. Each unit of data was then written on a colored index card. Once all units of data had been written on the index cards comparisons were made between participants' views and responses to look for commonalities that could lead to insight regarding the roles each individual played in gaining support, strategies counselors used to create change and factors that facilitated or hindered the implementation of comprehensive guidance and counseling programs. After comparing participants' views and responses, each unit of data was assigned to a 
category. The researcher separated each category using colored index cards. Each color represented a specific category.

The fourth step in analyzing the data involved naming the categories. According to Merriam (1998), categories can come from three sources: the researcher, the participants, and sources outside the study such as literature. Merriam further states, "Categories should reflect the purpose of the research" (p. 183). They are essentially the answers to the research questions of the study. As a result, all units of data were coded to identify key themes that related to the research questions of this study. This included the strategies counselors used to obtain support, challenges counselors described and strategies they utilized to overcome these challenges, the role that counselors and stakeholders played in creating change and factors that either facilitated or hindered implementing a comprehensive guidance and counseling program.

Once the categories were listed, the final step involved placing the data into major themes in relationship to the questions of the study. This allowed the researcher to easily compare participants' perspectives and views to discover themes related to the research questions of the study. The findings of this analysis are discussed in the following chapter.

\section{Reliability and Validity}

"Reliability refers to the extent to which studies can be replicated (Goetz \& LeCompte, 1984, p. 211). Typically, qualitative studies that rely on interviewing as the primary data collection method have small sample sizes making the reliability of a study questionable. According to Goetz and LeCompte, reliability "depends on the potential for subsequent researchers to reconstruct original analytic strategies" (p. 217). Although 
replicating this study may not yield the same exact results, as long as replicated studies do not yield "contradictory or incompatible results" the reliability of the study is not in question (Bogdan \& Biklen, 1998, p. 36). To reduce threats to reliability, the researcher ensured that "results are consistent with the data collected" (Merriam, 1998, p. 206) by using two methods of data collection such as interviewing and collecting documentation and by describing in great detail how the data was collected, how themes were derived and how decisions were made throughout the inquiry (Merriam). Furthermore, the researcher utilized a standardized interview protocol to increase the reliability of the study.

The internal validity of a study is concerned with whether the results of the study match the reality of life. According to Merriam (1998), "Because human beings are the primary instrument of data collection and analysis in qualitative research, interpretations of reality are accessed directly through their observations and interviews" (p. 203).

Therefore, as this study relied heavily on interviews as the data collection method and relied on a standardized interview protocol, it was anticipated that the internal validity of this study would be increased. In addition, the use of multiple sources of data (interviews, field notes and documentation) improved the internal validity of this study as it helped to ensure that the findings were consistent and not exaggerated. Last, the researcher encouraged participants to review the findings to ensure the accuracy and plausibility of the findings to further increase the internal validity of this study.

The external validity of a study is concerned with "the extent to which the findings of one study can be applied to other situations" (Merriam, 1998, p. 207). In order to improve the external validity of this study, the researcher obtained rich, detailed descriptions from 
each participant regarding their experience with creating change as well as demographic information on counselors and a school profile to help readers determine whether the results of this study could be applied to their own settings. The study attempted to include diverse schools (e.g. urban, suburban, etc.) in order to increase the likelihood that the findings of this study would apply to other situations. Firestone (1993) calls this "case-tocase" in which the reader determines how the results of a study can be useful to their own situation (p. 17). The more diverse the schools in the study, the more usefulness the findings can be to school counselors. However, as mentioned earlier, although an attempt was made to select schools that reflected diversity in student demographics, school budgets, base scores on the Academic Performance Index (API), and counselor-student ratios, the difficulty in locating schools that met both selection criteria and were able to participate in the study was difficult. Therefore results may not be generalizable to other guidance and counseling programs, however, the information gained may lead to further research studies in this area.

\section{Summary}

The purpose of this study was to uncover the meaning in how counselors' gain support from key stakeholders to implement comprehensive guidance and counseling programs based on the National Standards. As a result, a qualitative research methodology was used. Qualitative researchers are "interested in understanding the meaning people have constructed" (Merriam, 1998, p. 6). In other words, the purpose of qualitative research is to learn from the experiences of others regarding a specific area of interest. Qualitative research does not involve searching for evidence to prove or disprove hypotheses. Rather its goal is to uncover truths or meaning about a specific topic through the lived 
experiences and perceptions of others. In this search for "meaning" qualitative researchers examine a topic from participants' perspectives, not the researcher's (Merriam, 1998, p. 7).

Semi-structured interviewing is a common strategy used in qualitative research because it allows the researcher to emerge in the life experiences of the participants. Although a list of questions is created prior to the interviews, there is flexibility for the researcher to vary questions based on new emerging themes or ideas. During the interview, nothing is considered trivial. Every statement or description is considered significant as the purpose of qualitative research is to construct a picture by examining all parts (Bogdan \& Biklen, 1998).

Qualitative methodology involving semi-structured interviews allowed the researcher to uncover new insight on how counselors gain support to create change, the role key stakeholders play in supporting counselor's efforts to create change, and strategies counselors have used to overcome challenges. In chapter four, the results and findings of the study are presented. 


\title{
CHAPTER FOUR: FINDINGS AND ANALYSIS
}

\author{
Introduction
}

A qualitative methodology was used to investigate how counselors gain support from key stakeholders to implement comprehensive guidance and counseling programs. Specifically, a semi-structured interview protocol was followed to conduct individual interviews to learn about the experiences of counselors and administrative stakeholders in implementing this change. The researcher explored the following research questions:

1. What do counselors believe is their role in gaining support to implement comprehensive guidance and counseling programs?

2. What do administrators believe is their role in supporting counselors' efforts to gain support to implement comprehensive guidance and counseling programs?

3. What does district staff responsible for supervision of student support services believe is their role in supporting counselors' efforts to gain support to implement comprehensive guidance and counseling programs?

4. What strategies do counselors use to gain support from key stakeholders in implementing comprehensive guidance and counseling programs?

The individual interviews of counselors, administrators and district staff responsible for supervision of student support services produced findings that answered the research questions guiding the study: How counselors gain support to create change, the role key stakeholders play in supporting counselors' efforts to create change, and strategies counselors have used to overcome challenges.

The purpose of this chapter is to present findings based on analysis of 26 individual interviews - 16 counselors, 6 school site administrators and 4 district student support 
supervisors regarding their experiences with gaining support to implement comprehensive guidance and counseling programs based on the National Standards. This chapter begins by providing a profile of the participants. The findings of the study are then presented in relationship to the research questions of the study.

\section{Participant Profile}

The study was based on data from 26 individuals. Based on the selection criteria previously described in chapter three, 10 high school counselors, 4 middle school counselors, and 2 elementary school counselors involved with counseling programs at 6 schools in Southern California were selected to participate in the study. Table 1 and Table 2 describe the school and community profiles and ethnic background of the student population for each school. Nine of the 16 participants in the study have worked as counselors for ten or more years. Six of the participants have worked as counselors for five or more years. Only one participant has worked as a counselor for two to three years. Each school counseling program in the study had at least one counselor with over ten years of experience in the field. What is more, 8 participants had worked at their current school for over eight years. All of the counselors were female with the exception of one male counselor.

School counselors' caseloads varied significantly. One high school counseling program had a student caseload averaging 500 per counselor while another high school counseling program had an average of 700 or more per counselor. At the middle school level, one middle school counseling program had an average student caseload of 700 per counselor while another middle school counseling program had an average of 500 per counselor. Last, one elementary counselor had an average student caseload of 650 while 
another elementary counselor had 800 . This high number was a concern for all counselors interviewed because of the significant time constraints that such caseloads create especially when trying to find time to implement change.

Six administrators and 4 district student support supervisors were interviewed. Unfortunately, one interview with a district supervisor was unavailable for full analysis as the tape recorder malfunctioned during the interview. However, notes were taken during the interview, and those notes were used during the analysis of the data. Four administrators were school principals and two were assistant principals assigned to oversee counseling departments. For the district student support supervisors, two were assistant superintendents and two had other administrator designations.

Table 1

School and Community Profile

\begin{tabular}{lcccc}
$\begin{array}{c}\text { No. of } \\
\text { Counselors }\end{array}$ & $\begin{array}{c}\text { API } \\
\text { Score }\end{array}$ & $\begin{array}{c}\text { Total School } \\
\text { Population }\end{array}$ & $\begin{array}{c}\text { Average } \\
\text { Income }\end{array}$ & $\begin{array}{r}\text { Community } \\
\text { Population }\end{array}$ \\
\hline 4 & 535 & 1,962 & $\$ 35,000$ & 80,000 \\
6 & 777 & 3,490 & $\$ 56,000$ & 56,000 \\
2 & 698 & 934 & $\$ 44,000$ & 12,000 \\
1.6 & 809 & 977 & $\$ 47,000$ & 35,000 \\
$1-80 \%$ & 786 & 650 & $\$ 51,000$ & 487,000 \\
$2-20 \%$ & & & & \\
1 & 570 & 790 & $\$ 50,510$ & 155,000
\end{tabular}


Table 2

Summary of Student's Ethnic Background

$\begin{array}{ccc}\text { Caucasian Hispanic African } & \begin{array}{c}\text { Asian/ Other } \\ \text { American }\end{array} \text { Pacific }\end{array}$

\begin{tabular}{lccccc}
\hline High School \#1 & $2 \%$ & $86 \%$ & $1 \%$ & $6 \%$ & $5 \%$ \\
High School \#2 & $26 \%$ & $9 \%$ & $0 \%$ & $63 \%$ & $2 \%$ \\
Middle School \#1 & $78 \%$ & $19 \%$ & $1 \%$ & $1 \%$ & $1 \%$ \\
Middle School \#2 & $30 \%$ & $18 \%$ & $1 \%$ & $49 \%$ & $2 \%$ \\
Elementary \#1 & $48 \%$ & $22 \%$ & $17 \%$ & $12 \%$ & $1 \%$ \\
Elementary \#2 & $10 \%$ & $64 \%$ & $19 \%$ & $3 \%$ & $4 \%$ \\
\hline
\end{tabular}

All participants were interviewed individually and in person with two exceptions. One school requested a group interview due to time constraints and the high number of counselors. In addition, one participant was unavailable during the scheduled interview day with the school and as a result, the interview was conducted by telephone. All interviews were transcribed verbatim. The following section discusses the findings of the study.

\section{Findings}

The data analysis revealed five major themes relating to building support for implementing comprehensive guidance and counseling programs: (a) counselors stepping into a leadership role, (b) increasing the visibility of counselors and counseling programs, (c) working collaboratively to gain support, (d) strengthening support for counselors from 
district office, and (e) overcoming resistance to change. Following a detailed discussion of the five major themes, this chapter concludes with a discussion of the themes in relationship to each specific research question.

Definition of School Counseling Models

The findings of the present study revealed that counselors interchangeably used "comprehensive and guidance and counseling programs," "The National Standards for School Counseling Programs," The American School Counseling Association (ASCA) "National Model," and the "Support Personnel Accountability Report Card (SPARC)." All four designations provide frameworks that assist counselors in developing, implementing and evaluating programs. For clarification purposes, each model is discussed below prior to the discussion of the major themes.

Comprehensive guidance and counseling programs emerged in the 1970 s as a major focus in school counseling. According to Gysbers and Henderson (2000), comprehensive guidance and counseling programs consist of three components: content, an organizational framework and resources. Content "identifies competencies considered important by the school districts for students to master" (Gysbers and Henderson, 2001, p. 249) after participating in a comprehensive counseling program. "The organizational framework contains three structural components (definition, rationale, and assumptions), four program components (guidance curriculum, individual planning, responsive services, and system support) along with a suggested distribution of school counselor time" (Gysbers and Henderson, 2001, p. 249). Last, the resource component consists of "human, financial and political resources required to fully implement the program" (Gysbers and Henderson, 2001, p. 249). Combined together, the components constitute a 
comprehensive, developmentally-based counseling program that provides direct services to meet student needs.

The National Standards for School Counseling Programs were published in 1997 and provided a framework "for developing and writing a school counseling program, as well as a description of the components of a quality school counseling program" (Campbell \& Dahir, 1997, p. 4). These standards assist counselors in creating an effective school counseling program that help students develop in the academic, career and personal/social areas. Each of these areas has competencies that articulate the attitudes, knowledge and skills students should obtain by participating in a school counseling program (Dahir et al., 1998, p. 5). The National Standards:

Create a framework for a national model for school counseling programs, identify the key components of a school counseling model program, identify the knowledge and skills that all students should acquire as a result of the K-12 School Counseling Program, ensure that school counseling programs are comprehensive in design and delivered in a systematic fashion to all students, establish school counseling as an integral component of the academic mission of the educational system, and encourage equitable access to school counseling services for all students, provided by a credentialed school counselor (Campbell \& Dahir, 1997, p. 5).

Essentially, the National Standards provide a framework to help counselors develop, implement and evaluate school counseling programs that are "comprehensive, developmental, and systematic" (Campbell \& Dahir, 1997, p. 9).

The ASCA National Model was adopted in 2003 and reflects the National Standards. The National Model provides "a framework for the program components, the school counselor's role in implementation and the underlying philosophies of leadership, advocacy and systemic change" (ASCA, 2003, p 9). The model consists of four interrelated components: foundation, delivery system, management systems, and accountability (ASCA, 2003). Foundation includes building a counseling program based 
on a philosophy and belief system, creating a mission statement and incorporating services and programs that help students develop competences in academic, career and personal/social. Delivery system includes the activities and programs counselors develop such as guidance curriculum, individual student planning, responsive services and system supports. The management system focuses on the organization of the program, creating an advisory council, using data to drive what programs or services are created, developing action plans based on results, and ensuring that 80 percent of counselors' time is in direct services with students. The last component is accountability which involves sharing results and evaluating counselor performance based on standards.

The Support Personnel Accountability Report Card (SPARC) was developed in 2001 by an advisory group of the Los Angeles County Office of Education consisting of counselors, counselor supervisors, counselor educators and California Department of Education consultants (Los Angeles County Office of Education California Counselor Leadership Academy, February 6, 2004). The SPARC is modeled after the School Accountability Report Card (SARC) and is a "continuous improvement document that gives a school counseling program an opportunity to demonstrate effective communication and a commitment to getting results" (Los Angeles County Office of Education California Counselor Leadership Academy, March 23, 2005, \ 1). Proposition 98, The Classroom Instructional Improvement and Accountability Act, requires all public schools receiving state funding to prepare and distribute a SARC in order to "provide parents and the community with important information about each public school" (California Department of Education Web site, March 23, 2005, 1). The SARC is an effective way for schools to report their progress toward achieving their goals. Using the 
SARC model, The California Counselor Leadership Academy created the SPARC in order to help counselors advocate and demonstrate the positive results of their school counseling programs to stakeholders. The SPARC is useful in assisting counselors with preparing a self-evaluation, promoting counseling programs to stakeholders, preparing reports for school accreditations, and implementing ASCA National Standards and the National Model for School Counseling Programs (Los Angeles County Office of Education California Counselor Leadership Academy, March 23, 2005, I 2). Participation in creating the SPARC document is voluntary and counselors who choose to participate can be awarded the "National Standards for School Counseling Programs Academy Award" (Los Angeles County Office of Education California Counselor Leadership Academy, March 23, 2005, p. 2) if they meet certain criteria that include the following areas: Principal's comments, student support personnel team, school climate and safety, student results, major achievements, academic, career and personal/social measurements, community partnerships, parent/guardian involvement, focus for improvement, keep you informed, and clarity, congruity, continuity, and connectivity (Los Angeles County Office of Education California Counselor Leadership Academy, March 23, 2005).

Although all four of the terms discussed above are distinct, they do have overlapping characteristics that make it understandable why practitioners inadvertently use them interchangeably when discussing school reform efforts. From a program perspective, substituting one term for another is not advisable because each has its own history of development, specific vocabulary defining its components, and is authored by different professionals in school counseling. Yet, all four models have a similar goal, which is to create school counseling programs that are results-based, student-centered, and allow 
counselors to demonstrate accountability to stakeholders. This commonality makes it difficult for practitioners to separate one counseling model from another.

Theme One: Counselors Stepping into a Leadership Role

The first major theme supported by the interview data was the need for counselors to step into a leadership role. According to one counselor interviewed:

The leadership component is key because you have to see yourself as a leader. If you don't see yourself as a leader then you are going to have problems. Seeing yourself as a leader doesn't mean that you, in my point of view, it doesn't mean that you come in with a big stick. It means you come in and you assess the needs and then you address the needs and you kind of help guide your population where you need them to go. I think that's how you 'win them over.' You don't want to be the counselor in the office in the corner. You want to be 'The Counselor.'

Eleven of the counselors interviewed discussed the importance of counselors taking a leadership role in planning and implementing a comprehensive program. According to one interviewee, counselors need to be visible and to create opportunities to interact with all stakeholders to gain support:

Now, I think the counselor's role has to be more in coordination of the total education program. We're leaders. We need to be leaders in our school. And we need to be the ones who sit down at the academic center or whoever the governing body is in the school and have a place at the table. We should not be isolated.

What is more, several counselors interviewed discussed the importance of counselors establishing themselves as an integral part of the school. One counselor stated:

I think a counselor is integral to just about everything that goes on. I think that our role is dealing with kids who have things standing in [the] way of learning, being able to be there for teachers who are having trouble teaching because of problems with students in their classroom or their own. I think in terms of curriculum the counselor has a role. When you're talking about the general workings of a school, a guidance team should be part of the office of a school. And because in a way a lot comes through us, comes through guidance and it should. You need to have a really good relationship with the secretary because they're eyes and ears for you too, and the front office staff can be really helpful in screening. You have to have the custodian on your side. Everyone has a role. I think the role of the school counselor is to work with everybody for student results. 
Each counseling program in the study had at least one counselor who assumed the leadership role. The leader was the one who pushed for change, who organized the team and provided direction to help others through the process of gaining support. While discussing barriers that counselors faced, one counselor described the importance of having one individual to "drive" the process:

Buy-in. You have to get your whole team on board. And it is more work. You have to get everybody willing to not only do what needs to be done, but also document it, get those numbers, to do the pre and post, to really keep track of what they're doing until you are ready to compile the data. And everybody is overwhelmed. I mean everybody's job has so many challenges and its very time consuming. It's a huge document [SPARC], it's a huge undertaking, and it is a whole team process. It's not just the counselors. In my situation, I would drive it and I would be the organizer. I would be sending things to the team members saying I need information on this, but I'm not sure at each site there's somebody to do that.

This counselor further stated that counselors already possess the necessary skills to take on this role:

I think they [counselors] are used to being able to talk and to facilitate and certainly by the time you become a counselor, you are constantly collaborating and working so I think that it's natural the counselor would assume that role [facilitator] quite readily and should be prepared to assume that role.

In another example, a counselor interviewed described the "job" of aligning other counselors toward the goal of comprehensive guidance and counseling programs:

My job was to convince them that if you do the work or you get involved in the program that I am proposing it may be a little bit more work in the beginning but in the end it will really save you time ... Initially it was tough. And I just kept talking to them ... They just had to change their thinking a bit, the way of doing things. But eventually they got on.

One counseling program was comprised of a team of counselors who all took on a leadership role. They bought into the idea of the National Standards out of the desire to improve their counseling program and provide better services to students. They are a tight-knit group and have all worked equally to implement change. One of the counselors 
interviewed summarized their experience:

[A key factor that helped us implement this change was] I think wanting to serve kids better. Recognizing that something is not working and wanting to change it. First, you can't have any denial among your team. I think we're the most critical of ourselves. And I would say the other thing, you can't have any animosity among the team. There is absolutely complete buy-in from every single member of the team.

Whether there was only one counselor or a team of counselors willing to step into a leadership role to facilitate the change process, this role was vital to successfully implementing comprehensive guidance and counseling programs. Each of the counseling programs had at least one counselor willing to take leadership and accept the hard work and sacrifices that come along with being the leader of change. As one counselor interviewed summarized, "It was a long process. A painful process at times."

\section{Enthusiasm and Excitement for Change}

The data revealed that two-thirds of the counselors interviewed believed that a key element in the leadership role was to display enthusiasm and excitement for the change.

One counselor interviewed discussed the need for counselors to be a "positive force of change:"

I've had teachers stop and ask me, 'How are you always so positive?' I say, 'It's a choice.' And it really is a choice. You make the choice to be that person. It's like anything, like with negativity, it can snowball. But you know what? Positivity can snowball too. I think it doesn't have an easy downhill road because there are a lot of those negative trees that get in the way. You get to interface with everyone, next to the principal. You're probably the only person that interfaces with just about everyone on the campus.

This counselor further stated:

Be a positive force of change. Because Gandhi said, 'We must be the leaders that we wish to see in the world.' So, we can't wait for someone to be that. We're all sitting around waiting for the next Martin Luther King or Gandhi. So, do what you can. If you can't do great things, do little things in a great way. That's what you have to do. Child by child, session by session, person by person and then it doesn't become so overwhelming. 
Another counselor interviewed described the importance of having enthusiasm regarding the change as this enthusiasm can become contagious, "I think there has to be enthusiasm for it. Buy-in from the person who is targeted as the facilitator. I think it has to be there because I think it's contagious."

\section{Educating Stakeholders About the Change}

Three counselors interviewed believed that an important part of the leadership role was to become the "expert" in comprehensive guidance and counseling programs. In order to educate stakeholders and demonstrate the positive change implementing these standards has on students and the school, these counselors interviewed stressed the importance of counselors developing a strong knowledge base on comprehensive guidance and counseling programs. One counselor interviewed had this advice to share with other counselors wishing to implement change, "I guess the first thing is to read the National Model. I know it can be daunting. Don't let that deter you. Let that be your guideline." Another counselor interviewed stated:

I think if they believe in it themselves wholeheartedly, I can't see an administrator saying no to implementing standards. I mean that's what schools are all about anymore is standards. So why would they not be willing to do that for a counseling program too? I would say definitely have kind of a plan in mind with where you're going to go with it.

In fact, according to one counselor interviewed, a deterrent in implementing change is the lack of counselor training:

And speaking of deterrents in implementing the National Model. Counselors that haven't had the benefit of that training. Because if you don't understand the total concept you see it as more work. It's not more work. It's just a better approach to your job. It's going to make you a visible, viable part of your school population and that's what you want to be. That's what your job is. That is what you want to be because you want parents on your side. 


\section{Negotiating Duties}

A third component of leadership that counselors believed to be important was the ability to negotiate with stakeholders, particularly site administrators. All of the counselors in the study discussed how time consuming creating change was especially when they were still required to complete their regular job duties some of which were non-counseling duties. According to one counselor interviewed, "The job cannot be done between 8 am to $4 \mathrm{pm}$. Impossible. [It] can't be done. And if you want to do a good job you have to stay after. Just part of the deal. And a lot of people don't understand that."

As a result, negotiating with site administrators to either reduce non-counseling duties, increase clerical support, or receive funding for materials or training was critical for counselors in this study to successfully create change. The greatest use for negotiation skills was reduction of non-counseling duties. As mentioned above, the data revealed that some site administrators and district offices were unclear regarding counselors' role in a school. This was evident by a story shared by one counselor interviewed:

I interviewed for a position when I was in danger of losing my job at a school. They asked, 'Would you have a problem being the disciplinarian?' I knew, since it was the last question in the interview, that was going to be the make it or break it question. I thought, 'I need a job. So, what am I going to say? Am I going to say yes to satisfy what I know they want to hear? Or am I going to be true to my principles and say No, I would find that to be a problem because it would erode your trust?' If you're the one giving out discipline, who do they come to for support and encouragement? It really would erode your role. So I answered the question according to my principles and I didn't get the job.

Another good example of the continued misunderstanding regarding counselors' role in a school was a discussion between board members and one counselor interviewed about how much time is needed of a counselor during a crisis situation:

What I remember is there was, and it was every counselor in the district pretty much sitting there, and at one point one of the board members said, 'Well but when you 
have a crisis don't you refer out? It shouldn't take any time.' And every single counselor in the room sat forward. And we tried to explain to them, "This is what it involves," because it's a whole day process, not counting parent contact after, followup with the student coming back, you know. I don't think they have a sense . . . that's not real clear to the very top people in the district or our school board. That's just one part in terms of the challenge of getting the buy-in and support.

Yet another counselor interviewed discussed how the greatest challenge has been to clarify the job of a counselor:

A lot of the challenges have been centered around trying to change people's mindsets as to what a counselor should be doing, what they think a counselor should be doing and how their time should be spent. So that's been one of the larger obstacles.

One interviewee described the power that site administrators have in deciding the role counselors play within a school:

The communities, school climate, administrators all vary. They call our shots to a large extent unless we are there advocating for what we feel. A lot of administrators don't know how to use the services of a counselor effectively. Certainly a lot of the new administrators do not. Their experience coming up the ranks has been very limited as far as counselor use. They refer students for academic concerns or behavioral concerns but don't really understand the full capacity. Once administrators really know what's going on and what counselors' goals really are, I think they might not only tend to better use them but also support us as counselors come up on the chopping block.

From an administrative perspective, counselors are an extra body in times where

budget constraints have severely reduced the number of personnel. As one site

administrator interviewed stated:

I think it's difficult for counselors because they're not administrators, they're not teachers, they don't want to do discipline. So, when they go out and walk on the yard if they're counselors, they're not really disciplinarians and that plays a funny balance. So certain things that they deal with or help deal with they don't get the discipline stuff or if they do the discipline they can't do the counseling. That makes their world be very, very tough. A lot of teachers would say, 'Well, fix that kid. We sent down a kid and want you fixed. What's going on?' And now at my level I look and say you guys are two bodies and every once in a while we need you to go cover something or do something but you don't really want to because it's not within the standards and it's not what you're supposed to do. So it becomes a bunch of balances that we all have to negotiate. 
As leaders, three of the counselors in the study recognized the importance of negotiating with site administrators to reduce the amount of time associated with noncounseling duties. For example, when assigned to a new school, one counselor interviewed scheduled a meeting with her new principal in order to discuss expectations:

What I did when I was initially assigned to [one school] was I made an appointment with the principal and sat down with him and you know, 'What do you want?' 'This is what I want to do,' 'What are your goals?' 'These are my goals' because otherwise you do get drowned in all that other good stuff. If you come already knowing what you want to do and you present that, then you have a better chance of not getting swamped with non-counseling duties. It's a rare occasion that I'm asked to do something that I don't think is counselor related. I think the relationship that I set up initially makes all the difference. So having in mind what you're going to do when you walk in the door. Have your counseling philosophy down; know what you're going to do before you even go to an interview. You should really have that in your mind. And if you're not sure of it, spend time with counselors that do because that's what's going to help you be more effective and to keep you from being so frustrated.

Two of the site administrators in the study also discussed the need for counselors to be able to negotiate their job duties. When asked what advice to give counselors in trying to gain support from stakeholders, one site administrator stated:

I think I'd sit down and say here are all the things I should be doing and here's the things I'm not supposed to be doing. Of these things I'm not supposed to be doing right now what percentage of that do you want me to be doing? And I think you have to kind of negotiate a little bit with that part. I think if you are starting off there's probably a bunch of it you are going to have to do. But maybe that gets negotiated over time to be less and less and less and the things that you should be doing get to be more and more.

Another site administrator interviewed shared this advice for counselors trying to gain support from stakeholders:

Well, I think there has to be a needs assessment done too. Because if you don't have a concept of what the board perceives the role of a counselor, or what the district perceives the role of a counselor or what I perceive as the role of a counselor, it's a tough sell if all those things aren't in place. So, to have an understanding of that and then how do their needs fit into what we want to do with the standards. 
In times of budget crisis and increasing pressure from districts to demonstrate results, counselors are often seen as a luxury or a "spare body." In these conditions, creating change is challenging. Several counselors interviewed discussed their leadership role to include negotiating with site administration. In fact, three counselors interviewed relied on their negotiating skills and willingness to compromise to keep the change process moving forward.

\section{Administrators' Support Based on Trust}

The last leadership component was establishing a trusting and respectful relationship with site administrators. Interestingly, all counselors interviewed indicated that at least one if not all site administrators at their school fully supported their efforts in implementing comprehensive guidance and counseling programs. According to one counselor interviewed:

Our administrators are very willing; they let us do what we want to do. We get very little direction from them. And I think that's because they trust us, they see us doing a good job and they trust the job that we're doing and recognize us as being competent and capable. If there's something they want done they know they can come to us and let us know. But as far as the direction of our program we have total control over that. And they're supportive. I cannot think of anything that we've asked from him in the past that we've been denied when there's a financial cost to it, even the academy which was not cheap.

Another interviewee described the ease in which she obtained site administrator support,

"It was very easy to get [support] it. I just said to [my principal] this is something I would like to do and [my principal] went ok. [My principal] is wonderful." Common words that emerged when counselors discussed the support they received from site administrators were trust, respect and professionals. For example, one counselor interviewed stated:

Thankfully for the most part, administrators I've worked with have been pretty-hands off and have trusted me and let me do what I want to do basically with the kids. And I think, thankfully, there's been enough results that we've been able to show them 
through the SPARC and through other things that they trust the program. But there's still some administrators that question it because there's other ideas they have on what they think counseling should look like or what counselors should do.

Interestingly, when four site administrators discussed why they supported counselors'

efforts in creating change, the words trust and respect were used as well. For example,

one site administrator stated:

And then just sort of anecdotally for me, I think I got on board simply because I trust them. They're extremely talented and so if they tell me that this is a good idea for the most part I'm going to say go for it. Absolutely. So, personality probably was what brought me on board the best, I guess.

This site administrator further discussed the joy of working with a team of professionals:

And I have to tell you what's different about them for me as an administrators; they're innovative, reflective, professionals. And how does that help me? They need guidance, they don't need management. You just have to keep shaping their theory and vision, you don't have to bridle it.

The type of support provided by site administrators varied from equipment, finances,

and increasing personnel, to just being there to listen and motivate. One site administrator interviewed described key factors that helped counselors create change:

Well, I think we were willing to give them resources that they needed. More computers, you know, easy things. Whatever they needed physically to redesign who they were, communication, get it out to the community, this is new, pump it up. Being a facilitator to any of their ideas. They are limited like most people are in a community in what they can do to communicate what they do. So, to help them get the good word out. So, those types of paths of communication, those types of resources physically. Some monies . . . in the past we tried to give them clerical help and different types of clerical help. But unfortunately, the last two years because of budget restraints their clerical help has been cut.

Another site administrator interviewed discussed the importance of just listening and trying to reduce their non-counseling tasks so they could focus more on implementing the National Standards:

One is to listen. To see what is needed and how that is different in regards to trying to ... with their caseloads being as large as they are, so many times it becomes more of a 
clerical task rather than counseling tasks. And try to really differentiate between the two and say, 'Ok, fine. Will give you that support so you can work on these standards' and actually make a difference and so it's not as overwhelming. And that's the intent. That's what I'm trying to do in regards to [my role in supporting their efforts]. So to just listen so they can fully implement the Standards.

All site administrators interviewed indicated that their role was to provide support to counselors. The reaction of one administrator interviewed to the counselors' request to implement the National Standards was, "This was something that of course I would want to support because I feel good about what they're doing."

Interestingly, one site administrator interviewed discussed how the National Standards and implementation process were handled more at the district office and with the counselors. This site administration did not have any part in the implementation process:

I'm going to be truthful with you. They've [National Standards] been mentioned as far as counselors following standards, but I almost feel that ... the people that work at the district office with counselors deal more directly with counselors on those kinds of issues. Principals do go to meetings and those kinds of things are mentioned at meetings, but I don't recall that we've actually gone in depth at any principal's meetings about the National Standards model. I almost feel that that's worked out between the [personnel at the district office] that work with counselors. I don't know that that's a good thing. I think that principals would probably need to be as involved with counselor type standards or models as we do with regular instructional program models. I have a feeling that that's probably a need area.

Adding to the site administrator's statement, one counselor interviewed had similar thoughts regarding site administrations' lack of invitation to join the discussion of creating change in school counseling programs:

I think that unfortunately in this district there is a sense sometimes from the site administrators, that the counselors are off doing their thing but the site administration don't feel a part of that, don't' feel that they've had a chance to really buy into that or express their opinion on it.

All site administrators interviewed discussed the struggles counselors face because they are swamped with duties that take their focus away from students. One administrator 
interviewed stated, "School counselors [in my district] have to do so many different things. They get really tied into paper work, testing for the district. Because they are an extra person on site sometimes they are asked to do things that take them away from children." Another administrator interviewed shared similar thoughts:

I think what counselors used to do is not what they were ever trained to do. And I don't think we've ever figured out in schools how to deal with all of the things that we need to do for kids that are above and beyond being in the classroom. So, I don't know that we know a really good way to take care of all the scheduling, and take care of the discipline, and take care of the counseling in terms of kids' individual personal needs as well as their academic needs and then go deal with their parents and all the other things.

In lieu of these challenges, site administrators interviewed believed their role was to provide as much support as they could within the budget and time constraints that schools operate under. Four site administrators interviewed stated that the trust, respect and professionalism they saw in their counselors were important factors for why they chose to give support. From counselors' perspective, several echoed their site administrators' statement that trust and respect were important components of how they obtained support from their site administrators.

The data supported the importance of counselors stepping into a leadership role to gain support from key stakeholders to implement comprehensive guidance and counseling programs. In each school counseling program, at least one counselor took a leadership role to facilitate, motivate and educate stakeholders. For many counselors and stakeholders, the enthusiasm of the leader was contagious and led them to be wiling to share responsibility and take ownership for creating change. Along with counselors' willingness to step into a leadership role to promote and motivate stakeholders toward change, negotiating with site administrators regarding counseling job duties was an 
important component as it reduced some of the non-counseling duties for a few counselors giving them more opportunity to focus on implementing change. Last, building a trustful and respectful relationship with site administrators appeared to assist several counselors in getting initial buy-in.

Theme Two: Increasing the Visibility of Counselors and Counseling Programs

A second major theme that emerged from the data was the importance of counselors increasing their visibility to students, teachers, administrators and parents in order to gain support to create change. As one counselor interviewed stated, "I think the stakeholders make or break the program, period." All 16 counselors interviewed agreed that stakeholder support is necessary to fully implement comprehensive guidance and counseling programs. According to one counselor interviewed, "I think if you don't have buy-in from your staff, your teachers, you're fighting an uphill battle. So you want to win them over." After implementing a small pilot program based on the results of a needs assessment, one counselor interviewed discussed how it increased the visibility of both counselors and counseling program:

It (the service) wasn't earth shattering to us. I mean it was a little change but I think people saw results right away and that's how we got buy-in. Not only were we visible to the students, we were visible to the staff. The staff could see us, the administrators could see us, the parents could see us.

Another counselor interviewed emphasized the importance of counselors taking advantage of opportunities to become more visible:

Another way to just be visible and to be out there is at recess and at lunch. I can't even tell you the amount of informal stuff that goes around. It's huge. There's someone to talk to that's very unthreatening and you become a person they become comfortable with and used to seeing. You're not just hidden in the office for discipline. So that makes you more accessible. Whether it's an organized lunch group or whether it's just very informal, it's important to be visible to be effective. 
One site administrator interviewed also emphasized the need for counselors to "showcase their abilities" to demonstrate why counselors are vital to a school:

I think a lot of it is just the accountability piece. How they position themselves, how they're viewed by staff, how they integrate themselves in the teaching staff. To say yes we're teachers, we're counselors and these are the responsibilities and have that understanding. So that teachers and the community view them as such. To show them how their an integral part of your school and not just, you know, are you just an administrator, or what are you ... And to inform the staff these are things we do and this is what we do well and this is how we facilitate student learning. The burden is on them, I hate to say it, for them to showcase their abilities to the rest of the community and why they're vital to the school.

Visibility of both counselors and counseling programs was an important component of gaining support to create change. The data revealed three distinct strategies used by counselors that increased their visibility: Marketing, using data, and creating activities and services that brought counselors positive attention from stakeholders.

\section{Marketing}

All 16 counselors interviewed relied heavily on marketing to administrators, staff, district personnel, students and parents to educate stakeholders on why change was necessary and how comprehensive guidance and counseling programs could better assist students. In fact according to one counselor interviewed, poor marketing has been and continues to be a weak area for school counseling:

We reviewed our program and we did a lot of great things, but we didn't package it to our students very well. Or our parents. People really didn't know what the heck we did do. And it was like everyone expected that you would do it all but no one really knew what you were doing.

Another interviewee shared similar beliefs that counselors need to do a better job of marketing themselves to stakeholders:

The first year we did the SPARC we didn't show it to everyone. We won an award and went, 'Well, who knows about it?' And there were about ten of us. We still forget to invite people. We still need to work on some of those things instead of working in 
a vacuum.

In order to increase visibility, counselors in the study used a variety of marketing strategies. Marketing was targeted to three groups of stakeholders: Counselors and school support staff, administrators at both site and district level, and students and parents. Fourteen counselors interviewed discussed the need to focus their marketing toward gaining support from peers within the school and district. Many counselors used staff meetings as an opportunity to share information on the National Standards. According to one counselor interviewed:

When I first started the National Standards last year, I presented it at our counseling meeting. We have four or five counseling meetings a year. I introduced it and then said, 'This is a process I'm going to be working on.' So I talked about it at a spring meeting and then at the end of the year I had gotten an award so I was telling them again about that process.

In addition to staff meetings, 2 counselors interviewed presented the National Standards during staff development days as well:

We've done staff meetings. Actually at the district level the guidance team which is comprised of all of the school counselors and psychologists and district nurse - all of the mental health professionals in the district. And we meet every other week as a team at the district office to talk about mental health issues. We've done presentations at staff development days.

One counselor interviewed used the SPARC award as a way to market the National

Standards and the positive impact it has for students and the school:

Basically the introduction to the staff was through surveys, through staff meetings, through the SPARC itself, [which] is a great advertisement of course for the program and what we're trying to do. There wasn't a lot of time spent to be honest with handing them information on the National Standards at least not for me. So in a sense there wasn't a formal education probably done for the staff pertaining to the National Standards as far as a lot of documentation other than the SPARC.

All 16 counselors interviewed indicated they had presented the National Standards at various district meetings in order to gain support from both site and district 
administrators. One interviewee described the positive impact of presenting in front of

board members:

We asked for the opportunity to do a board presentation at a board of prestige meeting. We had a PowerPoint and handouts regarding the National Standards. As a guidance group within the district, as a support personnel team within the district we requested that the board adopt the National Standards for our district. And they did.

Another counselor interviewed described the positive outcome after presenting the

National Standards Model to their district supervisor:

At [one school in our district], it was interesting we had a good conversation with the administration about the philosophy and we did kind of negotiate a few changes in the philosophy so that they were willing to buy into the program. Unfortunately, the administration at almost every level has changed in the last five years. So, there's lots of new administrators who really weren't involved in the original discussion. But we developed the ends, [and then] got that approved by each administration and then we had a new superintendent. We wrote a letter to [the superintendent] asking to have an audience to present our program ... And within the first week [the superintendent] called a meeting of the guidance team which at that time was five counselors and really two school psychologists. We presented what we had in place and [the superintendent] was very supportive ... [and] immediately went to the business office and said, 'Is there money for two more counselors?' and authorized two counselors right away.

Yet another counselor interviewed described similar success after presenting the positive impact of the National Standards on student results:

I put together a program that involved counselors in two high schools going down to the four middle schools six times a year. We gave them a pre-test about graduation requirements. And then we went through four visits talking about various things that happen in high school. And then we give them a test at the end and they scored better on the post-test than they did on the pre-test. So, everybody liked that. I gave that information to the administrators. I spoke at the board of education meeting and did a PowerPoint presentation and showed them about our wanting to adopt the National Standards. They seemed to like that. We went ahead and began that process.

Educating stakeholders, especially site administrators and district student support supervisors, played a significant role in counselors becoming more visible to stakeholders. All of the counselors in the study indicated that stakeholder support was 
crucial to their success. What is more, the process of marketing the idea of the National Standards and gaining their support took time. Three counselors interviewed remarked that it took a minimum of one year or longer before support was given. For example, one counseling team interviewed was able to have the board officially adopt the National Standards about one year after they began pushing for it:

I felt like the National Standards was a very concrete way to legitimize what we do and show that if the schools and teaching are totally gearing and wrapping up with these standards for teaching then why wouldn't we do the same thing for our program? Because we really started looking at this at the time that standards was the big thing. You've got to push for standards. And just showing that hey, we want to be a part of what's happening too. We want to show that we're willing to be team players and support what you guys are trying to do. And then once we started working with them and understanding them a little bit better we did some presentations at board meetings talking about what the change was that was happening with counseling programs. And we were seeing some positive response so taking little baby steps. About a year after we really started working with the Standards we actually had the board officially adopt them for the district.

Another counselor interviewed discussed that buy-in from stakeholders occurred after being awarded a SPARC:

I shared the SPARC with my staff at the end of the year and some of them were actually surprised at all the things that were going on. They only knew it from their little shared specific experiences and [didn't] realize that there is a school-wide effect that happens. I think that was another thing that brought buy-in from the staff.

Unfortunately, several counselors interviewed remarked on the difficulty counselors have in marketing their programs and "tooting their own horns." Yet, without the ability to strongly market the role counselors need to play in a school, many of the counselors interviewed indicated they would not have gained the support needed to implement comprehensive guidance and counseling programs. As one counselor interviewed summarized:

I think the main thing you have to do is be sure your administrator is on board with you. That your administrator sees the value of what a SPARC can provide and sees 
that that is a great document to give to the community and that should go out to the hands of parents. And from there, you start talking to individuals whether it's your school psychologist, nurse, and all those people. We sat down and had meetings about it. What is our ideal for servicing our kids? What would make us most effective? Very few schools have that conversation. And you really need to send out invitations and say we have to meet and we're going to talk about this. And can we generate enough interest, enough excitement and enthusiasm to move forward on this. I think once it's really discussed and the benefits are discussed I think you're going to get good buy-in. I think it really has to be put out on the table and you have to be informed enough to do so. It has to be everybody's agreement and you have to have administrators behind you.

From site and district administrators' perspective, the presentations made by the

counselors regarding the National Standards was an effective strategy in gaining support.

One site administrator interviewed described the experience of being introduced to the

National Standards:

I think the formal presentation for me was probably at the school board. They did the overview for them and did the PowerPoint and that's sort of where we all got introduced to the categories. I think it was an easy sell for me. But I think the concept of sort of a narrow focus was what was most appealing. Sort of an umbrella of guiding principals so that everything that they did or they do leads toward one of those with the assumption that there's some value in those because they're nationally adopted. From that perspective, easy sell.

Another site administrator interviewed stated how important it was for counselors to get

the word out by using a variety of strategies:

Well, if they are trying to get the word out, I guess counselors need to somehow make presentations to the appropriate people. That's one way. They might make a presentation to the board, they might ask to be on school site council parent meetings, they might ask to speak at principals' meetings. Of course, I think principals already back up the need for counselors. But I think if they are trying to convince people like parents and the general public, then they should be speaking at board meetings or any meetings where people are there to listen.

One district supervisor interviewed even discussed the importance of counselors heavily marketing the positive impact of the National Standards to stakeholders, "Gain parent and community support. Attend board meetings and present the National Standards model. 
Tell stakeholders what it means to implement the National Standards. Show them how you can fit it with the goal of the school."

Seven counselors discussed the importance of marketing to parent and students about the National Standards. One counselor interviewed described her marketing strategy towards students and parents:

We do pre and post testing before a lesson or service is provided. We compute the results and put it into the SPARC and then that goes to every kid in their folder in the fall, and to the school board, the district office and all our teachers.

A great example of marketing the National Standards to students and parents was described by this counselor:

When we do our assembly they are organized. We start with the National Standards, and we start with personal/social, academic, college/career. Everything that's put out is organized in those kinds of categories. I think the parents, they may not completely understand the National Standards, but they know we have them and they know which area they come under. So when we do the Parent Nights, we do the same things. We think personal/social is important and here are the things that we are doing. So we kind of categorized them. PTA newsletter comes out with a lot of them kind of that way.

Another counselor interviewed described the impact increasing visibility has had on parents:

I think we have made ourselves noticeable whether it's working with the PTA or with the parent volunteer. [The] parents are really supportive us. Enough parents have gotten involved to see what we do and they were also protesting the reduction of a counselor. That wouldn't have happened four years ago. They've been really good to us, I think. So, I think the SPARC has helped.

Despite marketing the National Standards to stakeholders, once is not enough. Sometimes the message needs to be heard several times before buy-in is achieved. This is especially true since all counselors interviewed discussed the high turnover rate of site administrators. According to one counselor interviewed:

Although buy-in was positive, the administration at almost every level has changed in 
the last five years. So, there's lots of new administration who really weren't involved in the original discussion. So that makes for a difficult situation. So really, it's almost to me because of the turnover rate of administrators, you almost need it each year to sit down with the people that are new and just say, this is what it looks like, this is what we do, this is why we do it, and give them an opportunity to ask questions and express their concerns.

Another counselor interviewed shared similar experiences regarding the high turnover rate of site administrators:

We've had about four or five administrators in the last five years. We've had four principals. We've had different assistant principals in charge of the counseling program. As each principal came and went we had to kind of re-introduce some stuff. They really didn't know too much.

Twelve counselors interviewed emphasized the need to continuously market the National Standards because of the high turnover rate of site administrators. In fact, several counselors interviewed stated that any opportunity that arose (staff meeting, assemblies, etc.) they used it to market the idea of creating comprehensive guidance and counseling programs. Using various marketing strategies such as PowerPoint presentations on the National Standards, passing out brochures and booklets that incorporate the National Standards to parents and students, and meeting with staff, site administrators and district student support supervisors played an important step in improving the visibility of counselors in this study and their counseling programs to stakeholders.

\section{$\underline{\text { Using Data }}$}

Related to marketing was the use of data to demonstrate the positive results of programs and services in order to increase the visibility of counselors and counseling programs to stakeholders. Interestingly, ten of the counselors interviewed $(62 \%)$ asserted that they did not wait for stakeholder support before beginning to implement 
comprehensive guidance and counseling programs. In fact, these counselors began by piloting something "small" and then used the successful outcome of their pilot program as positive propaganda to gain support from stakeholders. As one counselor stated, "Start small. Pilot something. Make it good. And then add a little piece each year. Don't try to do it all at once. Find out where your support is and let that grow."

Although most counselors in the study presented information regarding the National Standards to their stakeholders, they also utilized hard data that supported the positive impact of the National Standards. These counselors saw utilizing data as a powerful strategy to not only gain new support but to maintain ongoing support for the changes made in their counseling programs. Piloting something small not only served to give counselors confidence that they were moving in the right direction, but gave them hard data they could use to persuade stakeholders that comprehensive guidance and counseling programs can lead to positive results. For example, one counselor interviewed described how the success of a tutoring program led to an increase of their budget toward the program:

The first year we hired about four teachers to tutor students a couple days a week. We kept the data, analyzed the data and students that enrolled in tutoring for 15 hours or more went up a whole grade level. So it was easy to get the funding next year. So, next year we had thirteen teachers. The data produced supported the program. And when you present that to an administrator or to the board of education, they can't balk at that because the data is in front of them.

Another counselor discussed how using data results saved them from having counselors cut in their district:

Over time with budget cuts there was talk about having just three counselors at the high school last year. But because of the results that we showed in our district, they did not cut anybody last year and this year.

All 16 counselors interviewed discussed the importance of sharing data that 
documents the impact counseling has on students. In fact, all counselors indicated that the biggest change after implementing the National Standards was the increased attention they gave to collecting data to determine the needs of the school and to assess whether counseling interventions were having a positive impact. These counselors recognized the importance of using data to show that counseling does positively impact stakeholders in a school. One interviewee stated:

Collecting data to show that your interventions increase attendance, lessen the discipline problems on your campus, those kinds of things are pretty valuable and they speak really loud in the district office. When they're looking at where they want to spend their dollars, you can say that, 'my program has done this' and have the data to show it.

Another counselor interviewed shared a similar belief regarding the importance of data,

"Through training we learned how important it is to have results. That teachers and classrooms have to have results. Counseling services needs results. And so it forced us to look at our work differently." When asked what advice could be shared with other counselors wishing to implement this change one counselor interviewed stated:

I would encourage that individual to get some training, visit some schools that are implementing the [National] Standards. There is a wealth of data with the SPARC document. Gather some of those, put some data together and do what we did, present that to at least site administration if not district administration in an effort to inform them.

Along with using data to showcase counseling results, 15 counselors interviewed discussed how data helped them to align counseling programs with student needs. Many counselors recognized that relying on data not only ensured that services met student needs, but met school and district goals as well. By demonstrating that counselors had specific programs and services that helped both students and schools meet their goals, it was a persuasive argument for the importance of comprehensive guidance and 
counseling programs. One interviewee indicated:

I think in this day and age of data you simply have to. It has to be apart of WASC [Western Association of Schools and Colleges], it has to be apart of API [Academic Performance Index]. You just have to show, you can't just say we think this works. Its like, how do we know? And that's the question we never asked before. We just said, this will be good for kids so will do it. But there never was, 'Did it work?' I don't know. We think it did.

Another counselor interviewed added:

I think the emphasis on data collection has made us rethink our jobs completely and for me, it's just made me less afraid to go out and try things because you can always fall back on the data and, 'Well, let's collect some data, see if it worked, it didn't work, see if the kids liked it, didn't like it, do we need to continue?' Where before you were just kind of shooting in the dark, 'Well, let's try this, let's try that.'

Using data as a strategy of becoming more visible assisted many counselors interviewed in the study. Additionally, counselors realized that they could use data to not only support counselor efforts in school, but to gain further support from stakeholders to fully implement comprehensive guidance and counseling programs. As many counselors used the strategy of piloting something small, they also collected the data to demonstrate how that particular intervention positively impacted students and other stakeholders in the school.

While collecting data was heavily used by counselors in the study to promote their new program, more importantly, many of the counselors discussed how data helped determine what services to provide to students. When asked how implementing comprehensive guidance and counseling programs has made a difference in their school, 14 counselors discussed how data has helped them continuously reshape their counseling programs to better serve all students. For example, one counselor interviewed shared:

I think [services provided to students] are different because I really feel like I have a grasp on what [student] needs are. The nice thing is you can be proactive rather than just reactive. And again I think the evaluation piece is so key in helping you develop 
the appropriate strategies and helping the students that way.

Another counselor discussed how data provides good feedback to determine what

services are helping students:

I think the National Standards have given us a framework that has made a real difference. We have a framework in which to develop our services. I think that is really helpful. We never set goals before. And we never asked for a lot of feedback or results, 'Is this working?' We're getting more input from students and parents on what would be helpful. Because sometimes what we think they absolutely are dying to receive they don't care.

One counselor interviewed discussed how collecting data revealed the weak areas of her counseling program:

When we separated our work into domains, when we looked at what we were doing we were so heavy on college/career. All we did was talk about college. We were isolating a huge group of students by focusing constantly on college. It was always college first. We were not balanced. It was not a balanced comprehensive program ... this forced us to see how we were divvying up our time and it was not appropriate.

Another counselor interviewed discussed how data allowed her to create a better counseling program that no longer only focused on the academic domain:

I think that one way in which [students are] different is that more than ever they know who we are and they know what we do. Additionally more of them have benefited from our services. Trying to implement the National Standards we have greatly increased the number of classroom lessons that we provide. Years ago I think we worked exclusively on a one-to-one basis and we don't do that anymore. We do much more of a one to thirty. I also think [students] have benefited in that they get much more service in the three domains ... So to summarize, I think [students] have benefited primarily in that they know more about who we are, what services we provide, we reach more of them than we used to, and we serve them in greater areas than just the academic area.

Overall, an important strategy revealed in the data was that counselors in the study did not have to wait for full support from stakeholders before implementing comprehensive guidance and counseling programs. In fact, waiting to collect data from small pilot programs may be a more effective strategy than simply try to educate stakeholders 
regarding what the National Standards are and how important they can be for a school.

This is further supported by one site administrator's advice to counselors:

I'd say standards are your friends. They can be your friends and they can be compelling evidence. Build the data and administrators will come to it. Show the administrators data and they can administer strategically for you. . Ideas without data become real scary and not very tangible for administrators. So, I'd say stay with what the standards disclose to you to do as steps to move forward.

Using positive results that demonstrate the effectiveness of programs and services offered was an important strategy that all counselors interviewed used that brought recognition to their school counseling programs. Although data helped bring visibility to counselors and counseling programs, counselors were also motivated to collect data to improve counseling services to students. As one counselor summarized when asked why she decided to implement comprehensive guidance and counseling programs, "I think wanting to serve the kids better. Recognizing that something is not working and wanting to change it."

\section{Activities and Services that Bring Recognition}

A last strategy that 8 counselors used to increase their visibility was creating activities and services that not only served students, but showcased their efforts in implementing comprehensive guidance and counseling programs. For example, one counselor interviewed described how the activities not only provided services to students but increased the visibility of the counseling program to stakeholders:

I'm active in just about every part of our school. I conduct [a program] here at our school ... It's a program that promotes safe and drug-free activities for kids . . and doing school-wide things like... that has made all the difference. I have more teachers that are willing to assist me with activities because they can see what it's doing for the entire school community. Those kinds of activities - it just makes you more of an integral part of the community.

In addition, this counselor further described how she created a parenting class in order to 
provide a needed service as well as connect with parents:

I also do parenting classes ... This year we had a really good turnout of about twenty parents. .. That's a good thing because if we don't' get the parents involved, that's our support. That's our main support. So, I try to do things and activities to bring in the parents as much as I possibly can.

Another counseling team interviewed described how one new service they had implemented helped improve their visibility to stakeholders as well as increased their availability to students, parents and teachers. This new service involves one counselor sitting at a desk that is located in a central area just outside the counseling office allowing for easy access. Each of the counselors sits at the desk one day per week and takes all counseling related calls or in-person questions. This allows the other counselors to have the opportunity to focus on their work. The impact of this service was amazing as the counselors interviewed described:

It really changed the sense of the entire counseling department. Because it had been seen as isolated, 'We can't get to our counselors. We never see them.' [We received] overwhelming support especially from the clerical staff because they were the ones who were dealing with all the questions like, 'Where do I do this?' . . . From the teachers point of view too it was so wonderful because so often the teachers don't know the answers to questions and students are asking it and you hate to constantly be calling a counselor who is overwhelmed ... And [our assistant principal] was thrilled.

So, just by introducing one service not only brought counselors and their counseling program visibility, but positive reinforcement and enormous thanks for being a team player and making a difference for students.

Increasing the visibility of counselors and counseling programs appeared to be a critical component of gaining support from stakeholders to implement comprehensive guidance and counseling programs. All of the counselors in the study relied heavily on marketing the idea of comprehensive guidance and counseling programs to administrators, staff, district personnel, students and parents in order to educate 
stakeholders on why change was necessary. Furthermore, all counselors discussed the importance of collecting data not only to help direct what services to provide to students but to showcase the positive impact that comprehensive counseling programs have for students and stakeholders. In addition to marketing strategies, several counselors created activities and services that not only provided valuable services to students, but secured counselors' role as an integral part of their school. These techniques combined together appeared to play a significant role in counselors gaining support from stakeholders to create change.

Theme Three: Working Collaboratively to Gain Support

Another important theme that emerged from the data was working collaboratively with peers, staff, teachers, parents, and administrators in support of comprehensive guidance and counseling programs. One important aspect of establishing collaboration with stakeholders was to have buy-in from the entire counseling team toward implementing comprehensive guidance and counseling programs. As one counselor interviewed emphatically stated:

You cannot have any denial among your team. I think we're the most critical of ourselves. And I would say the other thing; you can't have any animosity among the team. There is absolutely complete buy-in from every single member of the team.

Among all 16 counselors interviewed, having buy-in was a critical component of their success in gaining support from stakeholders to implement comprehensive guidance and counseling programs. This was supported by one site administrator interviewed who commented about the team spirit of the counseling team:

You go with a team. You help the team. Yeah, you're assigned but everyone pitches in. They [counselors] all pitch in and take over. And it's done with a spirit of caring love. For me, they kind of live those Standards. They live it out and they live out with the faculty too. 
In addition to creating a collaborative relationship with the immediate counseling team, counselors discussed the importance of establishing a collaborative relationship with all counselors within the district. In fact, three-fourths of the counselors interviewed revealed that one of their first steps was to obtain buy-in from fellow counselors within the district to create a collaborative effort toward creating change. One counselor interviewed stated:

We started talking to our sister schools. We had more conversations about the National Standards amongst that group which meets monthly. In fact, we started that. We all went up to the training with the other schools.

Another counselor interviewed emphasized the closeness that the counselors in the district have with one another:

We are a tight knit group [all counselors in the district]. We meet once a month at least and I would say almost every meeting we have the National Standards come up. That's not to say that we all share $100 \%$ buy-in.

The idea of establishing a collaborative relationship with fellow district counselors was further supported by this counselor's statement:

The more I learned about the Standards the more I liked them and the more I wanted to implement them. So we started sharing that information with the other counselors in the district. The district counselors have always come together once a month for a meeting. I think the standards not only have they helped our individual school programs but they've also helped our overall district program too because they've given us kind of a guide to follow so that were all sort of looking at the same types of programs.

Site administrators even discussed the importance of establishing a collaborative relationship based on respect. One site administrator interviewed stated:

The team of people who work together and the cohesive trust, mutual respect and all coming from the same place, that make it work. I really do believe that has a lot to do with it. We have a strong team. We've always worked very well together and I feel that we look for the needs of the children.

One district supervisor interviewed also discussed how counselors in the district saw the 
importance of collaboration to successfully implement the National Standards:

All district counselors agreed in both the content of the standards and their application in the district. The counselors were on the same page from the beginning of this movement, and they agreed that they needed to collaborate in order to strengthen their school-site programs.

When asked about challenges counselors faced in gaining support from stakeholders, one district supervisor commented on how counselors did not face as many challenges as others due to their collaboration efforts, "The counselors were on the same page from the beginning of the movement, and they agreed that they needed to collaborate in order to strengthen their school-site programs."

So although not every counselor had complete $100 \%$ buy-in when they began the discussion of implementing comprehensive guidance and counseling programs, through meeting regularly on both a school and district level, a team mentality was forged among many of these counselors. This collaboration strengthened their commitment and allowed them to approach stakeholders. This strategy appeared to play a significant role in counselors' ability to gain support.

Along with establishing a collaborative relationship among counselors in the school and district, counselors interviewed discussed the importance of opening that team spirit to other stakeholders including psychologists, teachers, school nurses, attendance workers, and clerical staff. "We're in this together and a lot of school sites don't see that. Don't see themselves as part of a team. The support staff is part of the team in SPARC, I mean everybody."

Another counselor interviewed stated:

We did a SPARC now for three years. Every year that we've done it we've been awarded an academy award. The SPARC is based on our program here, so it's really an evaluation of our program. We've had a lot of input from the various stakeholders 
here - school psychologist, administrators, counselors, teachers, nurse, attendance workers, secretaries - we all kind of worked on this together.

Another group of counselors interviewed discussed how they worked closely with different personnel in the school to create the mission statement and goals so they could present it to administrators as a team:

We met with the psychologist and other teams and drafted a mission statement, philosophy, etc. We got the program together and goals and competencies for the students. Then we presented it to the administration at each school for their buy-in.

One counselor interviewed discussed involving parents in the process of implementing comprehensive guidance and counseling programs:

We started with a one day conference just with all the counselors. And we had parents there. The assistant principal came for a while. We came up with our motto. We started putting it on a lot of our materials. We wanted the kids to recognize it.

The idea of establishing a collaborative team appeared to be an important strategy that all counselors interviewed used to gain support from stakeholders. The first layer of collaborative efforts began with the immediate counseling team. As many of the counselors interviewed indicated, without buy-in from the counseling team it was extremely difficult to create change. The second layer was opening the collaborative relationship to include all counselors within the district. Presenting the idea of comprehensive guidance and counseling programs as a united team was a powerful tool that worked for many of the counselors interviewed in the study. The third layer was to further extend the collaborative relationship to surrounding personnel including teachers, psychologists, nurses, and support staff. Having input from surrounding stakeholders not only helped to secure their support but helped to ensure that counselors were able to see the larger picture and strategize how to gain administrative and district support. Overall, establishing a collaborative team among counselors and support personnel appeared to 
play a strong role in counselors ability to obtain buy-in from stakeholders regarding implementing comprehensive guidance and counseling programs.

\section{Theme Four: Strengthening Support from District Office}

The fifth major theme was counselors' perception that they did not receive much support from the district office. Five counselors interviewed purported they had no district student support supervisor to represent them at district or board meetings as well as support their efforts in providing services to students. Out of the six participating schools, two school counseling programs indicated they did not have a district supervisor supporting counselors. Out of the four schools that did have a representative at the district office, only two had a background in counseling. Nine counselors revealed their desire to be more represented at the district office. According to one counselor interviewed:

When we started this the first thing we did is we tried to get someone from the district to be involved which was difficult. And we did have someone showing up at meetings from the district but they were not really an advocate or somebody who really pushed for counseling. [But even though we did not have a district liaison that was helpful] we did start having monthly meetings with all the counselors in the district. And we have become much more focused and much more supportive of each other and much more aware of the work we are doing. But that's probably the best thing that came out of it, I mean because at least we know we're not along and that we are kind of on the same wavelength and trying to do kind of the same thing. So the district has become more aware of us and what we're doing but I still think they don't have any real understanding.

Another counselor interviewed discussed how although they do have a supportive district student support liaison, the liaison does not have a counseling background:

Well, we kind of do [have a district liaison for counselors]. It's kind of a new thing this year. . I work very closely with [the liaison]. Before it was kind of done informally. [The liaison] actually represents the counseling group at the different ... level meetings ... [The liaison] advocates for us. [The liaison] does set up and organize meetings. [The liaison] is completely supportive. Does [the liaison] know them [National Standards] specifically? Probably not. Does [the liaison] have a copy? I doubt it. . . as long as we are keeping [the liaison] introduced with what we feel are our driving needs, I think we'll always be supported. 
In addition, twelve of the 26 participants discussed the invisibility of counseling with

their district office and board members. One counselor interview stated:

The board of education, they were pretty happy with it [National Standards]. They probably didn't know too much about the National Standards so when I approached them with it I'm sure they just thought, 'Oh, this is a good thing, Go ahead.' They're not that informed about us. It would be nice if they came over to the school. From time to time various board members have made some comments, sometimes derogatory about the counseling departments. But they really don't know. They don't come over here. So, there's a little bit of a disconnect I think between the counseling department and the board of education. They could be a little bit more involved.

One interviewee shared a story how despite the positive impact counselors had demonstrated, it made no difference in protecting counselor jobs:

Well they like the results. I think one of the good things is that they do give us credit when we produce a result that we've documented, and I think that's a really great picture of the National Standards because when you have the data that supports something that you've done and it's in black and white they can't give the credit to someone else. But, it's disappointing that you do the kind of job we do, and you win awards, and then you get cut a counselor. That's disappointing.

Yet another counselor interviewed discussed how although there was no one in the district office that would say no to implementing the National Standards, no one was encouraging it either:

Certainly we have access to implement them [National Standards] and no resistance. Nobody is saying, 'Don't focus that way.' We don't' have a real tight reign on it though, to be honest with you. There's nobody up at every meeting saying, 'These are the National Standards. You need to do this.' . . . And I see no resistance from our superintendents and the deputy superintendent.

Finally, one counselor interviewee discussed the "selected buy-in" from the district:

They have bought into the things that have produced results that us 'kudos' and that produce great results for the districts. But they certainly haven't bought into a lower caseload for us. They're kind of picking and choosing the [National] Standards that they like.

Even site administrators in the study remarked on the limited recognition and support provided by the district. According to one site administrator, despite winning a school 
counseling award, it made little difference at the district office:

We were not really recognized for having received this award from the district. It was like, 'Oh, ok.' It's not seen as one of the 'biggies.' It's nice to have more awards in our district but I think because we were the only school that applied they really didn't know what it was and the significant of it.

In fact, many participants discussed how districts still see counseling as a luxury,

especially at the elementary level. One site administrator interviewed stated:

Just having counselors in school. Nowadays at the elementary level I think that's very unique. So I think that's something other districts in California may be struggling with. Now in terms of budget constraints I'm very concerned that these additional personnel may be seen as added features, extra benefits but in reality it's critical to the success of our schools.

Another site administrator interviewed shared similar concerns regarding the view that elementary counselors are a 'luxury:'

Actually, elementary counselors in some districts are seen as a luxury. They'll tell you that. A lot of schools don't have elementary counselors. They're seen as an extra at the elementary level but not necessary at the secondary level.

Even district supervisors were aware that counselors continue to be misunderstood and not fully supported. According to one district supervisor interviewed, "Counseling is perceived as a 'luxury' is a prevalent thought. Counseling in general is still a misunderstood field." One district supervisor interviewed discussed the need to fight to keep the elementary counseling program alive in the district:

I believe that in our district the counseling program will first survive and second continue to evolve. I feel that the focus on National Standards, staff collaboration, district-wide emphasis, and administrative and board awareness of the program have strengthened it to the point that it has total district-wide support. I have to admit that at times I have to fight to retain the elementary counseling program, but it is recognized as effective and has the same support from all stakeholders.

Another district supervisor interviewed stated:

My opinion is that I think they [counselors] are phenomenal. The financial support has not been there that needs to be there in my personal opinion. The board values the 
counselors and they'll talk at meetings and they'll talk about how wonderful and how much they do, but I think there's a little bit of counter talk because when push comes to shove and we really need additional services... If you cut counseling it's going to affect so many other programs. That isn't always seen the same way. For me, it's hard because I can see when you cut a counselor; it's not just the counseling staff that's going to be impacted. It's a gigantic tidal wave, it goes all the way through the whole district because if you cut here then that means that this person isn't going to have support and it's just going to follow along. And so when you look at it that way the support isn't that strong.

While counselors were able to move forward with support from staff, school administrators and peers, to truly integrate comprehensive guidance and counseling programs at both the school and district level, counselors need support from the district as well. Counseling programs that have a liaison with a counseling background have an advantage in successfully creating change.

As only 4 district student support supervisors were interviewed in the study, limited data was collected to obtain districts' perception on the support they provided to their counselors. Given this limitation, one role that stood out was providing training to counselors. According to one district supervisor interviewed when discussing the role of a district counseling liaison, "Continuous training for counselors. Reminding them what needs to be done. Providing training to new counselors. We have monthly meetings with counselors." Another district supervisor interviewed discussed the importance of supporting counselor efforts:

I protect the counseling program in these times of budgets. My philosophy is, I believe the counseling position needs to be student-centered. I believe that it should be a balanced program based on the National Standards. It should not become a scheduling position or an assistant principal position. Counselors need to be available to assist students, parents and staff members to assure that all students learn and develop lifelong academic, social and self-help skills.

Many of the counselors and site administrators recognized the need to strengthen the relationship with the district office in order to better support counselor's efforts in 
implementing comprehensive guidance and counseling programs. One counseling program that was able to obtain board member approval for the National Standards established a connection with their district office. Although admittedly for many counselors, this connection is tentative, it allowed a few counselors to move forward in their pursuit of fully implementing comprehensive guidance and counseling programs within their school and district. However, two-thirds of the counselors admitted that they have to continuously use various strategies to strengthen the relationship with the district office, to increase their awareness and to maintain what support they may have initially gained. As one counselor interviewed stated with resignation:

We know we need to present at board meetings. And I think we would like to do that but it gets so hard with time, and that can't be an excuse, but it would be nice if we were asked to present.

\section{Theme Five: Overcoming Resistance to Change}

The last major theme that emerged from the data was counselors overcoming resistance to change. All counselors interviewed described a variety of challenges they faced in their efforts to implement comprehensive guidance and counseling programs: High student caseloads, high administrator turn-over, isolation, budget crisis, misunderstanding regarding counselor duties, and the need to work overtime in order to truly implement change. While all of these challenges created roadblocks, three-fourths of the counselors interviewed discussed how resistance from fellow counselors and/or teachers was a critical issue they had to overcome in the early process of implementing change. Three counselors in the study described the resistance they faced from their fellow counselors. According to one counselor interviewed:

The challenges were not so much from the administration. I would approach the administrator about something and they would say, give it a shot. However, my 
colleagues weren't always as willing to do that. Because it didn't really mean that the administrators had to do more work when they told me to go ahead and do it. Because they knew I was doing the work. But if I were to approach my colleagues with that, most of the time it meant they were going to do more work or at least the work they were going to do would be a little different. My job was to try to convince them that if you do the work or you get involved in the program that I am proposing it may be a little bit more work in the beginning but in the end it will really save you time. So, initially it was tough to get the other people on board. And I just kept talking to them. I'm sure they saw it as a good thing they just had to change their thinking a bit, the way of doing things. But eventually they got on.

This counselor further stated about the process of overcoming resistance:

So, it was a long process. A painful process at times. The other schools were a little reluctant to maybe jump into it. Because they were pretty safe in doing what they were doing. But, I think, for whatever reason they did get involved and they have been successful at this point.

Two counselors interviewed mentioned that resistance from fellow peers resulted from the perception that implementing this change would mean more work. For example, one counselor interviewed described the reaction of peers to implementing comprehensive guidance and counseling programs:

It was kind of like well what is this and why are we doing it? That kind of thing. We've already got our hands full, is this just going to be more work? So we tried to kind of point out that it's not, that it's not more work, it's just making sure that the work we are doing is the right kind of work.

Another counselor interviewed admitted difficulty in changing:

I think one of the most difficult things is to try and do some of these things for kids with our caseloads. It's hard to do with the caseload that we have. And it's hard to get rid of some of the old things we did that people kind of expect. That's us included especially like for me it's like, 'Well, we've always done it this way.' And then there is [another person] saying. 'Well, but can we try it a different way?' . . . So, that's difficult.

Overcoming this type of resistance was an important step in successfully implementing comprehensive guidance and counseling programs. As stated earlier, buyin from the entire team was an essential ingredient to gaining support. One counselor 
interviewed offered a solution to overcoming resistance:

I would say, what is it when they call ... when you are dealing with depression you go the underhanded route? That's the way it works. Because basically if people don't really see you're way of thinking ... you talk to different people and you try to get them to agree with you. You have this give and take where you befriend them, they get to know you, they like you, you talk, that kind of thing. You give them ideas like, "You know I have this idea, what do you think?" You kind of brainstorm a little bit one on one and then when they're are somewhat behind [you] and then you meet with them in a group and then you draw them in. So, that's pretty much the best way.

This counselor further stated:

And so in the beginning and I learned this the hard way, I would be in a meeting and I would throw out this great idea and they would be like, 'Well, this is the way we've always done it that kind of thing.' So after about two or three months I got a clue from somewhere, I don't know how finally, and I started talking to them individually, 'What do you think about this?' and kind of get their idea, their feedback or their support so by the time I made it to the meeting they already knew about it.

Another counselor interviewed discussed the importance of demonstrating how the change would benefit them as well as students:

I think you have to convince them that it will benefit them . . How will this benefit me? [Without it] I don't know if you'll get buy-in. You may initially get buy-in because they might think you're a good [person] or they're just going to support it. But for buy-in over a long period of time they may go, 'This is a lot of work. I don't know if I want to do it.' If they can see it can help them, it benefits them . . So my biggest advice was you got to get buy-in by the other guys. That's a given. But they will only buy-in if they can see that it will be beneficial for them.

In addition to overcoming resistance from peers, 11 counselors discussed having to overcome resistance from teachers as well. The National Standards emphasizes the importance of reaching all students and not just a select few. Traditional one-on-one counseling allows counselors only to reach a few students due to high student-counselor ratios. As a result, one difference in comprehensive guidance and counseling programs is conducting classroom guidance lessons so counselors are able to reach many students in one setting. However, this change has resulted in teacher resistance simply because 
teachers are under the gun to ensure students are able to meet certain standards on district

and state testing. According to one counselor interview:

Because there are so many time constraints on the teachers. So, yes large class presentations have become more difficult to provide. And yet, there are some classrooms that just simply need it. The teacher will come to you and say, 'My class they're not working together, they're not understanding, they're not something.' So, they will come to us, but the large class presentations aren't as much as they used to be again because of all these time constraints. Teachers guard their time.

However, counselors interviewed in the study were able to overcome resistance by using

a variety of strategies. One counselor interviewed shared how buy-in was obtained:

I think the biggest change in the new guidance is the idea that counselors go into classrooms and they deliver guidance curriculum. And so for me here at the school it was trying to figure out what guidance lessons are most important to deliver to students and how can I do that. And who's help do I need? And it was really a matter I think of working with the teachers. Over time ... I've slowly integrated more and more of the guidance curriculum and getting the buy-in from one academic core area teacher. I think the biggest obstacle probably for any new program is the guidance curriculum which is really crucial. But here, I mean our teachers understand, they see the results, they see how students are different because we're here and they want to be a part of it and they do it with us.

Another counselor interviewed shared ideas regarding overcoming teacher resistance:

If teachers can see how we fit, how counselors fit into the total educational program and especially with the teaching of study skills lessons, we teach about sexual harassment, we teach about stress, we teach about careers, trying to make connections and do needs surveys with the teachers as well as the students to develop the program. They can kind of see how we fit and how giving up time for us it not really a negative thing, it's positive and it helps the student.

In another example, one counselor interviewed used organizational skills to overcome

resistance from teachers:

That's where your organizational skills come through. What I did with that is I know all the constraints. I set up a grid of time blocks for all the teachers. I put them in their boxes with a nice letter that said, 'Hi, welcome to our school, from time to time I will need to pop into your class to do the guidance lessons.' What you're really doing is telling the teachers that 1) their time is respected and 2) you're getting the time you need so you don't bump heads with everyone else and all the other programs that are going on. I found that to be extremely helpful in me getting in the door. And that kind 
of breaks down that resistance because they're like, 'Wow, she's being respectful of my time, then I'm certainly going to be respectful of her time.' So now I have teachers asking me, 'When is a good time for me to come?' That's one of those little strategies you need to do.

Connecting counseling class lessons with the teacher's subject area was another strategy

used by this counselor interviewed:

We have increased the work with whole classrooms. The way I think we have managed that is that we don't just do it, we get permission. And we try to create buyin. For example at the beginning of the year we like to do a classroom lesson with our students on promotion requirements. So, this year we asked the PE teachers if we could have a period of their time. When there's another lesson we want to do, a perfect example would be our career lesson. That time we approached the language art teachers and we worked to get buy-in from them by suggesting that after our lesson they could use the information for a writing prompt. They bought right in. That worked for them. We've tried to spread out the time. And we've also tried in some way to connect it to something that's relevant to their subject matter. And then finally we have just thrown out the availability of this lesson and if they want it they tell us. So, in that way we might miss kids but we're going into a classroom where we're welcome. And sometimes they'll tell us too, well on this date I have a substitute teacher coming and it would be wonderful if you could just come in and take over. So we take advantage of those kinds of things.

In their quest to implement comprehensive guidance and counseling programs, counselors had to overcome resistance from peers and teachers. As one counselor interviewed stated:

I guess the challenges are resistance to change. That's just inherent in any organization, in any business, wherever you go. When you're coming in with something new people are hesitant, they don't understand the value of it. It has to do with your credibility as an individual, as an educator, how much do you know about kids. So the biggest challenge is really resistance to change. That's when you have to be even more proactive.

What is more, a few counselors discussed their own internal resistance to change. For example, one counselor interviewed admitted her reluctance to changing "the way we always did things:"

And it's hard to get rid of some of the old things we did that people kind of expect. That's us included especially like for me its like well, we've always done it this way. 
And then there is [someone else] saying well but can we try it a different way, you know? So, that's difficult.

Another counselor discussed the difficulty she had in starting to conduct to classroom lessons:

I think the biggest change in the new guidance is the idea that counselors go into classrooms and they deliver guidance curriculum. And so for me here at the school it was trying to figure out what guidance lessons are most important to deliver to students and how can I do that. And whose help do I need?

All counselors who faced this type of resistance to change employed various strategies including relying on their organizational skills, marketing ability, and making sure that services provided not only met student needs, but teacher needs as well.

\section{Summary}

Following is a discussion of the results as guided by the four research questions of the study. However, it must be noted that discussion of results are limited for several reasons. The interview data involved only 26 participants and thus may not be generalizable to other settings. Although participants were given the opportunity to review transcripts to ensure accuracy, data was based on the ability of participants to recollect their experiences within the last three to five years. The experiences and perspectives of participants are "subject to distortion because of the attitudes or roles of the informant in the community" (Sudman \& Bradburn, 1982, p. 115). Time constraints of site administrators and district student support supervisors resulted in limited time allowed for interviews. Given these limitations, the data is summarized in relationship to the research questions guiding the study: 


\section{What do counselors believe is their role in gaining support to implement} comprehensive guidance and counseling programs?

The data fully supported the importance of counselors stepping into a leadership role in order to gain support from key stakeholders to implement comprehensive guidance and counseling programs. Leadership took on a variety of forms including acting as the motivator and "cheerleader" to spread enthusiasm for the change and becoming the expert on the National Standards model to provide answers to questions and direct how change would proceed.

The data also revealed that when counselors took on the role of change agent they had to become skilled at overcoming resistance to implementing comprehensive guidance and counseling programs. Counselors stated that resistance came from fellow counselors, teachers and district supervisors. In order to overcome this resistance, counselors created strategies to help resistors cross over to become supporters. What is more, counselors relied on their negotiating skills and built up their knowledge base on the politics of their school in order to reduce non-counseling duties, demonstrated how comprehensive guidance and counseling programs meet school goals in general and established themselves as an integral part of the success of the school.

Site administrators and district supervisors in the study responded to the leadership of counselors and contributed by providing a united front for change. In addition, many of the administrators interviewed stated that it was the collaborative efforts of counselors that convinced them to give their support.

The data strongly supported counselors needing to step into a leadership role in order to successfully gain support from stakeholders to create change. Yet, questions remain 
regarding leadership and school counseling. For example, how did these counselors develop leadership skills? Research in the counseling field frequently discuss the lack of leadership counselors have displayed in their profession (Bemak, 2000; Louis et al., 2001). Where did the counselors in the study develop their leadership abilities? Did the training workshops that focus on reforming school counseling contain a leadership component? As many of the counselors in the study have worked in the field for over 10 years and several have worked for at least eight years in their current school, does length of time in the field increase leadership ability? Last, it is interesting to note that out of sixteen participating counselors, only one counselor was male. Does gender of the counselor have any significant impact on the leadership or perceived leadership among stakeholders? How does women's leadership work in relationship to developing comprehensive guidance and counseling programs? If leadership is an important part of counselors successfully gaining support for change, then investigating how these leadership skills develop and the relationship of gender to leadership is important.

2. What do administrators believe is their role in supporting counselors' efforts to gain support to implement comprehensive guidance and counseling programs?

Given the limitations on site administration interviews, the data revealed that support provided by administrators highly varied. One site administrator discussed the role as listening and acting as a sounding board for counselor ideas. Another site administrator discussed providing necessary equipment, clerical staff, and monies if available to assist counselors in creating change. Two site administrators discussed their role as being one of encouragement and instilling confidence in counselors' ability to succeed.

All site administrators interviewed discussed the importance of counseling and the 
need for counselors to be seen as an integral part of the school. This was one of the reasons why two site administrators felt comprehensive guidance and counseling programs were beneficial, that is, a comprehensive program establishes counseling and guidance as a critical element in a school's mission. Additionally, several site administrators described the respect and trust they have in their counselors as key factors making it easy for them to give support.

The high number of participants who agreed that trust and respect were a critical component of gaining support from stakeholders is interesting to note. This leads to further questions surrounding gaining administrative support: If respect and trust are critical in gaining support of site administrators, do counselors wishing to implement change have to establish that relationship prior to being successful in implementing a new model? Many counselors discussed the high turnover rate of administration and the need to continuously promote comprehensive guidance and counseling programs as a barrier to change. How much of a role does the trust factor and the high turnover rate of administrators play in preventing other counselors from implementing change? How do counselors establish this relationship of trust and respect? Was it the result of positive outcomes of services and programs delivered or is the establishment of trust and respect related more to personality factors? Research clearly states that administrative support is critical to create change in schools (e.g., Anderson \& Shirley, 1995; Berman \& McLaughlin, 1977; and Fullan, 1997). The present study points to this support in relationship to changes in the contours of counseling and guidance approaches. 
3. What does district staff responsible for supervision of student support services believe is their role in supporting counselors' efforts to gain support to implement comprehensive guidance and counseling programs?

The data overwhelming revealed that district support for counselors in the study was limited. In fact, two schools represented in the study did not have an active district supervisor for school counseling and out of the four schools that did only two district supervisors had backgrounds in counseling. One school that had a district supervisor with a counseling background was able to implement comprehensive guidance and counseling programs at the site level as well as have their district adopt the National Standards. The change effort swept throughout the entire school district and did not remain restricted to just one school. However, the data does tentatively show that even without strong district support comprehensive guidance and counseling programs can flourish at the site level. Although counselors can implement change at the site level without strong district support, the study suggests that maintaining momentum for change can be much more strenuous when counselors do not have an active and supportive district supervisor.

Despite some counselors' perception that district administrators generally do not support counseling, the district administrators interviewed in the study highlighted the importance of a counselor's role in a school. A few discussed how they fight to keep counseling alive at all levels within their district.

4. What strategies do counselors use to gain support from key stakeholders in implementing comprehensive guidance and counseling programs?

The data revealed several key strategies that counselors interviewed used to gain support from key stakeholders to create comprehensive guidance and counseling 
programs. First, all counselors relied heavily on marketing strategies including presentations to board members, site administrators, and staff, creating mission statements and logos to put on brochures and informational sheets that are sent to students and parents, and organizing assemblies and meetings based on the National Standards and/or National Model. Furthermore, all counselors interviewed used data to create services and activities that better served students as well as documented how comprehensive guidance and counseling programs impact students and the school. These marketing strategies appeared to be highly beneficial because they brought counselors visibility.

An interesting discovery that emerged from the data was the fact that many of the counselors did not have full support prior to implementing the National Standards. Rather, support for change was slowly won through the implementation process. As hard data proved to be a compelling tool to support change, counselors gathered data and then continuously showcased their efforts to stakeholders. While all of these counselors indicated that they had at least one site administrator supporting their efforts (and that support was based on trust and respect), support from other stakeholders such as teachers, parents, support staff, students, and district personnel came later.

Another strategy that counselors used to gain support was acquiring more knowledge and skills for maneuvering in the political world of education. All participants discussed the challenges that counselor face because of high caseloads and "other duties as assigned" that fall on their shoulders. Yet, several counselors were able to move around this barrier through the use of political skills. Counselors in the study conducted needs assessment not only to find out student needs, but to identify site administration and 
district needs. These counselors realized that although students are a priority, they need to have a better understanding of what the school and district goals are so that they can better align themselves and their work with these goals. Once this insight was gained, counselors negotiated their job duties. Most of the counselors in the study pointed to the non-counseling duties they perform as barriers to change. Yet, some of the counselors interviewed learned to negotiate their duties so that their time could be better spent focusing on students. The data from the present study supports the ability of counselors to understand the political situation of their school and to combine this understanding with the ability to negotiate and compromise in gaining support for change.

A third strategy that counselors in the study relied upon to gain support was working collaboratively with a variety of stakeholders. The data revealed strong support for the importance of counselors collaborating with stakeholders to gain support. This collaboration included counselors at the school and district level, and other support staff (e.g., psychologists and nurse), classified staff (e.g., secretaries, attendance clerk, etc.), parents, and administrators. By including all levels of stakeholders within the change process, each had some ownership and responsibility for the success of the change. In addition, counselors benefited from being able to see how other stakeholders' perceived the change. This equipped counselors to better market the programs they were implementing.

Last, the data strongly supported the importance of counselor leadership as an important strategy in gaining support from stakeholders to create change. Leadership included acting as the motivator and "expert" to answer questions and lessen the stress associated with change. Leadership also involved utilizing political strategies and 
negotiating skills to unburden counselors from their non-counseling duties in order to have more time to focus on implementing comprehensive guidance and counseling programs. Most importantly, the counselors' leadership allowed them to establish a team spirit among counselors, school personnel, and to some extent the district office and helped all visualize how comprehensive guidance and counseling programs can contribute to student success.

Counselors interviewed faced many challenges that created barriers to gaining support to implement comprehensive guidance programs: High student caseloads, performing non-counseling duties, working overtime, high site administrator turnover, isolation, current budget crisis, and limited district support. Yet despite these barriers, counselors in this study were able to successfully gain support to create change. These counselors have been able to overcome barriers by relying on the strategies described above. The following chapter further analyzes the implications of these results as well as discusses recommendations for future research. 


\section{CHAPTER FIVE: SUMMARY, IMPLICATIONS AND RECOMMENDATIONS}

Summary

This study investigated the phenomenon of elementary and secondary counselors gaining support to implement comprehensive guidance and counseling programs based on the National Standards for School Counseling and Guidance Programs. Four research questions guided this study:

1. What do counselors believe is their role in gaining support to implement comprehensive guidance and counseling programs?

2. What do administrators believe is their role in supporting counselors' efforts to gain support to implement comprehensive guidance and counseling programs?

3. What does district staff responsible for supervision of student support services believe is their role in supporting counselors' efforts to gain support to implement comprehensive guidance and counseling programs?

4. What strategies do counselors use to gain support from key stakeholders in implementing comprehensive guidance and counseling programs?

\section{Key Findings}

Following is a summary and discussion of key findings that emerged from participant interviews, documents collected and field notes taken by the researcher.

\section{The Role of Counselors}

The counselors in this study believed their primary role in gaining support to implement comprehensive guidance and counseling programs was to provide leadership. Although research indicates that counselors have been reluctant to step into a leadership role and/or do not have leadership skills (e.g., Baker, 2000; Bemak, 2002; House \& 
Hayes, 2002), counselors in this study demonstrated their willingness to accept that role in order to create change. What is more, the counselors' ability to gain buy-in from stakeholders despite resistance demonstrated that the counselors in this study did have the leadership skills needed to implement comprehensive guidance and counseling programs. Counselors demonstrated their leadership skills in several ways: (a) aligning stakeholder support through marketing, educating, sharing data, and implementing services that brought positive attention to both counselors and counseling programs; (b) successfully negotiating with administrators to reduce non-counseling duties; (c) overcoming resistance from other counselors and teachers by relying on strategic planning and organizational skills; and (d) recognizing the multiple layers surrounding the implementation of comprehensive counseling programs in school systems and recognizing the need to involve stakeholders in the change process. Although this study was based on the experiences of 16 counselors and results must be viewed cautiously, it may be that counselors are willing and in many cases already have the skills needed to lead their school toward positive changes. Furthermore, the findings suggest that support for implementation of comprehensive guidance and counseling programs requires strong leadership from counselors.

\section{The Role of Site Administrators}

Administrators in the study believed their role in supporting counselors' efforts included providing motivation, encouragement and opportunities to discuss ideas, and providing resources such as equipment and materials and budget for training and clerical support. While this role appeared to generally support counselors in their efforts to create change, site administrators in the study played what appeared to be a mostly non- 
participatory role in the change effort. Only one site administrator described a more robust participatory role, which involved attending all counseling meetings, discussing specific strategies to implement comprehensive guidance and counseling programs, and helping counselors market the change to other stakeholders.

An interesting finding in the study was the perception of one site administrator that there was no invitation from the district supervisor to become more involved in implementing comprehensive guidance and counseling programs. In fact, this site administrator stated that a weakness of district involvement with counseling is the fact that site administrators are not encouraged to be more involved in the implementation of comprehensive guidance and counseling programs at the site level. The principal discussed the need for greater involvement with guidance and counseling just as site administrators are involved with teacher practice and standards.

As instructional leaders, site administrators work closely with teachers to guide and evaluate their practice. While this close working relationship is common practice between site administrators and teachers, it is not with counselors. In fact, counselors are often isolated at school sites working individually with students or performing largely clerical tasks. The interaction between site administrators and counselors does not focus on "counselor practice" but rather on the general duties that counselors perform. However, comprehensive guidance and counseling programs require counselors to focus on their "counseling practice" and how their activities and services help students obtain competencies in the area of academic, career and personal/social development. It is not really surprising that site administrators in this study, although supporting counselors' efforts to create change, did not have a more participatory role in guiding and evaluating 
counselor practices based on comprehensive guidance and counseling programs, the National Standards, and the National Model. Many counselors are themselves just being trained in the new approaches (Mariani, 1998; Paisley \& McMahon, 2001). However, as site administrators become more educated regarding the new role counselors are establishing for themselves based on the comprehensive guidance and counseling program model, perhaps they will see the need to become more involved in monitoring and evaluating counselor practices.

\section{The Role of District Supervisors}

The data in this study revealed that the district student support supervisors interviewed believed their role in supporting counselors' efforts to create change was listening and providing opportunities for counselors to discuss ideas freely, creating opportunities for staff development and training, and encouraging and motivating counselors. One district supervisor interviewed discussed the need to take on a "protector" role toward the counselors in the district. According to this supervisor, the district office needs constant reminding regarding the importance of counselors at all school levels. This is especially true at the elementary level where counselors are often viewed as a "luxury." In this role as "protector" the district supervisor defends and protects counselors especially in times of budget crisis where laying off counselors is often seen as a solution to district financial problems. Additionally, the district supervisors' role was discussed as being the connection between counselors and the district office. To further counselors' efforts toward implementing change, the district supervisor helps by arranging meetings with board members, marketing the idea of change to district personnel, and opening the doors for counselors to begin their push for change. 
The role of the district supervisor appears to be critical in allowing counselors to not only create change in their school, but to convince board members and the district office to adopt the National Standards so that they apply to all schools within the district. Counselors who do not have a district student support supervisor who is active, present, and willing to be a part of the change process would appear to be at a significant disadvantage. The present study provides tentative support regarding the important role that district supervisors play in assisting counselors' efforts toward program change.

\section{Strategies to Gain Support}

Counselors utilized a variety of strategies to gain support from stakeholders in implementing comprehensive guidance and counseling programs. These strategies were not only used to gain initial support, but also to maintain support through the long process of creating change. The most heavily used strategy was utilizing data to promote their cause. In marketing the positive aspects of comprehensive guidance and counseling programs, counselors in the study recognized the importance of hard data. The idea of collecting data was relatively new for most of these counselors, but they understood that collecting data that demonstrates the positive impact services and activities have on students and the school builds support for counselors and helps sell counseling programs to stakeholders. As a result, many counselors interviewed shared how they began by piloting a program or service and then collected data to demonstrate the impact of the piloted program or service on both students and the school. Collecting this type of data and presenting it to stakeholders allowed counselors to not only continue to market the idea for change, but also demonstrated how positive it could be for everyone.

Although collecting data helped bring visibility to counselors, the true motivation to 
begin collecting data did not stem from wanting to promote comprehensive guidance and counseling programs. Initially, counselors in the study were motivated to collect data in order to design a comprehensive guidance and counseling program that better served students. Most counselors in the study stated that past services and activities were created based solely on counselors' perception of what students needed. However, after reviewing data results, counselors recognized the usefulness of data in determining institutional barriers that negatively impact students, evaluating the effectiveness of services and activities, and determining new services to be offered to students. Only when counselors began to share data results with stakeholders did they begin to realize that data not only helps create a more comprehensive counseling program but also helps bring recognition regarding the benefits of comprehensive guidance and counseling programs to students and the school.

Another strategy that most of the counselors in the study relied upon was creating PowerPoint presentations on the National Standards to present to school board members, administrators, and staff during staff development days and at administrative meetings. Some incorporated the National Standards and/or National Model in counseling brochures, websites and flyers. Others used district counseling meetings as a setting to promote the change. Any opportunity to promote and market the change was taken advantage of by all counselors in the study in order to educate stakeholders on the positive benefits of comprehensive guidance and counseling programs.

Several counselors in the study created activities and services that brought positive attention to counselors and counseling programs based on recognizing the importance of becoming more visible to stakeholders. Implementing new activities and services not 
only helped students, but also demonstrated counselors' role in meeting school goals and was an important part of gaining buy-in from stakeholders. This helped increase the visibility of counselors to all stakeholders and demonstrated how beneficial comprehensive guidance and counseling programs are for students and the school.

A last strategy used by the counselors to gain support was to include stakeholders in the initial discussion of change. Collaborating with the support staff, psychologist, nurse, teachers, and other personnel helped these stakeholders become more comfortable with the idea of change. This also allowed counselors to learn directly from these stakeholders regarding barriers toward creating change. By collaborating with stakeholders early in the change process the result was (a) stakeholders gradually accepted the idea of change and after investing their time, became supporters of the change and (b) counselors became more knowledgeable regarding concerns and possible barriers to creating change.

Implications and Recommendations

Implications of the present study and recommendations for further research regarding implementing comprehensive guidance and counseling programs are discussed in this section.

Implications

This study has four major implications regarding counselors' ability to gain support from key stakeholders to implement comprehensive guidance and counseling programs based on the National Standards and/or National Model: (a) importance of counselor leadership skills, (b) broadening counselors' view of politics and school counseling, (c) importance of strengthening advocacy efforts at the district level, and (d) competing school counseling program models create confusion among school counselors and can 
lead to policy incoherence.

\section{Leadership}

Leadership proved to be a critical factor in how counselors in the present study gained support to implement comprehensive guidance and counseling programs. This is not surprising since research in leadership, organizational change, and school counseling all discuss the critical importance of leadership in creating lasting systemic change (e.g., Baker, 2000; Dollarhide, 2003; Fullan, 1997; Gysbers and Henderson, 2002; Hatch \& Bowers, 2002; Heifetz, 1994; Johnson \& Johnson, 2002). Specifically, in the present study, leadership played an important part in counselors (a) understanding the adaptive challenges they faced, (b) recognizing that change is not a solitary event, and (c) overcoming resistance to change and aligning stakeholders to support the counselor's intention to implement comprehensive guidance and counseling programs.

Organizations are surrounded by uncertainty and confusion because of changes associated with advanced technology, global marketplace and instant access to information. Schools are constantly changing as a result of political influence and societal issues that arise. Creating change under these conditions is challenging and requires leaders to understand the impact that changes may have on the school system and the larger community in which the school resides. As Heifetz (1994) states, a leader needs to reach the balcony in order to truly observe what is happening in the school and community so that an understanding about the true heart of the problem is reached. In other words, leaders need to see the multiple layers associated with any problem in order to strategize how to overcome barriers to change.

Counselors in this study demonstrated their leadership ability by understanding the 
importance of uncovering the adaptive challenges associated with implementing comprehensive guidance and counseling programs. Adaptive challenges are problems or issues that are not easily seen on the surface level but are hidden deeply within the heart of an organization (Beerel, 1998). Uncovering adaptive challenges is important as they have the potential of undermining any change efforts and usually work to stagnate organizations and keep them inflexible. One adaptive challenge faced by a few counselors in the study was the marginal role counselors had played within their schools in the past. The increased focus on accountability requires that counselors move from being marginal players to having a seat at the governance table. Counselor leaders faced resistance from other counselors because the latter did not recognize the need for change. These resistant or reluctant counselors had accommodated themselves to being in a marginal role and initially did not want to budge. A second adaptive challenge many counselors in the study faced was the perception of counselors' role by the district office and/or site administrators. This was evident in counselors frequently being required to perform non-counseling duties as well as the lack of support received by some counselors from their district office to create change. It sometimes seemed that top administrators at the district level failed to recognize counselors as professionals equipped to make unique and essential contributions to student success.

A last adaptive challenge several counselors in the study faced was changing teachers' perception of the role of counselors in a school. According to some counselors, teachers were of the opinion that counselors generally meet with students individually in an office. The concept that counselors should step inside a classroom to conduct guidance lessons or to lead groups was often resisted by teachers. As some counselors saw it, when this 
occurred it was because teachers had a too narrow view of what counselors do.

In order to build support for change, counselors in the study conducted needs assessments of stakeholders including students, teachers and site administrators; collaborated with stakeholders and involved them early in the change process; and interacted with other counselors within their district or the broader community of school counseling. The process of uncovering the adaptive challenges included shedding light on persistent barriers to change such as: (a) non-counseling duties that are accepted by district office, site administrators, school staff, and even some counselors; (b) isolation and invisibility of counselors who are not seen as an integral part of the school; and (c) invisibility of counselors at the district office. Counselors in the study learned that overcoming these barriers required strategies to address both putting new program elements in place and working on deeper level reluctance and resistance to change. At a deeper level, passivity, bureaucratic rigidity and inertia appeared to play a part in counselors' struggles to create change. Whether or not the counselors started out with a clear understanding of what awaited them in the "shadow side" (Egan, 2002) of change, they came to the realization that building support for change included challenging deeper level issues associated with how counselors are seen by others and by themselves.

The second leadership component was understanding the impact that change has on every department within a school system. Many System and Chaos theorists discuss the difficulty of creating change in today's organization because change in one part of a system causes a ripple effect leading to changes in other parts of the system (Keys, 1999; Morgan, 1997). Therefore, any changes made in a school counseling department have a ripple effect on all other departments within a school. The ripple of change creates fear 
and anxiety among stakeholders causing many to hold tightly to the "old ways" of performing their job duties. According to Pecca (1994), in order for these stakeholders to accept change they must give up their old values and beliefs in lieu of new ones.

However, this transformation produces fear because it takes people in new and unfamiliar directions.

Recognizing the impact that change has on an organization as well as on individuals was important in helping counselors in the present study strategize how to overcome resistance to change. The counselors all faced resistance especially from peers and teachers. They understood that people do not change simply because they are asked to change. According to Goens and Clover (1991), "Neither people nor organizations change unless they perceive the necessity to do so" (p. 19).

One strategy that all counselors used to overcome the fear associated with change was to include stakeholders in the initial discussions of creating change. Gordon (2001) stated, "Collaborative efforts by members of a community to effect school change have proven to be a viable strategy." (p. 7). In fact, a study by Peterson et al. (1997) revealed that having stakeholders participate in shared decision making about change played an important role in schools' ability to create change. This statement is further supported by this study in that the use of collaboration helped counselors by: (a) giving stakeholders the time to slowly accept the change as well as for them to see the necessity for the change, (b) helping stakeholders see the long-term benefits of implementing the change, and (c) learning from stakeholders what fears or concerns they had regarding the change.

In addition to relying on collaboration, the counselors in this study appeared to recognize that accepting change takes time. Many counselors discussed how they used 
every opportunity to share information regarding comprehensive guidance and counseling programs and to discuss the positive benefits of implementing this program. Counselors made themselves available to stakeholders and did not push stakeholders to become a part of the change process until they were ready. They motivated, educated, and guided stakeholders toward accepting the change.

Counselors in the present study relied on many resources and skills to overcome resistance to change. They increased their visibility to stakeholders by marketing the idea of change, continuing collaboration efforts with stakeholders and implementing activities and services that brought counselors and counseling programs to the forefront. The counselors helped stakeholders overcome fears associated with change by encouraging and motivating them, sharing knowledge regarding what the change could mean, and using data to demonstrate the benefits of implementing comprehensive guidance and counseling programs. Through the use of these resources and skills, counselors helped stakeholders see the need for change and motivated them to take the risks associated with creating change.

Leadership proved to be a significant factor for counselors in this study to successfully gain support from stakeholders to create change. Counselors in the study who stepped into a leadership role faced numerous barriers associated with change. These counselors understood the importance of aligning with stakeholders including their peers, school staff, teachers, administrators, parents, students and district personnel. They understood that change in the counseling department would result in changes for all departments and thus all school personnel. Understanding the dynamics associated with today's organizations and learning leadership strategies to overcome barriers associated with 
creating change is essential for counselors wanting to build support for implementing comprehensive guidance and counseling programs.

One implication of the study's findings in this area is that school counseling training programs need to add leadership, strategic planning and organizational change to their curriculums. Counselors need these skills in order to create change that is lasting. Training focused on school counseling reform will need to include these components as well. Gaining the initial buy-in from stakeholders is one of the most difficult steps in the change process and must be more specifically addressed in training if counselors hope to succeed. Trainings and associated workshops need to include strategies for gaining support, developing leadership that addresses deeper level barriers to change, and the application of organizational change theories along with step-by-step program implementation process.

What is more, some school counseling research identifies an unwillingness of counselors to step into a leadership role or participate in school politics as one of the barriers counselors face in creating change (e.g., Allen, 1998; Baker, 2000; Bemak, 2000; Gysbers et al., 2000). The present study reaffirms this assertion. Yet, the present study indicates that at least some counselors do have the skills to be leaders, whether or not they willingly stepped into a leadership role. Perhaps it is less an unwillingness to step into a leadership role and more a belief that counselors do not have the leadership skills to handle the job. Perhaps if counselors had more support and encouragement from their counseling peers or were provided leadership training as a part of school counselor preparation programs and counseling reform workshops, they might be more likely to challenge this belief, whether held by others or by themselves. 


\section{$\underline{\text { Political Involvement }}$}

Historically, counselors had little involvement in school politics due to a lack of training (Lee, 1988) or fear and anxiety associated with politics (Dollarhide, 2003).Yet creating systemic change requires an understanding and an awareness of social and political trends and dynamics since they often dictate the types of school reforms that are implemented (Bemak, 2000). While traditionally counselors may have avoided school politics, counselors interviewed in this study demonstrated that they do have some political skills in addition to an awareness of the importance of becoming involved in school politics in order to be successful at gaining support from stakeholders.

According to Bolman and Deal (1997), the political leadership frame requires the ability to build stronger relationships with stakeholders, use persuasion and negotiation skills to create change, become aware of the informal and formal structures of power in the school, and advocate for change. Counselors in this study demonstrated that they have the skills to be successful players within this frame as demonstrated by (a) counselors' ability to build stronger relationships with site administrators, (b) counselors' negotiating skills in reducing non-counseling duties and (c) counselors' continuous efforts to advocate for change.

Several studies have demonstrated the importance of gaining site administrator support in order to successfully create program changes (e.g., Anderson \& Shirley, 1995; Berman \& McLaughlin, 1977; Fullan, 1992; Louis et al., 2001). According to Fullan (1992), "When principals pay attention to particular innovations, there will be a greater degree of implementation in the classroom of the school" (p. 82-83). Counselors in the present study all recognized the need for site administrator support and they made sure to 
market heavily to that particular stakeholder group. What is most interesting to note is that administrator support was perceived to be based on the trusting relationship that counselors had established with their site administrators. Most of the counselors indicated that their site administrators easily supported their intention to create change and provided resources and encouragement, including equipment, clerical support, and budget for training. From the counselors' perception, trust was the most significant factor in how they easily obtained buy-in from administrators.

Site administrators in the study shared similar thoughts as the counselors. Most site administrator indicated that they were happy to provide support because they trusted their counselors. When counselors decided that change was necessary, administrators were willing to provide support because the counselors had already demonstrated their counseling expertise and commitment to students.

The strengthening of counselors' and site administrators' relationships may put counselors in a better position to negotiate their role in the school. More specifically, in the present study strong administrator-counselor relationships provided counselors with leverage to negotiate their job duties. As many researchers (e.g., Baker, 2002; Gysbers \& Henderson, 2000; Louis et al., 2001; Paisley \& McMahon, 2001) have indicated, counselors continue to be required to perform non-counseling duties such as scheduling, substitute teaching, testing coordination, etc. There also continues to be a general confusion about the role counselors should play in a school.

In addition to issues with job duties, counselors continue to struggle with high student caseloads. Caseloads of counselors in the present study ranged from a low of 500 to a high of 800. Although the American School Counselor Association (ASCA, 1999a) 
recommends a counselor-student ratio of 1:250, this ratio is rarely found. For example, Astramovich and Holden (2002) randomly surveyed 241 ASCA members regarding counselor-student ratios and found that the mean counselor-student ratio of the participants was 1:465. Although ratios may be more of a district and state funding issue, leverage with site administrators sometimes motivates them to make sure that sufficient counselors are funded to keep ratios as low as possible.

The last component of political involvement in the present study was counselors' understanding of the need to continuously advocate for implementing comprehensive guidance and counseling programs. Counselors in the study recognized that stakeholders needed constant reminding of why change was needed and the benefits that change would have for everyone. As a result, counselors used every opportunity they could find to showcase the benefits of comprehensive guidance and counseling programs, including presentations at school and district meetings, incorporating comprehensive guidance and counseling in the counseling mission statement, and by including statements on the benefits of comprehensive guidance and counseling programs in counseling brochures and/or websites. In other words, every opportunity was used by counselors to advocate for the change. What is more, counselors continued to market their programs despite already having gained support because they realized how quickly that support could disappear.

Political involvement and awareness was recognized by counselors as important to gaining the support of stakeholders, and the counselors in the present study utilized skills such as negotiating, marketing, and persuasion to sustain their political involvement. Yet, results of the study indicate that an area that needs improvement is counselors' 
understanding of informal and formal power structures in a school. Counselors do have informal power in a school based on their expertise in counseling, conflict management skills, and interactions with all stakeholders within a school. Yet, it is uncertain from the results of this study the extent to which counselors recognized that power. In addition, counselors need to increase their awareness regarding the important stakeholders within the school and community. Much of the focus of gaining support was on counselors, teachers and site administrators. Other important stakeholders who did not receive as much attention by many of the counselors were parents and students who both hold a great deal of informal power within a school.

Although the nature of the present study limits any claims of generalizability, the findings point to critical themes evident in the literature of school counseling, school reform and leadership. Counselors need to have a better understanding of current political trends, better recognition of the needs of stakeholders within their school and community, increased involvement with school politics through committees or involvement at the district office, and increased focus on the establishment of trusting relationships with site administrators. Of course, all of this understanding, recognition and involvement does not happen at once. Counselors need to establish trusting relationships with administrators before they begin discussing the idea of creating change. Trust often comes from establishing good rapport and demonstrating that you are a trustworthy individual. In other words, trust is not automatic but has to be earned. Collecting data that demonstrates the positive impact of comprehensive guidance and counseling programs is a fairly straight-forward enterprise. However, establishing a trusting relationship is not something easily accomplished. Trust depends on the personality of individuals, the ability to create 
a rapport based on some commonality, and a willingness of both parties to share some intimacy so that trust can be built. Trusting relationships take time to build.

As site administrators continue to move in and out of schools, the trust issue has significant implications for counselors' ability to continue to move forward in their change efforts. Many counselors in the present study shared their frustrations with the high-turnover rate of site administrators. Once trust was established and a measure of support was gained, the site administrator was often reassigned leaving counselors to have to restart the entire process. This often slowed the change process and required that counselors once again educate, market and encourage stakeholders to support it. On the other hand, the impact of administrators turn-over rate can be somewhat limited if counselors gain support at the district level and work to ensure that comprehensive guidance and counseling programs become solidly instituted within a district.

\section{Limited District Support}

According to Gysbers et al. (2000), "When policies for guidance and counseling are written from a program perspective it places guidance and counseling conceptually and structurally in the middle of school reform and educational improvement" (p. 353). Aligning current district educational policies with comprehensive guidance and counseling programs can solidify the counselors' role as an integral part of a school. Unfortunately, several counselors and a few site administrators in this study reported that their district office does not fully support counselors' efforts toward implementing comprehensive guidance and counseling programs. In fact, many counselors and site administrators discussed how the district office does not understand the importance of counselors in schools, especially at the elementary level. Several counselors shared their 
disappointment regarding the district not responding or appearing to care when they won the SPARC award, demonstrating the success of their counseling program. Other counselors shared their dismay over counselors being cut in the district despite having provided data demonstrating the positive impact counselors have had on students and the school in general.

Furthermore, only four district student support supervisors were interviewed in the study as the other schools did not have a district supervisor that actively worked with counselors and their efforts to create change. Out of the four district supervisors interviewed, only two had a background in counseling. It is interesting to note that one school counseling program that had a district student support supervisor with a counseling background was able to gain support not only from site administrators, but from the district office as well. In fact, this school convinced their district office to adopt the National Standards so that they resonated throughout the district.

Yet, despite the lack of district support, several school sites in the study were able to implement comprehensive guidance and counseling programs. The support of site administrators and other school personnel helped counselors begin the change process within their school sites. However, whether these counselors can spread this concept to other schools in the district is uncertain, and may be extremely difficult without representation at the district level. A study involving comprehensive guidance and counseling programs in Nova Scotia revealed that the "success of their program was directly related to the strong leadership and support given by the Department of Education, school boards, and principals" (Lehr \& Sumarah, 2002, p. 297). Without strong leadership and support from the district office, counselors may continue to face 
major difficulties in fully implementing and sustaining comprehensive guidance and counseling programs throughout a district despite current advocacy for the National Standards and National Model.

If counselors are to convince districts to adopt the National Standards and align current district educational policies with comprehensive guidance and counseling programs, they must advocate at the district level for the selection of counseling supervisors who are well informed regarding current efforts to create change in school counseling. They must also seek counseling supervisors who are supportive of comprehensive guidance and counseling and the National Standards. Also, counselors must focus some of their attention on school board members to convince them of the important role that counselors play within schools and help them understand how comprehensive guidance and counseling programs not only lead to better support services to students but also help meet school goals. Last, other stakeholders including students, parents, and community members can not only provide great support for counselors' efforts to create change, but also can assist counselors in making sure district offices begin to pay attention to efforts to improve student support services.

\section{Competing School Counseling Program Models}

The counselors in this study interchangeably used "comprehensive guidance and counseling programs," "The National Standards," "The National Model," and "SPARC" when describing the changes they had made in their counseling programs. Comprehensive guidance and counseling, The National Standards, and The National Model are similar because they all emphasize programs that are comprehensive in scope, results-based, and developmentally sound. Such programs allow counselors to 
demonstrate accountability to stakeholders. The overall goal of these frameworks is to shift the focus from listing of counselor duties to the creation of comprehensive programs that serve all students.

According to Fullan (1997), change is difficult for schools to maintain because of the numerous innovations that are continuously being implemented in schools. Once stakeholders finally accept change, often times a subsequent change is introduced that require stakeholders to begin the change process again. What is more, constant introduction of new changes creates an organizational culture where change is not valued and is perceived as useless and unimportant (Fullan, 1997). The introduction of and increased advocacy for various new school counseling program models has created some confusion among counselors in the field as evidenced by the interchangeable use of terms by counselors in the present study.

One implication of the proliferation of school counseling program models is that counselors may become overwhelmed and confused when trying to learn about the different models and implement them in their schools. As Fullan (1997) stated, too many innovations can have a negative impact destroying any chance that change will become rooted within the organization. What is more, the constant introduction of new program models exacerbates the issue of policy incoherence in education (Hatch, 2002; Honig \& Hatch, 2004). Honig and Hatch (2004) state, policy coherence can be reconceptualized as a "craft" (p. 27) developed in the context of an ongoing process of establishing school goals and strategies and deciding whether to bridge to or buffer against (p. 26) external policy demands. In this regard, national and state advocacy for any number of counseling program models represents the introduction of a new class of external policy demands. 
That is, in addition to policy demands related to curriculum and instruction and school management, schools and school districts increasingly will force policy demands in relationship to student support. The counselors in the present study may be the emerging craftsman best equipped to respond to these demands.

The adoption of The National Model by ASCA, a national organization for school counselors, may represent a new highpoint in the development of counseling and guidance within American education. The National Model was an explicit attempt to combine the work of leading theoreticians and model developers in guidance and counseling including Gysbers and Henderson (2000), Johnson \& Johnson (1997) and Myrick (2003) (L. Rowell, personal communication, March 23, 2005). By crafting their own internal policy coherence, school counselors are free to strengthen their focus on strategies for implementing counseling and guidance in all schools.

\section{Recommendations for Further Study}

The present study was a preliminary examination of strategies school counselors use to gain support for implementing comprehensive guidance and counseling programs. No previous studies could be found that focused on specific strategies counselors use to gain support for change efforts related to the National Standards and the National Model for School Counseling Programs. Because this study utilized descriptive data closely tied to the perspective and experiences of a limited number of participants, the recommendations for further study include gathering more empirical data as well as broadening the scope of investigation of creating change in school counseling.

One recommendation for further study is to examine the relationship between site administrators and school counselors. As gaining site administrator support is critical in 
counselors' efforts to implement comprehensive guidance and counseling programs, further research into the phenomenon of trust as a component of gaining support is important. What is more, as site administrators have high turnover rates, researching the impact that turnover may have on counselors' ability to gain support is important to developing strategies to overcome this barrier.

A second recommendation is comparative research examining similarities and differences in National Standards, National Model, and other comprehensive guidance and counseling based program implementation efforts across states. Counselors in this study interchangeably used the terms "comprehensive guidance and counseling programs," "National Standards" and "National Model" when discussing implementing comprehensive guidance and counseling programs. Although many counselors in the study may have begun their implementation efforts based on the National Standards, the recent publication of the National Model (ASCA, 2003) may now take precedence in their continued efforts to create change. A useful line of research may be to examine similarities and differences in program implementation efforts based on established models (e.g., Gysbers \& Henderson's (2000) Comprehensive Guidance and Counseling Programs; Johnson \& Johnson's (1991) Results-Based Model) versus implementation efforts based on the National Model.

A third recommendation is examining school district efforts to align educational policies related to curriculum and instruction with policies related to comprehensive guidance and counseling programs. The creation of the National Model (ASCA, 2003) highlights an important step toward combining the efforts of theoreticians and model developers into creating one counseling program model that is used by all counselors. 
The adoption of the National Model by ASCA potentially could allow policymakers and counselors to become the "craftsmen" (Honig \& Hatch, 2004) of student support policy that is coherent and can lead to the alignment of comprehensive guidance and counseling programs with district and state educational policies. As aligning current educational policies with comprehensive guidance and counseling programs may be the only way to ensure that change is not only supported, but becomes institutionalized within the culture of schools and districts, it is important to research the alignment of academic standards for student success with program standards and student competencies associated with comprehensive guidance and counseling programs.

A fourth recommendation is to increase research on gender and leadership in school counseling. According to the American Association for Marriage and Family Therapy, counselors are mostly younger females, "65 percent of whom have been in practice for less than 5 years" (April 30, 2005, 15 ). To be an effective leader Hogue, Yoder, and Ludwig (2002) believe, "not only must one have the power to induce action, but subordinates also must be willing to accept and act on the leader’s directives" ( $₫ 2$ ). Hogue et al. further state that "women are less likely to be viewed as leaders" ( $(2)$. As leadership was a key component that enabled counselors in the study to implement comprehensive guidance and counseling programs, researching the role that gender plays in counselors' leadership capacity could provide further understanding regarding the phenomenon of how school counselors gain support to create change.

A final recommendation is to research the inclusion of leadership and knowledge and skill of organizational change in the curriculum of counselor training programs. Although counselors in this study demonstrated leadership skills and political awareness, much 
more education in organizational change, strategic planning, and political structures of schools appears to be needed. College and university programs that prepare counselors and/or professional development workshops and in-service trainings that focus on school counseling reform provide excellent opportunities to educate counselors on leadership and organizational change issues. Discussing the different comprehensive guidance and counseling program models alone does not provide the tools counselors need to be successful in creating change, especially within school systems where resistance to change is strongest. Research is needed on counseling curriculum linking leadership and organizational change with the development of comprehensive guidance and counseling programs.

Creating systemic change in school systems is a complex and difficult undertaking. Counselors wishing to implement comprehensive guidance and counseling programs face many barriers. One critical barrier is gaining support from key stakeholders. To date, virtually no research has focused on how counselors can gain support to successfully create change in school systems. Yet, if counselors are to be successful in overcoming resistance to change, they must strengthen their knowledge and understanding of organizational change; they must increase their involvement in and awareness of social and political trends of their schools, districts, and states; and they must increase their visibility in their school and at the district level as well.

\section{Concluding Remarks}

This study investigated how elementary and secondary counselors gain support from key stakeholders to implement comprehensive guidance and counseling programs. Counselors in this study gained support from stakeholders by: (a) creating a collaborative 
team comprised of counselors, administrators, teachers, support staff, and in some cases parents and students who fully supported the change; (b) continuously marketing the idea of comprehensive guidance and counseling programs at every opportunity including staff meetings, student assemblies, staff development, and board meetings; (c) collecting hard data that supported the positive benefits of comprehensive guidance and counseling programs; (d) becoming more visible through providing student activities and services and classroom guidance lessons; (e) becoming more involved in school politics by joining committees, conducting needs assessment of stakeholders, and negotiating with site administrators to allow time and funding to create change; and (f) by becoming leaders within their schools to motivate, educate and persuade other stakeholders of the importance of school counseling reform efforts.

The role that counselors believed they played in gaining support to create change was leadership. This was evident by the various strategies counselors used to gain support, as described above. Counselors in the study relied on their knowledge and skills of leadership to gain the necessary support to create change. Researchers (Baker, 2000; Beerel, 1998; Dollarhide, 2003; Fullan, 1997; Johnson \& Johnson, 2002) emphasize the importance that leadership skills play in creating change such as collaborating with stakeholders, negotiating job duties and managing stress associated with change. Counselors in this study further support current organizational change and leadership research regarding the criticalness of leadership in successfully creating change. Ultimately, it was counselors' leadership skills that enabled them to overcome resistance and align stakeholder support to implement comprehensive guidance and counseling programs. 
The findings indicate the importance of leadership in overcoming the barriers to change, recognizing the interconnectedness of people working within school systems, and creating strategic plans to guide change efforts. In addition, the findings suggest the importance of counselors becoming more involved in school politics including establishing trusting relationships with site administrators, negotiating the reduction of non-counseling duties, and continuously advocating for counseling program improvement. Although initial buy-in for change may have been accomplished, counselors need to continue to use a variety of strategies to maintain the support and to increase and maintain their visibility within a school. In essence, counselors need to position themselves as key members of the school community and as strong advocates for the best practices of their profession. Last, district support appears to be an important factor in implementation of comprehensive guidance and counseling programs. In order to formalize comprehensive guidance and counseling programs into district policy that shapes all schools, counselors need to advocate at both the site and district levels.

The ability of some counselors to implement comprehensive guidance and counseling programs in their schools despite barriers to change gives hope to all counselors wishing to impact school reform efforts. Counselors in the present study saw decay in school counseling and realized the importance of both revitalizing their programs and demonstrating accountability to stakeholders. What is more, these counselors had a genuine desire to provide better services to their students, teachers, and to the entire school community. This provided the motivation to take risks associated with change, and to become leaders in their schools, and in the school counseling field. Although each counselor studied faced somewhat different barriers and relied on somewhat different 
strategies, they were all able to overcome resistance and make necessary changes. As leaders, these counselors shared a vision of comprehensive guidance and counseling and led their schools in new directions. 


\section{References}

Allen, J. M. (1998). School counseling: New perspectives and practices. Greensboro, NC: ERIC / CASS Publications.

American Association for Marriage and Family Therapy. Retrieved on April 30, 2005 from American Association for Marriage and Family Therapy web site: http://www.aamft.org/Press_Room/Press releases/compare.asp.

American School Counseling Association (1999a). The professional school counselor and counselor supportive staff (Position Statement). Alexandria, VA: Author.

American School Counseling Association (2003). The asca national model: A framework for school counseling programs. Alexandria, VA: American School Counselor Association.

Anderson, R. S. \& Reiter, D. (1995). The indispensable counselor. School Counselor, 42(4), 268-276).

Anderson, L. W. \& Shirley, J. R. (August, 1995). High school principals and school reform: Lessons learned from a statewide study of project re:learning, Educational Administration Quarterly, 31(3), 405-423.

Astramovich, R. L. \& Holden, J. M. (February, 2002). Attitudes of American school counselor association members toward utilizing paraprofessionals in school counseling. Professional School Counseling, 5(3), 75-83.

Baker, S. B. (2000). School counseling for the twenty-first century ( $\left.3^{\text {rd }} \mathrm{ed}.\right)$. New York, NY: Merrill/Prentice Hall.

Baker, S. B. (December, 2001). Reflections on forty years in the school counseling profession: Is the glass half full or half empty? Professional School Counseling, $5(2), 75-83$.

Beerel A. (1998). Leadership through strategic planning. London: International Thomson Business Publishing.

Bemak, F. (June, 2000). Transforming the role of the counselor to provide leadership in educational reform through collaboration. Professional School Counseling, 3(5), 323329.

Bemak, F. \& Hanna, F. J. (1998). The twenty-first century counsellor: an emerging role in changing times. International Journal for the Advancement of Counseling, 20, 209218. 
Berman, P. \& McLaughlin, M. (1977). Federal programs supporting educational change: $V 7$ factors affecting implementation and continuation. Santa Monica, CA: Rand Corporation.

Bogdan, R. C. \& Biklen, S. K. (1998). Qualitative research for education: An introduction to theory and methods. Needham Heights, MA: Allyn \& Bacon.

Bolman, L. G. \& Deal, T. E. (1997). Reframing organizations: Artistry, choice, and leadership, $\left(2^{\text {nd }}\right.$ ed.). San Francisco, CA: Jossey-Bass Inc.

California Department of Education. Retrieved on March 23, 2003 from California Department of Education School Accountability Report Card Web site: http://222.cde.ca.gov/ta/ac/sa/legislation.asp.

California Department of Education. Retrieved on October 19, 2003 from California Department of Education School Accountability Report Card Web site: http://www.cde.ca.gov/ope.sarc/.

California Department of Health Services (1998). Retrieved February 2, 2003 from California Teen Health Web site: www.californiateenhealth.org/download/facts figures.ppt.

Campbell, C. A. \& Dahir, C. A. (1997). The national standards for school counseling programs. Alexandria, VA: American School Counselor Association.

Carpenter, W. (January, 2000). Ten years of silver bullets: Dissenting thoughts on educational reform. Phi Delta Kappan, 383-389.

Center for Student Support Systems', University of San Diego. Retrieved February 2, 2003 from University of San Diego Center for Student Support Systems Web site: http://www.sandiego.edu/soe/instcenter/studentsupp/.

Chein, I. (1981). Appendix: An introduction to sampling. In L. H. Kidder Selltiz, wrightsman and cook's research methods in social relations $\left(4^{\text {th }}\right.$ ed) (pp. 419-444). Austin, TX: Holt, Rinehard and Winston.

Dahir, C. A. (June, 2001). The national standards for school counseling programs: Development and implementation. Professional School Counseling, 4(5), 320-327.

Dahir, C. A., Sheldon, C. B. \& Valiga, M. J. (1998). Implementing the national standards for school counseling programs. Alexandria, VA: American School Counselor Association.

Dahir, C. A. \& Stone, C. B. (February, 2003). Accountability: A m.e.a.s.u.r.e. of the impact of school counselors have on student achievement. Professional School Counseling, 6(3), 214-221. 
Dollarhide, C. T. (June, 2003). School counselors as program leaders: Applying leadership contexts to school counseling. Professional School Counseling, 6(5), 304-308.

DuFour, R., Guidice, A., Magee, D. Martin, P. \& Zivkovic, B. (2002). The student support team as a professional learning community. In C. D. Johnson \& S. K. Johnson (Ed.), Building stronger school counseling programs: Bringing futuristic approaches into the present (pp. 19-35). Greensboro, NC: CAPS Publications.

Egan, G. (2000). The skilled helper. Monterey, CA: Brooks/Cole Publishers.

Evans, R. (1996). The human side of school change: Reform, resistance, and the real-life problems of innovation. San Francisco, CA: Jossey-Bass Publishers.

Fields, T. H. \& Hines, P. L. (2000). School counselor's role in raising student achievement. In G. Duhon \& T. Manson (Eds.), Preparation, collaboration and emphasis on the family in school counseling for the new millennium (pp. 135-162). Lewiston, NY: Edwin Mellen.

Fields, G. \& Manley, P. (1997). The comprehensive guidance program at cassville, missouri. In Gysbers, N. \& Henderson, P., Comprehensive guidance programs that work-II (pp. 75-88). Greensboro, NC: ERIC/CASS Publications.

Finnan, C. \& Hopfenberg, W. (1997). Accomplishing school change. Journal for a Just and Caring Education, 3(4), 480-495.

Firestone, W. A. (1993). Alternative arguments for generalizing from data as applied to qualitative research. Educational Researcher, 22(4), 16-23.

Fullan, M. (1992). Successful school improvement. Briston, PA: Open University Press.

Fullan, M. (1997). Challenge of school change. Arlington Heights, IL: IRU/SkyLight Training and Publishing, Inc.

Fullan, M. (1999). Change forces the sequel. Philadelphia, PA: Falmer Press, Taylor \& Francis, Inc.

Fullan, M. (2001). Leading in a culture of change. San Francisco, CA: John Wiley \& Sons, Inc.

Fullan, M. G. \& Stiegelbaurer, S. (1991). The new meaning of educational change. New York: Teachers College.

Goens, G. A. \& Clover, S. I. R. (1991). Mastering school reform. Needham Heights, MA: Allyn and Bacon. 
Goetz, J. P. \& LeCompte, M. D. (1984). Ethnography and qualitative design in educational research. Orlando, FL: Academic Press, Inc.

Goff, K. E. (1998). Chaos, collaboration, curriculum: A deliberate process. Journal of Curriculum and Supervision, 14(1), 29-42.

Gordon, R. K. (2001, April). Collaboration for educational change. Paper presented at the Annual Meeting of the American Educational Research Association, Seattle, WA.

Gunter, H. (1995). Jurassic management: Chaos and management development in educational institutions. Journal of Educational Administration, 33(4), 5-20.

Gysbers, N. C. (December, 2001). School guidance and counseling in the $21^{\text {st }}$ century: Remember the past into the future. Professional School Counseling, 5(2), 96-105.

Gysbers, N. C. \& Henderson, P. (1997). Comprehensive guidance programs that workII. Greensboro, NC: ERIC / CASS Publications.

Gysbers, N. C. \& Henderson, P. (2000). Developing and managing your school guidance program ( $3^{\text {rd }}$ ed.). Alexandria, VA: American Counseling Association.

Gysbers, N. C. \& Henderson, P. (April, 2001). Comprehensive guidance and counseling programs: A rich history and a bright future. Professional School Counseling, 4(4), 246-256.

Gysbers, N. C. \& Henderson, P. (2002). Implementing comprehensive school guidance programs: Critical leadership issues and successful responses. Greensboro, NC: CAPS Publications.

Gysbers, N. C., Lapan, R. T., \& Jones, B. A. (June, 2000). School board policies for guidance and counseling: A call to action. Professional School Counseling, 3(5), 349353.

Hannah, L. M., Smeltzer-Erb, C., \& Ross, J. (2001). Building change capacity within secondary schools through goal-driven and living organizations. School Leadership and Management, 21(3), 271-287.

Hatch, T. (2002). When improvement programs collide. Phi Delta Kappan, 83(8), 626639.

Hatch, T. \& Bowers, J. (May/June, 2002). The block to build on. School Counselor, 39(5), 13-17.

Heifetz, R. A. (1994). Leadership without easy answers. Cambridge, MA: The Belknap Press of Harvard University Press. 
Herr, E. (April, 2001). The impact of national policies, economics, and school reform on comprehensive guidance programs. Professional School Counseling, 4(4), 236-245.

Herr, E. L. (April, 2002). School reform and perspectives on the role of school counselors: A century of proposals for change. Professional School Counseling, 5(4), 220-234.

Hogue, M. B. (June, 2002). Increasing initial leadership effectiveness: assisting both women and men [Electronic version]. Sex Roles: A Journal of Research, 45(11-12), 377-384.

Honig, M. I. \& Hatch, T. C. (November, 2004). Crafting coherence: How school strategically manage multiple, external demands. Educational Research, 33(8), 16-30.

House, R. M. \& Hayes, R. L. (April, 2002). School Counselors: Becoming key players. Professional School Counseling, 5(4), 249-256.

House, R. M. \& Martin, P. J. (Winter, 1998). Advocating for better futures for all students: A new vision for school counselors. Education, 119(2), 284-292.

Jensen, L. \& Petersen, J. (1997). The comprehensive guidance program in utah. In Gysbers, N. \& Henderson, P. (Ed.), Comprehensive guidance programs that work-II (pp. 89-106). Greensboro, NC: ERIC / CASS Publications.

Johnson, L. S. (October, 2000). Promoting professional identity in an era of educational reform. Professional School Counseling, 4(1), 31-40.

Johnson, C. D. \& Johnson, S. K. (1997). Results based student support programs. San Juan Capistrano, CA: Professional Update.

Johnson, S. K. \& Johnson, C. D. (1991). The new guidance: A systems approach to pupil personnel programs. California Association for Counseling and Development Journal, 11, 5-14.

Johnson, S. K. \& Johnson, C. D. (2002). Future student support programs: Distinction or extinction? In Johnson, C. D. \& Johnson, S. K., Building stronger school counseling programs: Bringing futuristic approaches into the present (pp. 303-312). Greensboro, NC: CAPS Publications.

Johnson, S. K. \& Johnson, C. D. (February, 2003). Results-based guidance: A systems approach to student support programs. Professional School Counseling, 6(3), 180-184.

Johnson, S. K. \& Whitfield, E. A. (1991). Evaluating guidance programs, a practitioner's guide. Iowa City: American College Testing Program. 
Keys, S. G. (December, 1999). The counselor's role in facilitating multisystemic change. Professional School Counseling, 3(2), 101-107.

Keys, S. G. \& Bemak, F. (March, 1997). School-family-community linked services: A school counseling role for changing times. School Counselor, 44(4), 255-263.

Lapan, R. T. (April, 2001). Results-based comprehensive guidance and counseling programs: A framework for planning and evaluation. Professional School Counseling, 4(4), 289-299.

Lapan, R. T. \& Gysbers, N.C., \& Sun (March/April, 1997). The impact of more fully implemented guidance programs on the school experiences of high school students: A statewide evaluation study. Journal of Counseling and Development, 75(4), 292-309.

Lee, C. C. (1988). Counselors are agents of social change. In C. C. Lee \& G. R. Walz, Social action: A mandate for counselors (pp. 3-14). Alexandria, VA and Greensboro, NC: American Counseling Association and ERIC Clearinghouse on Counseling and Student Services.

Lehr, R. \& Sumarah, J. (April, 2002). Factors impacting the successful implementation of comprehensive guidance and counseling programs in nova scotia. Professional School Counseling, 5(4), 292-297.

Lincoln, Y. S. \& Guba, E. G. (1985). Naturalistic inquiry. Thousand Oaks, CA: Sage.

Los Angeles Office County of Education. Retrieved February 6, 2004 from California Counselor Leadership Academy Web site: http://www.lacoe.edu/orgs/233/index.cfm.

Los Angeles Office County of Education. Retrieved March 23, 2005 from California Counselor Leadership Academy Web site: http:/www.lacoe.edu/orgs/233/index.cfm.

Louis, K. S., Jones, L. M. \& Barajas, H. (May, 2001). Districts and schools as a context for transformed counseling roles. NASSP Bulletin, 85(625), 62-72.

Luke, J. S. (1998). Catalytic Leadership: Strategies for an interconnected world. San Francisco, CA: Jossey-Bass Publishers.

MacDonald, G. \& Sink, C. A. (August, 1999). A qualitative developmental analysis of comprehensive guidance programmes in schools in the united states. British Journal of Guidance and Counseling, 27(3), 415-430.

Maliszewski (1997). Developing a comprehensive guidance system in the omaha public schools. In Gysbers, N. \& Henderson, P. (Ed.), Comprehensive guidance programs that work-II (pp. 89-106). Greensboro, NC: ERIC / CASS Publications. 
Mariani, M. (Fall, 1998). National standards for school counseling programs: New direction, new promise. Occupational Outlook Quarterly, 43(3), 41-42.

Marris, P. (1975). Loss and change. New York: Anchor Books Garden City.

Merriam, S. B. (1998). Qualitative research and case study applications in education. San Francisco, CA: Jossey-Bass Publishers.

Morgan, G. (1988). Riding the waves of change. San Francisco, CA: Jossey-Bass.

Morgan, G. (1997). Images of organization ( $2^{\text {nd }}$ ed.). Thousand Oaks, CA: Sage.

Myrick, R. D. (1987). Developmental guidance and counseling: A practical approach. Minneapolis, MN: Educational Media Corporation.

Myrick, R. D. (February, 2003). Accountability: Counselors count. Professional School Counseling, 6(3), 174-179.

Napierkowski, C. M. \& Parsons, R. D. (May, 1995). Diffusion of innovations: Implementing changes in school counselor roles and functions. The School Counselor, 42, 364-369.

Neukrug, E. S. \& Barr, C. G., Hoffman, L. R., \& Kaplan, L. S. (May, 1993). Developmental counseling and guidance: A model for use in your school. School Counselor, 40(5), 356-363.

O'Dell, F. L. \& Rak, C. F. (May/June, 1996). Guidance for the 1990s: Revitalizing the counselor's role. Clearing House, 69(5), 303-308.

O'Neil, J. (1992). Preparing for the changing workplace. Educational Leadership, 49(6), 6-9.

Otwell, P. S. \& Mullis, F. (April, 1997). Academic achievement and counselor accountability. Elementary School Guidance and Counseling, 31(4), 343-348.

Paisley, P. O. \& McMahon, G. (December, 2001). School counseling for the $21^{\text {st }}$ century: Challenges and opportunities. Professional School Counseling, 5(2), 106115.

Pecca, K. (June, 1994). Focusing on the individual change process in school restructuring. Keynote address at the Texas Education Agency Institute on Reaching All Students: Building School District Capacity, Austin, TX.

Perelman, L. J. (1987). Technology and transformation of schools. National Board Association. 
Peterson, P. L., McCarthy, S. J. \& Elmore, R. F. (1997). Learning from school restructuring. In M. Fullan, The challenge of school change (pp. 191-234). Arlington Heights, IL: IRU/ Skylight Training and Publishing, Inc.

Quinn, R. E. (1996). Deep change: Discovering the leader within. San Francisco, CA: Jossey-Bass, Inc.

Rowell, L. (2002). Preparing students for the globalized society of the twenty-first century: A comparative perspective on the ideological roots of guidance. In Johnson, C. D. \& Johnson, S. K., Building stronger school counseling programs: Bringing futuristic approaches into the present (pp. 247-286). Greensboro, NC: CAPS Publication.

Schein, E. (1992). Organizational culture and leadership. San Francisco: Jossey-Bass.

Schein, E. (1985). Organizational culture and leadership ( $1^{\text {st }}$ ed.). San Francisco, CA: Jossey-Bass Publishers.

Schwallie-Giddis, P., Maat, M. \& Park, M. (February, 2003). Initiating leadership by introducing and implementing the asca national model. Professional School Counseling, 6(3), 170-173.

Schwann, C. \& Spady, W. (April, 1998). Why change doesn't happen and how to make sure it does. Educational Leadership, 55(7), 45-47.

Sears, S. J. (May, 1993). The changing scope of practice of secondary school counselors. School Counselor, 40(5), 384-388.

Sears, S. J., Haag, D. \& Granello, D. H. (February, 2002). School counseling now and in the future: A reaction. Professional School Counseling, 5(3), 164-171.

Senge, P. M. (1990). The fourth discipline: The art and practice of the learning organization. New York: Doubleday.

Sink, C. A. \& MacDonald, G. (December, 1998). The status of comprehensive guidance and counseling in the united states. Professional School Counseling, 2(2), 88-94.

Sink, C. A. \& Yillik-Downer, A. (April, 2001). School counselors' perceptions of comprehensive guidance and counseling programs: A national survey. Professional School Counseling, 4(4), 278-288.

Snyder, K. J., Acker-Hocevar, M. \& Wolf, K. M. (September, 1995). Chaos theory as a lens for advancing quality schooling. Tampa, FL: School Management Institute College of Education University of South Florida. (ERIC Document Reproduction Service No. ED413630). 
Support Personnel Accountability Report Card (SPARC) 2005-2005 Instructions and Scoring Rubric. Retrieved March 23, 2005 from Los Angeles County Office of Education California Counselor Leadership Academy Web site: http://www.lacoe.edu//orgs/1077/index.cfm?ModuleId=1, p. 1-19.

Sudman, S. \& Bradburn, N. M. (1982). Asking questions: A practical guide to questionnaire design. San Francisco, CA: Jossey-Bass Inc.

Taylor, L. \& Adelman, H. S. (2000). Connecting schools, families, and communities. Professional School Counseling, 3(5), 298-307.

Taylor, S. J. \& Bogdan, R. (1984). Introduction to qualitative research methods: The search for meanings. New York, NY: John Wiley \& Sons, Inc.

Tyack, D. \& Tobin, W. (1994). The "grammar" of schooling: Why has it been so hard to change? American Educational Research Journal, 31, pp. 453-479.

United Stated Department of Education. Retrieved February 6, 2004 from United States Department of Education National Education Goals Web site: http://www.ed.gov/legislation/GOALS2000/TheAct/sec102.html.

United States Department of Education. Retrieved March 6, 2006 from United States Department of Education Student Support Services Program Web site: http://www.ed.gov/programs/triostudsupp/index.html.

Walz, G. R. (1997). Knowledge generalizations regarding the status of guidance and counseling. Washington, DC: The Education Trust.

Webster's new world dictionary (1987). New York, NY: Warner Books, Inc. 


\author{
Appendix A \\ National Standards for School Counseling Programs \\ (Dahir, Sheldon, \& Valiga, 1998)
}

\title{
I. ACADEMIC DEVELOPMENT
}

Standard A: Students will acquire the attitudes, knowledge, and skills that contribute to effective learning in school and across the life span.

Standard B: Students will complete school with the academic preparation essential to choose from a wide range of substantial postsecondary options, including college.

Standard C: Students will understand the relationship of academics to the world of work, and to life at home and in the community.

\section{CAREER DEVELOPMENT}

Standard A: Students will acquire the skills to investigate the world of work in relation to knowledge of self and to make informed career decisions.

Standard B: Students will employ strategies to achieve future career success and satisfaction.

Standard C: Students will understand the relationship between personal qualities, education and training, and the world of work.

\section{PERSONAL/SOCIAL DEVELOPMENT}

Standard A: Students will acquire the attitudes, knowledge, and interpersonal skills to help them understand and respect self and others.

Standard B: Students will make decisions, set goals, and take necessary action to achieve goals.

Standard C: Students will understand safety and survival skills. 


\section{Appendix B}

Interview Questions

1. Can you describe any concerns that you had in being able to implement a comprehensive guidance and counseling program in your school?

2. Can you tell me a story about your experience with introducing the National Standards for School Counseling Programs to your peers?

3. Can you tell me a story about your experience with introducing the National Standards for School Counseling Programs to your administrators?

4. Can you tell me a story of how you did gain the support of your administrators to be able to begin implementing the National Standards for School Counseling Programs?

5. What were the key factors that helped you to implement a comprehensive guidance and counseling program in your school?

6. What were the key factors that interfered with your ability to implement a comprehensive guidance and counseling program in your school?

7. What advice would you give to other school counselors wishing to implement comprehensive guidance and counseling programs? 
Appendix C

School Counseling Program Selection Questionnaire

Prior to our interview, I would appreciate if you could fill out this questionnaire in order to obtain a profile on your school counseling program. Your responses will remain confidential.

INSTRUCTION: $\quad$ Please circle the appropriate answer.

$$
\begin{array}{ll}
Y= & \text { Yes } \\
N= & \text { No } \\
\text { NA }= & \text { Not Applicable }
\end{array}
$$

\section{PROGRAM DESIGN}

1. The administrators in my school have been educated about the National Standards for School Counseling Programs.

2. The administrators in my school believe in the vital role of the student support personnel team in academic success.

3. The administrators in my school support the implementation of the National Standards for School Counseling Programs.

4. The goals of my school counseling program are supported by my administrators.

$\begin{array}{lll}\mathrm{Y} & \mathrm{N} & \mathrm{NA} \\ \mathrm{Y} & \mathrm{N} & \mathrm{NA} \\ \mathrm{Y} & \mathrm{N} & \mathrm{NA} \\ \mathrm{Y} & \mathrm{N} & \mathrm{NA}\end{array}$

\section{PROGRAM CURRICULUM AND SERVICES}

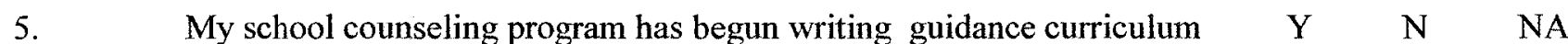
that includes student competencies in career development.

6. My school counseling program has begun writing guidance curriculum $\quad$ Y $\quad N \quad$ NA that includes student competencies in academic development.

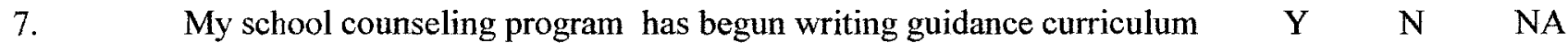
that includes student competencies in personal social development (interpersonal skills, decision-making skills, respect of others).

8. My guidance program supports students through group counseling. $\quad$ Y $\quad$ N

$\begin{array}{lllll}\text { 9. } & \text { M guidance program supports students through individual counseling. } & Y & \text { N } & \text { NA }\end{array}$

10. My guidance program supports students through classroom presentations. $\quad Y \quad N \quad$ NA 
Appendix D

Letter of Introduction to School Counselors

Dear School Counselor:

My name is Jo Ann Grant and I am a school counselor at Vista Adult School. I have recently attended a workshop with the San Diego County of Education that provided information on creating comprehensive guidance and counseling program within secondary schools. For this reason, I have decided to make the implementation of a comprehensive guidance and counseling program the focus of my dissertation, which will fulfill my requirements for a doctorate in Leadership Studies with the University of San Diego School of Education!

The purpose of my dissertation is to investigate strategies that school counselors have used to gain support to implement a comprehensive guidance and counseling program. Currently there are no studies concentrating on San Diego County schools about the extent to which school counselors have implemented a comprehensive guidance and counseling program, nor have their been studies concentrating on the strategies that school counselors have used to create such change. The information you provide will be of great use to the San Diego County of Education in further providing training workshops for counselors who have a desire to learn more about implementing comprehensive guidance and counseling programs within their schools. Your participation in this study will provide school counselors and the San Diego County of Education with an honest appraisal of how prevalent comprehensive guidance and counseling programs are in San Diego County schools.

As you have already verbally agreed to participate in this study during our telephone conversation on June 1, 2003, please review and complete the following:

- Informed Consent Form

- School counseling program profile questionnaire

Please sign the Informed Consent Form and answer every question on the questionnaire and return it to me in the self-addressed stamped enveloped by June 10, 2003. Again, please be assured that participation in this study is strictly voluntary and confidential. If you have any questions, please contact me at (619) 688-1992 or via e-mail at igrant@vusd.k12.ca.us. Once I have received both the informed consent form and questionnaire I will contact you to schedule an interview at your earliest convenience. 
I would greatly appreciate your participation and will be happy to send you a summary of the findings whether you participate in this study or not. If you wish to receive a summary, please send me an email within the next few months. I hope to receive your completed questionnaire soon.

Sincerely,

Jo Ann Grant

Ed.D. Candidate

Enclosures: Questionnaire

Informed Consent Form 
Appendix E

Informed Consent Form

Research Study Name: How School Counselors Gain Support To Implement a Comprehensive Guidance and Counseling Program

Investigator: Jo Ann Grant

Telephone Number: (619) 992-6939

\section{INTRODUCTION}

You are invited to take part in a research study. Before you decide to be a part of this study, you need to understand the risks and benefits. This consent form provides information about the research study. The researcher will be available to answer your questions and provide further explanations. If you agree to take part in the research study, you will be asked to sign this consent form. This process is known as informed consent. Your decision to take part in the study is voluntary. You are free to choose whether or not you will take part in the study.

\section{PURPOSE}

Jo Ann Grant, a doctoral student in the Leadership Studies program at the University of San Diego is carrying out a research study to investigate school counselors' efforts to gain support for implementing comprehensive guidance and counseling programs. The researcher is conducting this study in order to fulfill requirements to obtain a doctorate in Leadership Studies from the University of San Diego School of Education.

\section{PROCEDURES}

The research will be conducted at your school site and at your convenience. You will be interviewed and asked questions regarding implementing a comprehensive guidance and counseling program. Interviews will be audio taped and the researcher will be taking notes during the interview. Interviews will last approximately one hour and follow up interviews, lasting approximately 30 minutes to one hour, will be held as needed. The total amount of time you will be asked to volunteer for this study is approximately 5-10 hours over a 6-month period.

\section{POSSIBLE RISKS}

To the best of my knowledge, the things you will be doing have no more risk of harm than you would experience in everyday life.

\section{POSSIBLE BENEFITS}

You will not get any personal benefit from taking part in this study with the exception that you are helping other school counselors to improve their ability to be able to successfully implement comprehensive guidance and counseling programs in their schools.

\section{COSTS}

There are no costs associated with taking part in this study. 
VIII. COMPENSATION

You will not receive compensation for participating in this study.

IX. RIGHT TO WITHDRAW FROM THE STUDY

Your participation in this research study is voluntary. You may decide not to begin or to stop this study at any time. Your records will be used for research purposes only.

\section{CONFIDENTIALITY OF RESEARCH RECORDS}

Your records will be private. No one will know except for the researcher that you are a part of this study. Your records will be kept private unless you permit their release or if the records are asked for by court order. Your records will be used for research purposes only and will be destroyed after a minimum of 5 years. During that time, your records will be safeguarded and will remain under lock and key. The transcripts from the interview and the questionnaire will be coded with an ID number so that only the researcher will know the name of the person who participated in the study.

\section{QUESTIONS}

If you have questions about the procedures of this research study, please contact Jo Ann Grant by telephoning (619) 992-6939 or email at jgrant@vusd.k12.ca.us. If you have questions about the informed consent process or your rights as a research subject, please contact Dr. Lonnie Rowell, Director of the Counseling Program at the University of San Diego and chairman of this dissertation study.

\section{SIGNATURES}

By signing this consent form, you confirm that you have read this informed consent form, that the study has been explained to you, your questions have been answered, and you agree to take part in this study. You do not give up any of your legal rights by signing this informed consent form. You will receive a copy of this consent form.

\section{Participant (Print Name)}

Signature

Date

\section{RESEARCHER STATEMENT}

I certify that the research study has been explained to the above individual by Jo Ann Grant including the purpose, the procedures, the possible risks and the potential benefits associated with participation in this research study. Any questions raised have been answered to the individual's satisfaction.

Investigator (Print or type name)

Signature

Date 
Appendix F

Demographic Questionnaire

\section{DEMOGRAPHIC INFORMATION}

11. Please indicate the level of school that you currently work in:

Elementary
Middle
High School

Elementary/Middle Alternative High School Alternative Middle School

12. Please indicate the number of years you have worked for your current school:

$\begin{array}{lll}1 \text { year or less } & 4-5 \text { years } & 8-9 \text { years } \\ 2-3 \text { years } & 6-7 \text { years } & 10 \text { years and over }\end{array}$

13. Please indicate the overall number of years you have worked as a school counselor:

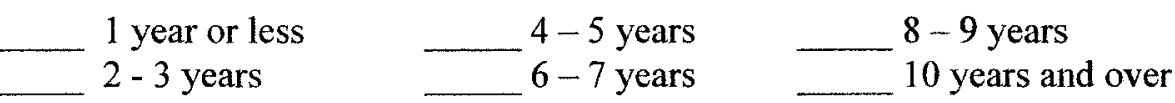

14. Please indicate how many years you have been working on creating a comprehensive guidance and counseling program?

1 year or less
2 - 3 years

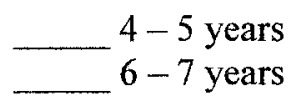
8 - 9 years
10 years and over

15. Please indicate the number of students currently in your caseload?

$\begin{array}{cccc}100 \text { or less } & 201-300 & 401-500 & 601-700 \\ 101-200 & 301-400 & 501-600 & 701 \text { and over }\end{array}$

16. Please indicate the number of full-time school counselors that are with your school?
$-1$
3
4
5
6
-

17. Please indicate the number of part-time counselors that are with your school?
$-\frac{1}{2}$

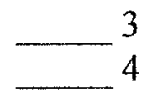
5
6 or more

18. Please indicate whether you attended the San Diego County of Education Workshop on Implementing a Comprehensive Guidance and Counseling Program?

Yes No

Thank you for taking the time to complete this survey! 


\section{Appendix G}

Letter to Participants with Transcribed Interview

\section{Dear Participant,}

Enclosed is the transcription for our interview on November 1, 2004. I am sending you a copy of the transcription to provide you the opportunity to review the written interview for accuracy. If you want to add, delete or change anything please feel free to do so. If you see a question mark, it just means that I was unsure of the spelling. Just as a reminder, I will be using your general experiences and ideas that arose from the interview regarding the process of implementing the National Standards and gaining support from key stakeholders. If I use any direct quotes, your identity will not be revealed. To ensure confidentiality, you were assigned a number instead of using your name when I transcribed the interview. Last, I will be sure to send your school one copy of my dissertation for you to review.

I have enclosed an envelope and stamps in case you do want to make changes. If you do not have any changes to make you do not need to send back the interview. If I do not hear from you by December 15, 2004 I will assume you did not wish to make changes and the interview is fine as it is.

Thank you again for taking the time to participate in my study. If you have any questions, you can reach me at (619) 992-6939 or jgrant@vusd.k12.ca.us.

Sincerely,

Jo Ann Grant 